\title{
Evaluation of the Public Health England and Sport England Funded Sport and Exercise Medicine Pilot in Secondary Care
}

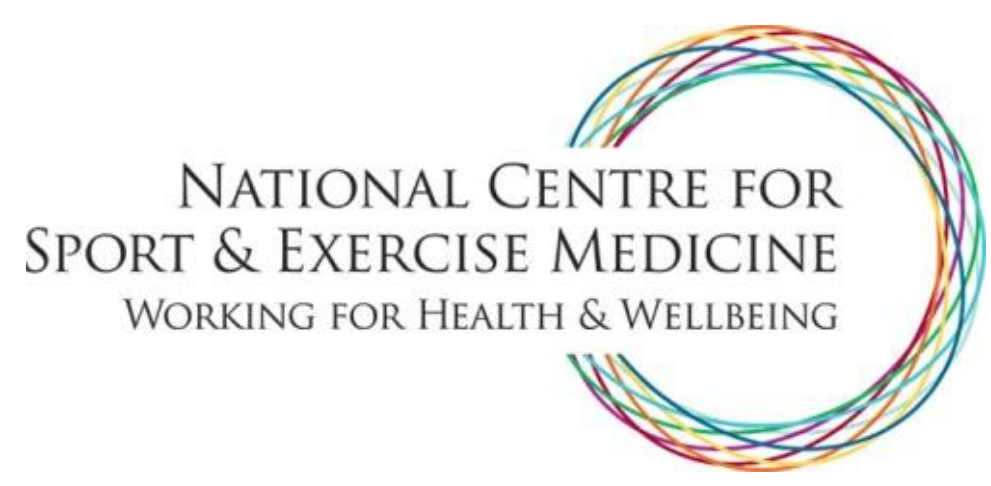

\section{Sheffield | Centre for Sport \\ Hallam and Exercise \\ University $\mid$ Science}

Report prepared by Professor Robert Copeland, Dr Anna Myers, Dr Helen Quirk, Dr Helen Crank, Dr David Broom \& Simon Goldsmith

March 2019 


\section{Executive summary}

\subsection{Background}

In 2014 Public Health England (PHE) launched the national physical activity (PA) framework 'Everybody Active, Everyday'. The framework included a key domain for action called 'Moving Professionals'. The Moving Professionals Programme aimed to build expertise and leadership across key professional sectors and to raise awareness and understanding of the health benefits of PA among professionals and the wider public. The Moving Professionals Programme comprised a number of innovative work packages that are described elsewhere (See Brannan et al., 2019). The Sport and Exercise Medicine (SEM) pilot was one element of the Moving Professionals Programme, and aimed to embed an SEM consultant led PA service within an NHS Trust to integrate PA in to the care plans of patients. This was termed creating an 'Active Hospital'.

PHE and Sport England invited expressions of interest (Eols) from NHS Trusts with the capacity to deliver the SEM pilot through a competitive process. Three Trusts were invited to interview and Oxford University Hospital NHS Foundation Trust (OUHFT) were selected to deliver the pilot. The successful Trust was tasked with developing an SEM pilot that strengthened existing core resources and expanded existing capacity to integrate specialist PA advice into the care pathways for adults inpatient care. This was tested across five clinical pathways within OUHFT where PA had not previously been targeted as a treatment intervention.

Two lead SEM consultants were responsible for developing and implementing the SEM pilot, which targeted five clinical pathways and was underpinned by the COM-B model. These were; Maternity, Enablement, Renal, Complex Medical Unit (originally Critical Care), and Cardiology.

\subsection{Evaluation}

As part of the National Centre for Sport and Exercise Medicine (NCSEM) network, academics at Sheffield Hallam University (SHU) were commissioned to conduct an independent evaluation of the SEM pilot. The NCSEM were not responsible for the implementation or delivery of the SEM pilot. The evaluation aimed to explore the acceptability and feasibility of the SEM pilot and followed a mixed methods approach. Data was collected from patients and healthcare professionals (HCPs) using surveys, face-to-face and telephone interviews and audits between June 2018 and March 2019. 


\subsection{Key findings}

Data suggests that whilst it is feasible and acceptable to embed PA interventions within secondary care pathways (with the exception of Critical Care), discrepancies exist in how advanced these interventions are in each pathway (see Table 2).

Three key mechanisms appear crucial to the setup phase of the SEM pilot:

1. A supportive context prior to implementation that includes the backing from a departmental lead/senior clinician.

2. Dedicated resource (commonly an SEM registrar) working directly in the pathway to champion the pilot and deliver the interventions in situ.

3. A senior SEM consultant with gravitas, long-standing and trusted relationships within an NHS Trust, that can navigate the local system politically and culturally.

Peer mentoring featured in two of the five pathways. Data here identified that formal peermentoring is a complex process that requires certain competencies to deliver successful outcomes. Moreover, this evaluation suggests that it cannot be assumed that the peer-to-peer support model will suit everyone even where these competencies are met. With this in mind, it might be sufficient to create the conditions for patients to informally support one another rather than establish formal structures to achieve what appears to happen naturally.

A particular strength of the SEM pilot is that the interventions were grounded in behaviour change theory. The SEM team mapped the interventions for each pathway using the COM-B framework (Michie et al., 2014), and included a description of explicit Behaviour Change Techniques. This helped to understand how change might occur in the different pathways. It also provides a 'map' for translation of the interventions to other Trusts. The subject specific knowledge provided by the SEM team was crucial for this process.

Leadership is always important in the introduction of new programmes, particularly so in complex systems like the NHS, and it was unsurprising that the lead SEM consultant(s) were central to the implementation and acceptability of the SEM pilot here. The programme leads [SEM consultant(s)] needed to be visible, excellent communicators, and have an ability to make connections across a complex system. They also needed to be sensitive to the demands placed on existing services and empathetically work with service leads to make small but sustainable changes to the physical, social and cultural environment within clinical services. Now that the content and a road map for implementation has been produced for an 'Active Hospital' it is plausible future programme leads for 'Active Hospital' programmes could come from disciplines beyond SEM, providing they possess the personal skills, gravitas and connections across the local system. 
There have been challenges with staffing and generating capacity to deliver the various SEM pathways, as such it might be helpful for future programmes to map capacity prior to implementation to determine where capacity to undertake roles such as PA champions might be more or less likely. In the pathways that worked well (i.e. Maternity), the visibility of SEM staff appears to be an important factor. The approach to the SEM pilot relied heavily on the visible presence of a member of the SEM team in each pathway. To achieve a scalable intervention, system wide changes will be important to reduce the reliance on key individuals in delivery, moving to a responsibility of the system to effect change supported by a SEM team to plan change and assess outcome as a result of those changes. Starting with a coalition of the willing will help to build momentum and drive culture change, but establish system prompts (e.g. embedding PA assessment in booking appointments) and identifying local leaders within clinical services is crucial to the growth and sustainability of culture change.

External funding is often required to support innovative projects like the SEM pilot. This funding tends to be short-term however, which makes demonstrating the impact and value of such interventions challenging. This is particularly the case with something like PA, when the benefits are likely to be seen much further downstream. With this in mind, we propose that interventions of the nature of the SEM pilot are funded for a minimum of 3 years from the outset BUT with clear feasibility and acceptability goals that come with stop/go milestones. This longer-term approach to funding would help determine the true impact of the work and avoid a constant cycle of pilots that finish without an opportunity to demonstrate impact.

\subsection{Implications/recommendations}

- A PA culture isn't created overnight and it is crucial to recognise this when scaling SEM pilots in other Trusts. So much of the culture change observed at OUHFT was driven through longstanding and trusted relationships and whilst this can potentially be achieved through force of personality on occasion, we observed the importance of a long history of SEM as a key driver for change.

- Future programmes might need to lengthen any 'set-up' phase where these long standing relationships do not already exist.

- The experience, connections and trusted relationships of the senior SEM consultant were extremely valuable in this pilot, especially in being able to navigate the political climate of a large Trust with competing agendas and limited resource.

- Undertaking a mapping exercise at the outset of the pilot to explore the physical and social environment of the hospital, who is working where, what can be fitted in where, what's being done well in the hospital, where things can be augmented and where the key partners are, would be a sensible first step in implementation of future SEM pilots. 
- New initiatives need a flexible approach to implementation. SEM lead(s) need to be responsive and sensitive to where new opportunities exist, looking for opportunities across the system to intervene.

- The COM-B approach to intervention mapping helped engender consistency across the pilot and it is recommended that future programmes follow a similar approach.

- The sell to commissioners needs to include the contribution that SEM will make to the day to day activity of the Trust and not just on the basis of a culture change. If proposed outcomes can be aligned to current challenges, as well as the future vision then they are more likely to be accepted.

- The pilot has delivered a road map for an 'Active Hospital' and it is plausible that leads for future programmes could come from disciplines beyond SEM, providing they possess appropriate leadership skills. 
Table of contents

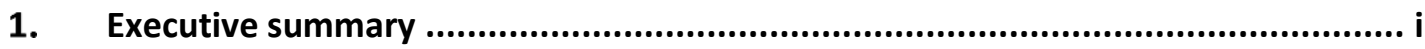

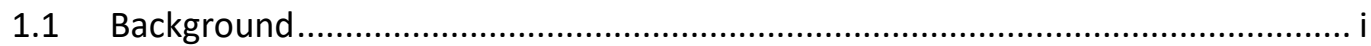

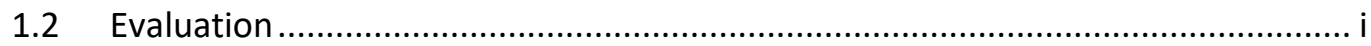

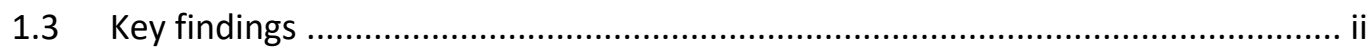

1.4 Implications/recommendations ...........................................................................ii

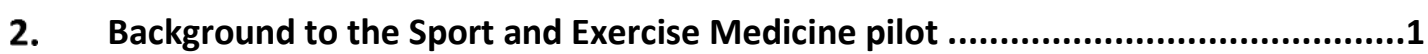

2.1 The Sport and Exercise Medicine pilot ................................................................. 1

2.1.1 Aims of the Sport and Exercise Medicine pilot ........................................ 2

2.1.2 Sport and Exercise Medicine pilot clinical pathways ................................ 2

3. The evaluation of the Sport and Exercise Medicine pilot ......................................2

3.1 Primary and secondary aims of the Sport and Exercise Medicine pilot evaluation2

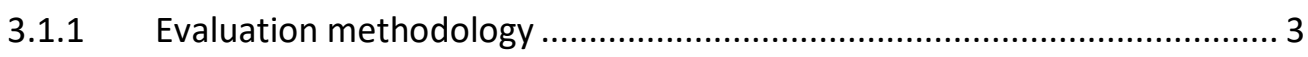

4. Study 1: Understanding the culture of physical activity within OUHFT....................8

4.1 OUHFT is a large multi-site Trust that values innovation ...................................... 8

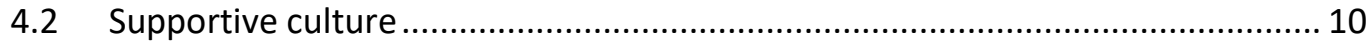

4.3 Physical activity provision and the role of Sport and Exercise Medicine ............. 11

4.4 Barriers to the implementation of the Sport and Exercise Medicine pilot .......... 13

4.5 Facilitators of the implementation of the Sport and Exercise Medicine pilot ..... 15

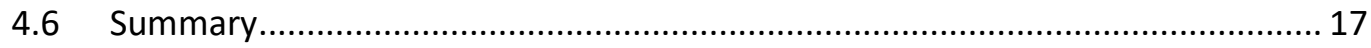

4.7 Implications for this evaluation .................................................................. 17

5. Studies 2-7: Exploration of interventions delivered across individual clinical pathways

18

6. Study 2 - Impact of a bespoke Sport and Exercise Medicine led Clinical Champions

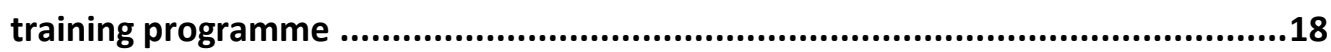

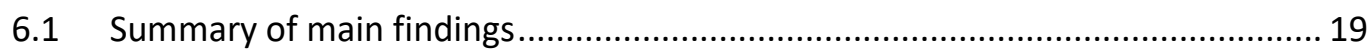

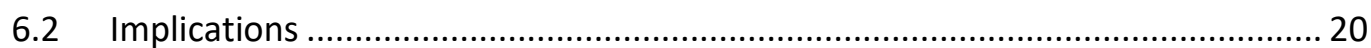

7. Study 3 - Enablement patients' experience of a physical activity class and their perceptions of the role of a peer mentor.....................................................21

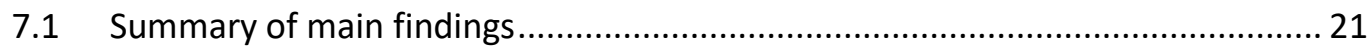

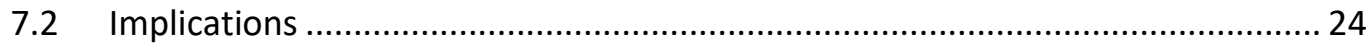

8. Study 4 - Impact of the Sport and Exercise Medicine intervention on the behaviour of healthcare professionals in the Maternity and Complex Medical Unit pathways ..24

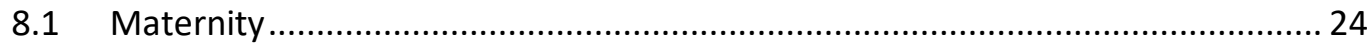

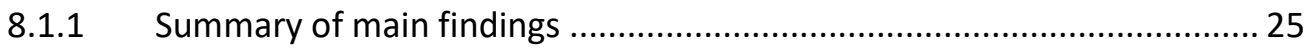




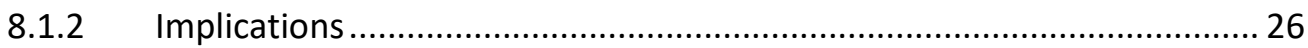

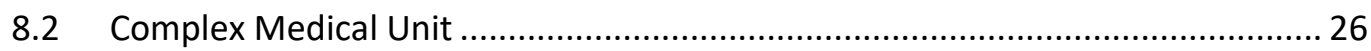

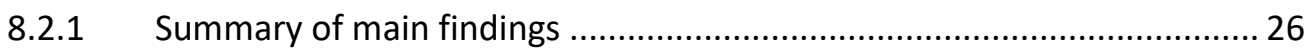

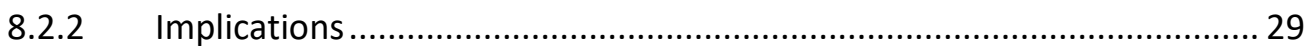

9. Study 5 - Acceptability of an active ward in the Renal pathway...........................29

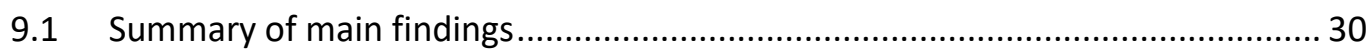

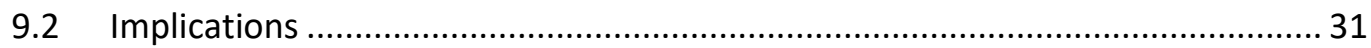

10. Study 6 - Patient centred physical activity intervention in the Complex Medical Unit

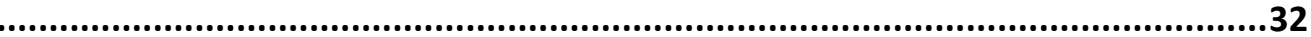

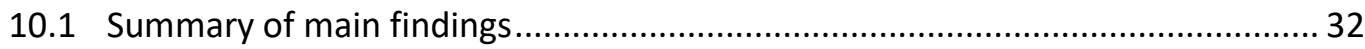

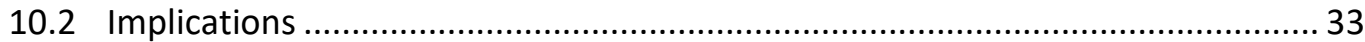

11. Study 7: Experiences of lead Sport and Exercise Medicine consultants in delivering the Sport and Exercise Medicine pilot ........................................................................34

11.1 Leadership that is trusted and enduring …........................................................ 34

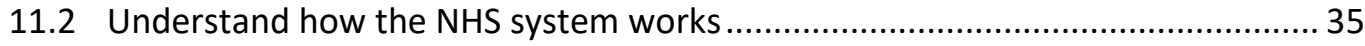

11.3 Create the team from a coalition of the willing …............................................. 36

11.4 A flexible approach and a willingness to fail fast ............................................... 37

11.5 System supporters to drive change and ensure sustainability.............................38

11.6 More than just physical activity ...................................................................... 40

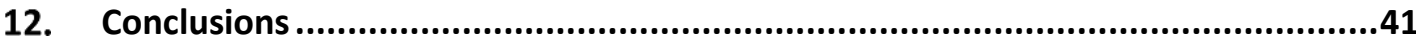

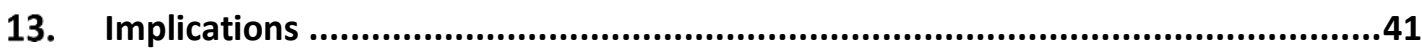

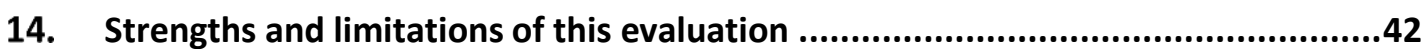

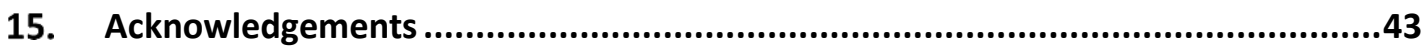

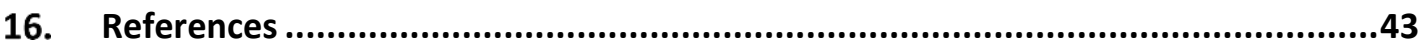




\section{Background to the Sport and Exercise Medicine pilot}

Physical inactivity is the fourth leading cause of death worldwide (Kohl et al., 2012) and is directly responsible for a huge burden of non-communicable disease (Lee et al., 2012). Importantly here, the majority of NCDs can be ameliorated through moving more. Healthcare is cited as one of the ' 7 best investments' (GAPA, 2012) to promote an active population and provides a unique point of access to a section of the population who are likely to gain the most from only small improvements in increasing their PA. Inactive individuals are more likely to develop chronic illness and chronic illness itself is a well-recognised cause of activity reduction (Lee et al., 2012). This combination results in the morbid population being amongst the least active members of society, but whose health stands to gain most from even marginal increases in PA (Woodcock et al., 2010).

As part of their strategy 'Everybody Active Every Day' (Public Health England, 2014), PHE identifies the role that HCPs can play in promoting PA. Termed 'Moving Professionals', the aim build expertise and leadership across key professional sectors and to raise awareness and understanding of the health benefits of PA among professionals and the wider public.

Whilst progress has been made in developing PA pathways in specific diseases and primary care settings, little ground has been made in the secondary care setting. This is a key omission in healthcare's contribution to improving population PA since leadership from a specialist service has proved to be fundamental to a system wide change in culture in the NHS (Finlay, 2001). Historically SEM in the NHS has focused on musculoskeletal disease clinical pathways, despite the significant evidence base that demonstrates the potential for PA to improve management and treatment outcomes of a range of long term conditions (Gleeson et al., 2011). With training in exercise medicine, population health, musculoskeletal medicine and multidisciplinary team work, SEM physicians are uniquely positioned to support a transition toward empowering patients to lead active lifestyles. The SEM pilot is part of the Moving Professionals Programme.

\subsection{The Sport and Exercise Medicine pilot}

In 2017, PHE and SE invited Eols from applicable NHS Trusts (i.e. the Trust employs a SEM consultant) to deliver an SEM pilot in secondary care. Three Trusts were invited to interview; OUHFT were successful and were commissioned to deliver an SEM pilot that focused on the integration of PA into care pathways within secondary care. 


\subsubsection{Aims of the Sport and Exercise Medicine pilot}

The aim of the SEM pilot was to create an 'Active Hospital' by embedding an SEM consultant led PA service within an NHS Trust to integrate PA in to the care plans of patients. This was tested across five clinical pathways within OUHFT where PA has not previously been targeted as a treatment intervention.

\subsubsection{Sport and Exercise Medicine pilot clinical pathways}

SEM consultants at OUHFT were responsible for developing and implementing the SEM pilot. With guidance from the evaluation team, the SEM consultant leads and wider team at OUHFT designed and developed each component of the intervention using the COM-B model and the behaviour change wheel (Michie et al., 2014). The programme aimed to influence the value of PA within five clinical care pathways, each with a different intervention protocol. An overview of each pathway can be found in Appendix A. In addition, an example of how the COM-B framework was used to map the intervention within each pathway is provided in Appendix B. The aims of each pathway are outlined in Table 2.

\section{The evaluation of the Sport and Exercise Medicine pilot}

The NCSEM, in partnership with SHU, were commissioned by PHE and Sport England to conduct an independent evaluation of the SEM pilot. NCSEM/SHU were not responsible for the implementation or delivery of the SEM pilot.

\subsection{Primary and secondary aims of the Sport and Exercise Medicine pilot evaluation}

The primary aim of the evaluation was to explore the acceptability and feasibility of multidisciplinary SEM teams delivering targeted and tailored support to integrate PA into the care plans of OUHFT patients.

The secondary aims were to:

i) Explore secondary care HCPs baseline perceptions of SEM clinical advice in the context of clinical patient care.

ii) Determine clinical acceptability of SEM intervention with HCPs and with patients.

iii) Identify what works and what doesn't work in establishing this model of SEM PA provision in secondary care.

iv) Understand the uptake of SEM PA provision in different clinical pathways and by different clinical teams within secondary care. 


\subsubsection{Evaluation methodology}

The evaluation adopted a mixed methods approach and comprised seven discrete studies to assess the feasibility and acceptability of the intervention. The number and breadth of the studies is indicative of the ambition and complexity of the SEM pilot. A summary of these studies is presented in Table 1 with more detailed information available in Appendix C. Data on the experience of engaging in the pilot was gathered from patients and HCPs using surveys, face-to-face and telephone interviews and clinical audits. Data was also gathered from formal reports from the SEM leads to PHE and informal discussions between the SEM leads and the evaluation team. For further information about data analysis see Appendix C. Collectively this data was used to determine the extent to which a) it was possible to deliver the proposed interventions within the time, resources, cultural, political and financial climate and medical context of OUHFT (i.e. feasibility) and b) the interventions hit their targets, and patients and staff engaged (i.e. acceptability).

It was beyond the scope of this report to provide a detailed account of progress against the deliverables for each of the pathways in the SEM pilot - this is the remit of OUHFT and for PHE and Sport England as the funders of the programme. That said a broad summary of progress is included in Table 2 along with RAG ratings of the feasibility and acceptability of individual pathways within the SEM pilot. 
Table 1 Summary of evaluation studies to explore the acceptability and engagement with the SEM pilot.

\section{Study Description of works}

Understand the current culture of PA within the hospital from the perspective of

Study 1 operational directors and HCPs. This study will provide the context within which the pilot is being delivered.

a) Explore the impact of a bespoke SEM led Clinical Champions training programme (with PA team as recipients) on attitudes, knowledge, confidence, and intentions to

Study 2 promote/engage in a conversation about PA as part of routine practice.

b) Audit the number of subsequent HCPs receiving Clinical Champions training programme delivered by a PA team member.

Study 3 Investigate the feasibility of a peer-to-peer support programme in the Enablement pathway.

Study 4

Explore the impact of the SEM intervention on the behaviour of HCPs in the Maternity

Study 5 Acceptability of an 'active ward' - case study using the Renal pathway. Explore patients experience of a patient centred PA intervention (a PA plan using the

Study 6 iCAN tool - see Appendix D) in the Complex Medical Unit (CMU) pathway. Furthermore, explore the acceptability of this type of intervention with ward staff.

Study 7 Capture the experience of lead SEM consultants implementing a broad programme of PA in a hospital Trust. 
Table 2 Summary of feasibility and acceptability of clinical pathways within the SEM pilot.

\begin{tabular}{|c|c|c|c|c|c|c|}
\hline Pathway & Aims & Intervention components & Delivery of the intervention & Receipt & $\begin{array}{l}\text { Rating for } \\
\text { feasibility }\end{array}$ & $\begin{array}{l}\text { Rating for } \\
\text { acceptability }\end{array}$ \\
\hline Maternity & $\begin{array}{l}\text { To influence the PA } \\
\text { of pregnant women } \\
\text { directly through the } \\
\text { gestational diabetes } \\
\text { management and } \\
\text { silver star services } \\
\text { and indirectly by } \\
\text { changing staff } \\
\text { behaviour, the } \\
\text { environment and } \\
\text { culture. }\end{array}$ & $\begin{array}{l}\text { PA calculator has been } \\
\text { integrated into the } \\
\text { Maternity booking form on } \\
\text { the electronic patient } \\
\text { records. } \\
\text { Staff trained to deliver brief } \\
\text { PA advice using motivational } \\
\text { interviewing to pregnant } \\
\text { women. } \\
\text { Short film and posters } \\
\text { displayed in waiting area. }\end{array}$ & $\begin{array}{l}\text { Work has progressed as planned } \\
\text { in this pathway. Early indications } \\
\text { suggest the intervention is having } \\
\text { an impact on the PA levels of } \\
\text { patients in the service. }\end{array}$ & $\begin{array}{l}\text { The intervention was well } \\
\text { received by staff in the } \\
\text { Maternity pathway. There has } \\
\text { been strong support from the } \\
\text { Consultant Obstetrician from } \\
\text { the outset. A dedicated PA } \\
\text { champion (midwife) has been } \\
\text { appointed. }\end{array}$ & 4 & 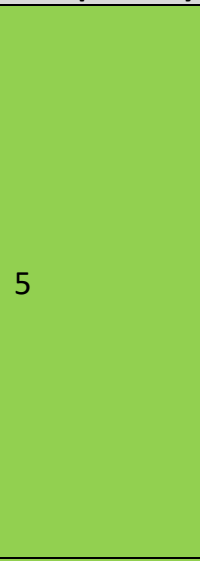 \\
\hline Enablement & $\begin{array}{l}\text { To encourage PA by } \\
\text { providing patients } \\
\text { access to a PA class } \\
\text { and a peer support } \\
\text { group. This pathway } \\
\text { focused on medical } \\
\text { amputees. }\end{array}$ & $\begin{array}{l}\text { An exercise class to support } \\
\text { physiotherapy rehabilitation } \\
\text { programme. } \\
\text { Motivational interviewing } \\
\text { integrated in to the exercise } \\
\text { class. } \\
\text { PA calculator and brief PA } \\
\text { interventions within current } \\
\text { pathways to support all } \\
\text { patients coming through the } \\
\text { service whether they go on } \\
\text { to get prosthesis or not. } \\
\text { Development of peer } \\
\text { support group with } \\
\text { education sessions. }\end{array}$ & $\begin{array}{l}\text { The majority of the planned } \\
\text { activities are underway. However, } \\
\text { there has been no formal training } \\
\text { of patients to become peer } \\
\text { mentors as yet. Two patients } \\
\text { have been identified and } \\
\text { approached to be trained as peer } \\
\text { mentors by charity Limb Power - } \\
\text { OUHFT are awaiting responses. } \\
\text { Patient transportation has been a } \\
\text { challenge; nearly all patients rely } \\
\text { on patient transport which is } \\
\text { notoriously unreliable. }\end{array}$ & $\begin{array}{l}\text { Patients described how much } \\
\text { they enjoyed and valued } \\
\text { taking part in the Enablement } \\
\text { PA class. A consistent } \\
\text { reflection reported by all the } \\
\text { participants was the universal } \\
\text { praise for all staff involved in } \\
\text { the delivery of the Enablement } \\
\text { class and in their patient } \\
\text { journey to date. }\end{array}$ & 4 & 4 \\
\hline
\end{tabular}




\begin{tabular}{|c|c|c|c|c|c|c|}
\hline Pathway & Aims & Intervention components & Delivery of the intervention & Receipt & $\begin{array}{l}\text { Rating for } \\
\text { feasibility }\end{array}$ & $\begin{array}{l}\text { Rating for } \\
\text { acceptability }\end{array}$ \\
\hline Renal & $\begin{array}{l}\text { To develop an activity } \\
\text { permissive } \\
\text { environment (active } \\
\text { ward) and a social } \\
\text { support network to } \\
\text { foster peer-to-peer } \\
\text { support to increase } \\
\text { the PA of in-patients } \\
\text { on the Renal ward. }\end{array}$ & $\begin{array}{l}\text { Daily walk round. } \\
\text { Individualised motivational } \\
\text { support and goal setting. } \\
\text { Social support network to } \\
\text { foster peer-to-peer support. } \\
\text { Posters and patient } \\
\text { information. }\end{array}$ & $\begin{array}{l}\text { The SEM team found the peer-to- } \\
\text { peer support element of the } \\
\text { Renal pathway challenging. It was } \\
\text { not possible to establish a peer } \\
\text { support programme in the first } \\
\text { phase of the pilot. Patients' stay } \\
\text { on the Renal ward is brief, } \\
\text { making it difficult to establish a } \\
\text { peer support system. There were } \\
\text { also issues with staffing on the } \\
\text { Renal ward. }\end{array}$ & $\begin{array}{l}\text { HCPs were extremely positive } \\
\text { about the intervention and } \\
\text { they also suggested additional } \\
\text { activities for the future. HCPs } \\
\text { were keen to explore the } \\
\text { possibility of increasing PA } \\
\text { prior to surgery. Patients were } \\
\text { also positive about the } \\
\text { intervention and felt PA } \\
\text { should be a part of every } \\
\text { patient's treatment }\end{array}$ & 3 & 3 \\
\hline Critical Care & $\begin{array}{l}\text { To implement a } \\
\text { patient centred PA } \\
\text { intervention (the } \\
\text { iCAN tool) to set PA } \\
\text { goals and follow up } \\
\text { patients on their } \\
\text { destination ward } \\
\text { following discharge } \\
\text { from the intensive } \\
\text { care unit. }\end{array}$ & $\begin{array}{l}\text { Motivational interviewing } \\
\text { and goal setting. } \\
\text { Bed-based, chair-based and } \\
\text { standing exercise program } \\
\text { leaflets. } \\
\text { iCAN tool that documents } \\
\text { each patients' physical } \\
\text { capability so ward staff are } \\
\text { aware of what the patient is } \\
\text { able to do. }\end{array}$ & $\begin{array}{l}\text { The intervention on the Critical } \\
\text { Care ward evolved to focus on } \\
\text { the CMU. The Critical Care } \\
\text { pathway was challenging as it is a } \\
\text { relatively chaotic setting; patients } \\
\text { are only on the ward for a short } \\
\text { time and are then transferred on } \\
\text { to one of } 23 \text { other wards. }\end{array}$ & $\begin{array}{l}\text { The intervention was not well } \\
\text { received in the Critical Care } \\
\text { pathway. Patients in this } \\
\text { pathway are very sick and } \\
\text { therefore medical care was } \\
\text { prioritised over patient } \\
\text { mobilisation. } \\
\text { Changing the culture within } \\
\text { this pathway was problematic } \\
\text { as there are a vast number of } \\
\text { HCPs involved in the patients } \\
\text { pathway of care. }\end{array}$ & 1 & 0 \\
\hline $\begin{array}{l}\text { Complex } \\
\text { Medical } \\
\text { Unit }\end{array}$ & $\begin{array}{l}\text { To implement a } \\
\text { patient centred PA } \\
\text { intervention to } \\
\text { increase the amount } \\
\text { of PA patients do } \\
\text { during their stay on } \\
\text { the ward. }\end{array}$ & $\begin{array}{l}\text { Motivational interviewing } \\
\text { and goal setting. } \\
\text { Bed-based, chair-based and } \\
\text { standing exercise } \\
\text { programme booklet. } \\
\text { iCAN tool that documents } \\
\text { each patients' physical }\end{array}$ & $\begin{array}{l}\text { This strand of the SEM pilot is still } \\
\text { in its early stages but the } \\
\text { intervention is beginning to } \\
\text { gather momentum. The iCAN tool } \\
\text { is being used along with the } \\
\text { exercise booklet with patients. } \\
\text { However, it was clear that this } \\
\text { only happened when there was a } \\
\text { dedicated member of staff (PA }\end{array}$ & $\begin{array}{l}\text { HCPs perceived a clear need } \\
\text { for this intervention on their } \\
\text { ward. It was regarded as a } \\
\text { positive move towards a shift } \\
\text { in culture for both ward staff } \\
\text { and patients. Anecdotal } \\
\text { evidence from the staff } \\
\text { suggested that the exercises } \\
\text { were well received by those }\end{array}$ & 3 & 3 \\
\hline
\end{tabular}




\begin{tabular}{|c|c|c|c|c|c|c|}
\hline Pathway & Aims & Intervention components & Delivery of the intervention & Receipt & $\begin{array}{l}\text { Rating for } \\
\text { feasibility }\end{array}$ & $\begin{array}{l}\text { Rating for } \\
\text { acceptability }\end{array}$ \\
\hline & & $\begin{array}{l}\text { capability so ward staff are } \\
\text { aware of what the patient is } \\
\text { able to do. }\end{array}$ & $\begin{array}{l}\text { champion) on the ward. There } \\
\text { also needs to be engagement } \\
\text { from other ward staff going } \\
\text { forwards. }\end{array}$ & $\begin{array}{l}\text { patients who experienced } \\
\text { them. }\end{array}$ & & \\
\hline Cardiology & $\begin{array}{l}\text { To introduce PA to } \\
\text { patients prior to } \\
\text { undergoing } \\
\text { transcatheteraortic } \\
\text { valve implantation } \\
\text { (TAVI) and to provide } \\
\text { them with a PA plan } \\
\text { and support with } \\
\text { finding local PA } \\
\text { services post-surgery. }\end{array}$ & $\begin{array}{l}\text { Motivational interviewing, } \\
\text { goal setting and exercise } \\
\text { advice with a leaflet. }\end{array}$ & $\begin{array}{l}\text { Activity within the Cardiology } \\
\text { pathway was slow to start due to } \\
\text { a lack of dedicated support; a PA } \\
\text { champion was not appointed } \\
\text { until January } 2019 \text {. }\end{array}$ & $\begin{array}{l}\text { At the time of this report we } \\
\text { have no information on the } \\
\text { implementation of this } \\
\text { pathway }\end{array}$ & & - \\
\hline \multicolumn{5}{|c|}{ Mean overall score for feasibility and acceptability of the SEM pilot } & 3 & 3 \\
\hline
\end{tabular}

Key:

- Feasibility: To what extent was it possible to deliver the proposed interventions within the time, resources, cultural, political and financial climate, and medical context of OUHFT.

- Acceptability: Did patients engage in the interventions, did staff engage in the interventions, did interventions hit their targets, is there evidence of progress.

- RAG Scores; score of 0-1 Red little or no progress made; score of 2-3 Amber some progress but barriers in two or more areas of implantation, score of 4-5 Green interventions implemented as designed with little or no barriers identified. 


\section{Study 1: Understanding the culture of physical activity within OUHFT}

The aim of this study was to explore the culture of PA within OUHFT and the perceptions of SEM clinical advice among operational directors and HCPs. In other words, this study aimed to provide the context within which the pilot was delivered and was designed to shed light on why different elements of the pilot were successful or otherwise.

A total of nine interviews were conducted with HCPs and NHS managers across OUHFT. A critical narrative of the data emerging from these interviews is provided below. In depth analysis can be found in Appendix F.1.

\subsection{OUHFT is a large multi-site Trust that values innovation}

Staff described OUHFT as an innovative Trust which strives to push the boundaries of patient care by implementing evidence-based practice. The SEM pilot was a good fit for this ethos with the aim of developing new ways of integrating PA into patient care plans.

"I think they're very keen on innovation and new ideas" S2P06

"We're constantly looking for new ways to deliver the care and sort of innovate and bring in new ideas and certainly this pilot is one of those." S2P01

OUHFT was described by all participants as a very large Trust, which makes it potentially difficult for new services and concepts to gather traction simply because of the volume of employees. This is further exacerbated by poor staff retention, a problem raised by many staff who were interviewed as part of this study. Citing high living costs with no supplement to pay as a contributing factor, staff shortages could mean HCPs have limited time to implement the project in addition to their usual duties and will certainly make it difficult to build momentum and change the culture within the different clinical pathways.

"The trust has a major problem with recruitment and retention. It's a high cost area of living with no cost of living supplement. It has a high turnover of staff." S2P04

"The unit l've just come from is massively short staffed with nurses. So it's difficult to drive new initiatives" S2P05

"You've not got a cohesive team and that's what you need to get that culture to move forward as a cohesive team, that when new people come in they join an already forward-thinking team rather than treading water team. And there feels like a lot of treading water." S2P05 
OUHFT is spread over four locations and this added to the complexity of implementing a programme of culture change such as that described here. A coordinated and consistent approach was therefore necessary for the SEM pilot to influence behaviour across the whole Trust. Moreover, this is where the longevity of relationships and understanding of the political and social climate of OUHFT that was manifest in the lead SEM was so important. This is discussed more in study seven. Given the size of the Trust and its complexity, many of those interviewed believed that if the SEM pilot could be successfully implemented in OUHFT then the model is likely to be transferrable to smaller Trusts.

\footnotetext{
"We operate on four big sites and employ about 12,000 staff in those" S2P01

"I imagine that to be much more difficult just because... it's got to be quite a big message, so it's got to be pervasive throughout the whole psyche if you like, rather than be in sort of the little strands that pop up ad hoc." S2P05

"I think actually if you can implement it in this Trust which is massive, then you can implement it anywhere" S2PO9
}

A prominent theme highlighted by eight out of the nine interviewees was that OUHFT, and the NHS as a whole, is very outcome driven. Unless a new service or programme can demonstrate impact through improved outcomes (i.e. length of stay) it is unlikely to receive long-term funding through the hospital. It is difficult to demonstrate the benefit of a project like the SEM pilot as the impact on outcomes may not be apparent straight away. For example, being more physically active during and after a hospital stay might not impact upon length of stay, but may reduce the number of readmissions in the future.

"The culture in the NHS is that if you want to have a service that is continually funded, you have to show the outcome." S2P04

Furthermore, one interviewee indicated that acute Trusts might not perceive PA interventions like the SEM pilot to be their responsibility to fund because the focus is on long term prevention rather than treatment of acute conditions.

\footnotetext{
"As well as doing it, you're keeping people well for 10, 20, 30 years from now with the exercise programme or the health and promotion rather than preventing the disease. But a lot of acute Trusts, they spend all their day managing acute disease. You're so busy doing the heart attacks in A\&E or chest infections, actually someone says well we'll invest lots of money now for stopping heart attacks, but that's going to be in 20 years' time, that's great. But people see that then as a very Public Health England role, but not in the role of an acute Trust I think." S2P03
} 
With this in mind, programmes that have culture change at their heart, such as the SEM pilot, need to be given sufficient time to demonstrate their value not only to patients but to the economic, social and cultural drivers of a Trust.

OUHFT is one of the largest Trusts in England. If the SEM pilot is successful in a Trust as big as OUHFT then the model is likely to be transferrable to smaller Trusts. This will be crucial to explore if the SEM pilot is scaled up and trialled in other Trusts. It remains unclear whether, in Trusts without SEM consultants, a programme of work such as this could be led by other types of HCP (i.e. physiotherapist, occupational therapist); but now that the content and a road map for implementation has been produced for an 'Active Hospital' it is plausible future programme leads for 'Active Hospital' programmes could come from disciplines beyond SEM, providing they possess the personal skills, gravitas and connections across the local system. This model would need to be tested however.

\title{
4.2 Supportive culture
}

When interviewees were asked about OUHFT as a place of work, staff described it as friendly, supportive and nurturing; a place where senior staff support more junior staff. This was perhaps at odds with the poor staff retention data.

\author{
"business has always been done in the corridor on first name terms in a very social and \\ friendly manner." (S2PO3) \\ "The Trust are incredibly supportive." (S2P08)
}

All nine interviewees noted that there are services available to support staff wellbeing at OUHFT. However, the level of enthusiasm for the staff wellbeing programme varied. Some staff were enthusiastic about the services on offer:

"There are gym facilities I think near the site or aligned with the site. There are various sports groups. So there's five-a-side football and all of those usual kind of groups. There is Pilates, yoga." S2P08

None of those interviewed reported actually taking up any of the services available to them and others felt the Trust paid 'lip service' to staff wellbeing: 
"The trust does a lot to promote health and wellbeing and it pays a lot of lip service to, go for a walk at lunchtime, do your mindfulness training for that, you know, it really does, but actually I think a lot of that is just lip service." S2P03

When asked about the SEM pilot specifically, staff perceived the SEM pilot to be supported at senior leadership level, but it was acknowledged that there are multiple competing interests for the Trust and PA is not always top of the Trust's strategic priorities.

"it's [PA] on the Trust's strategic priorities, but I can't pretend it's the top of them." (S2PO9)

\subsection{Physical activity provision and the role of Sport and Exercise Medicine}

When asked who is responsible for promoting PA to patients, the majority of staff believed it was "everyone's responsibility" (S2P01).

"I think that it's [promoting PA] any opportunity or interaction with a healthcare professional ideally." (S2PO2)

Although most believed there was a shared responsibility to promote PA, interviewees suggested that it should be led by SEM specialists.

"it's the remit of all of us but maybe the leadership comes from people who have specialised in sport and exercise medicine." S2P02

"it needs to be figure headed by somebody, it may as well be the exercise medicine people, delivered by anybody." (S2P04)

It was acknowledged that whilst the promotion of PA was deemed to be everyone's responsibility, it was less clear whose responsibility it was to promote PA at a strategic level.

"That's interesting actually because I don't know if anyone could take responsibility for it [promote PA]... I suppose the very naïve simple answer is to say well it's everyone's responsibility... But if you wanted someone to be an overarching point of contact to say these are strategies that the Trust want to develop and we want to implement with our patients, then does that sit with the rheumatology, does it sit with the orthopaedics, does it sit with SEM, or does it sit with the chief executive" (S2P03) 
A key theme that emerged was staff believed that for PA to sit higher in the Trust's priorities there would need to be a formal policy, making PA a mandatory part of secondary care provision. Staff felt that other areas took priority especially if they had a formal target or standard to meet, such as the "four hour wait in A\&E" or "the 18 week cancer wait" (S2P04).

"the PA is a bonus in an inpatient ward environment...there isn't a CQUIN [Commissioning for Quality and Innovation] or anything in any inpatient pathway that says a patient should, PA is involved... there is no stick to beat the executive board with to say if patients aren't physically active" (S2P04)

SEM was recognised as a medical specialty in 2005 and yet it was clear from interviews that the role of an SEM consultant within the Trust was perhaps not well defined or understood. This could be explained by the wide variety of services and roles that the speciality interacts with. That said, interviewees tended to highlight musculoskeletal injury as one of the main areas of work for SEM consultants.

\footnotetext{
"I think that's where we're trying to figure out as a specialty what our role is: are we leaders that just overview things and try and implement these things and have a knowledge about what works; or is that public health's actual goal to refer to; or are we working with them? I think that's still something that's going to be ironed out in the future." (S2P06)

"looking after elite athletes and people with musculoskeletal problems and getting them back to activity" (S2P06)
}

Those interviewed also made a distinction between the types of patients SEM consultants might treat. The first being elite athletes after an injury with the goal of treatment being to regain preinjury performance levels. The second type of patient was those receiving treatment in the NHS for a musculoskeletal injury.

"looking at sports medicine for those higher performing athletes and that seems to be a bit of a focus." (S2P04)

"for the more general population is the role of sport and exercise chaps managing low level tendinopathies, sort of sprains, strains that where they can bring to bear their expertise of high end athletes to the average population." (S2PO3) 
There was less emphasis placed on the role of the SEM consultant in promoting PA within the NHS in the interest of public health, but this was discussed. This preventative public health role is a new area of work for the SEM specialism.

"there's really a public health role for us to have in promoting PA and getting people more active now, I think that's evolving and that's something that hopefully we'll develop in the future." (S2P06)

\subsection{Barriers to the implementation of the Sport and Exercise Medicine pilot}

Interviewees said that the Trust has numerous priorities and targets to meet and PA is not currently one of them.

"It's not a priority, it's not a trust priority, and PA isn't a trust priority." (S2P04)

Although PA might not be a Trusts priority currently, others thought it was still high on the Trust's 'to do' agenda.

"I think the trust is very, it's definitely, high on their agenda is PA in preventative medicine" (S2P06)

Because of competing demands, PA is often seen as complementary rather than core treatment and is the first thing to go if time or resources are tight, at both a strategic level and in practice.

"I do still think it's seen as an extra, and not an essential." (S2PO4)

"And by the time they've done all that and they've gone through all this big booking form and they're doing the damn thing, the PA has really fallen off the end" (S2P02)

Another challenge was the differences in how care is delivered across the different pathways. Something that works in one pathway might not necessarily work in another. These differences mean it is essential that interventions are developed in collaboration with staff who work within the different pathways. Furthermore, for interventions to be acceptable they must be designed with sufficient flexibility that they can be adapted to fit and be delivered within different circumstances. 
"Well it's different in different areas, what will be important both to the patients and to the staff and accepted as is really worth investing in in terms of time and other resources in Maternity will be very different to what is important in the dialysis unit to what is important in the amputee unit. And so it's having it localised enough that it carries on, not just having a sort of one size fits all model." (S2P09)

It was clear from the interviews that resources (time and money) are a major determining factor to the short-term success and long-term sustainability of an intervention like the SEM pilot.

\begin{abstract}
"I don't think there's been a pushback in terms of a worry that it's not important or that it's dangerous or any of those things, it really has just been about time and, well mostly time I suppose and money I suppose." (S2PO2)

"I think the challenges are it was a short period of time to try and deliver something and to spend longer doing more and to get the sustainability element together into a field that it's something that will continue to benefit." (S2PO2)
\end{abstract}

External funding is often required to support innovative projects like the SEM pilot to 'buy-out' staff time to focus on delivering the project. This funding tends to be short-term however, which makes demonstrating the impact and value of such interventions challenging. This is particularly the case with something like PA, when the benefits are likely to be seen much further downstream (with the exception perhaps of prehabilitation before major surgery). With this in mind, we propose that interventions of the nature of the SEM pilot are funded for a minimum of 3 years from the outset BUT with clear feasibility and acceptability goals that come with stop/go milestones. This longerterm approach to funding would help determine the true impact of the work and avoid a constant cycle of pilots that finish without an opportunity to demonstrate impact.

\footnotetext{
"But yeah I'm not sure to be brutally honest what would happen if they said like there's no money for this, what we going to do? I think they'd say OK we'll just use the leaflet because that's what they may have done." (S2P06)

"I think what they've achieved is huge in that short timeframe and what we need is a bit longer to then start to do the next bit." (S2P02)
}

Safety concerns were raised about encouraging patients to be more physically active. Some interviewees worried that by encouraging patients to be more active they might increase the risk of injury. This was perceived to be a barrier to promoting PA within the hospital and a potential reason why other lifestyle factors are targeted more readily. 
"So I guess lifestyle intervention has been something that's been on our radar for a long time. I would probably say that the dietetic element of it has taken precedence over the PA element. Often because people just, you know, again it's about the safety issues and worried about it [PA]" (S2P02)

"Am I going to break this person, yeah I think so." (S2P05)

"what we also need to be careful of is that by promoting more PA we're also not putting patients at risk of falls and that of course, that's another thing that is perhaps a bit or a barrier is this patient safety" (S2PO5)

\title{
4.5 Facilitators of the implementation of the Sport and Exercise Medicine pilot
}

Interviewees reported that buy-in from senior management was crucial for the success of a project like the SEM pilot.

\begin{abstract}
"the practical barrier of making a service change and the inertia that you face with a large organisation to influence an effect, getting buy-in from senior management" (S2PO3)

"I think you need buy-in and I think, it's almost like you need to go and prove a business model, as in proving it's effective and then they'll buy onto it." (S2P06)
\end{abstract}

Early engagement with and ownership of the SEM pilot was evident among the interviewees. Staff at all levels across the hospital, from ward staff to senior management, were supportive of the project. A number of interviewees reported that the SEM pilot had been well received and some staff had even completed training related to the pilot on their days off.

\footnotetext{
"there's been a hugely positive response to the work that the sport and exercise team have been doing to promote PA in pregnancy. There have been very few barriers to educating staff and all the rest of it and given the fact that we're asking staff to come on their days off or whatever who haven't been able to take out of their time in order to come to education sessions we've had a really good uptake." (S2PO2)

"I think at a management level, all the managers have been very positive about it." (S2P02)
}

"the Trust are really behind it, they do endorse it and they are keen on it" (S2P06)

However, there were a couple of exceptions and some aspects of the SEM pilot were met with resistance. One interviewee suggested that senior staff were reticent because they did not fully understand the purpose of the project. Another interviewee believed that a lack of understanding on 
the part of the SEM leads around how individual wards work could hinder the acceptability and feasibility of delivery and therefore success in certain pathways.

"I mean it felt a little bit as though there was some resistance from above, initially, but I think that was not fully understanding the aims of the project, what we were trying to do. But the moment that was discussed and we'd had that conversation it became very very easy." (S2P07)

"So initially they said they wanted to do pre-op, which isn't necessarily intensive care. And I don't think, I think they got quite a frosty reception from preadmission clinic, so then they moved to inpatients." (S2P04)

There were mixed opinions about whether the SEM pilot leads had engaged with key stakeholders sufficiently early in the project. One interviewee felt the pilot would have been more successful if the SEM leads had engaged with stakeholders in each of the five pathways from the outset.

"I think the setup would have been significantly more successful if they'd have contacted the stakeholders of the five areas prior, because they probably would have been able to focus more and foreseen some of the problems that have come up in the different areas, and would have probably been a better tailored intervention." (S2PO4)

However, another interviewee felt the central team had engaged with them early on.

"[the SEM leads] have been very engaged from the beginning." (S2P07)

Some interviewees indicated they had an interest in PA prior to the SEM pilot. A PA intervention like the SEM pilot is more likely to be met with enthusiasm if staff already value PA, which in turn will facilitate the implementation of the pilot. Furthermore, the Trust staff are more likely to buy-in to something they think is of value to the patient. Interviewees also said there have been other PA initiatives within the Trust prior to the SEM pilot and this may have 'warmed up' the hospital (or localised areas) to PA interventions making them more susceptible to change.

"I suppose the first thing what helps is if they've had, if they understand the value of it [PA] and understand why they should be doing it" (S2P06)

"I think they tried to implement an active ward previously over at the Churchill before we'd been doing that sort of thing. So I don't think we're coming into a group of people that have never, the doors have been closed and this has never been entertained before." (S2P07) 


\subsection{Summary}

OUHFT staff thought that PA in general was valued by the Trust and that they were supportive of the work that was being carried out as part of the SEM pilot. Despite senior level buy-in it was acknowledged that there are competing interests and PA is not always top of the Trust's strategic priorities. PA promotion was perceived to be the responsibility of all HCPs within the hospital but staff felt it should be driven by SEM consultants.

A number of challenges were highlighted when implementing a Trust wide intervention such as the SEM pilot. A lack of time and resource and competing interests (i.e. A \& E wait time targets) make it difficult to implement changes to encourage PA within a hospital setting. Although PA was valued by staff, it is seen as an extra and is often the first thing to go when time or resources are lacking. Variations in how different pathways operate also meant that the delivery of the pilot had to be flexible and interventions needed to be designed specifically for each setting. Including staff from each pathway in the development phase of any intervention is recommended in order to minimise the risk of the intervention failing.

Interviewees felt there was senior leadership buy in for the SEM pilot and this had helped with the implementation of the project. However, to gain more traction, secure long term funding and ensure the sustainability of the pilot there needs to be changes to policy to make PA a mandatory component of patient care. There has been a shift towards prevention in recent years, evidenced by the recent 'Prevention is better than cure' document from the Secretary of State for Health and Social Care, Matt Hancock. The SEM pilot aligns well with this vision.

\subsection{Implications for this evaluation}

Based on the results from interviews with operational directors and HCPs at OUHFT, the evaluation findings should be interpreted in light of the following:

- The context within which the pilot was delivered may not be reflective of other NHS Trusts:

- OUHFT is considered an innovative teaching hospital - a place where new things happen and as such staff might be receptive to change and new processes.

- It is a large Trust situated across a number of sites.

- Incentive - there was an incentive for this to work - i.e. external funding and possibility of further funding if success is demonstrated.

- $\quad$ SEM is a relatively young discipline, and it's role in preventative public health is not widely recognised or understood. OUHFT had SEM consultants already in situ prior to the start of the pilot and this might not be the case in other Trusts. Scaling the interventions described here through similar models of delivery will require careful thought and may need to be adapted to suit different Trusts. 
- Whether a programme of work such as the SEM pilot could be led by other types of healthcare professional (i.e. physiotherapist, occupational therapist) is unclear and this model would need to be tested. Now that a road map for implementation of an 'Active Hospital' programme has been produced, it is plausible that leads could come from disciplines beyond SEM, providing they possess the personal and leadership skills, gravitas and connections across the local system.

\section{Studies 2-7: Exploration of interventions delivered across individual clinical pathways}

The SEM pilot worked to implement PA within five clinical pathways. The following sections explore the feasibility and acceptability of these interventions through five discrete studies (studies 2-7 in Table 1). The data from these studies is presented here in the form of case studies. The first case study focuses on the bespoke PA training for OUHFT staff. Subsequent case studies explore; Enablement patients' experience of a group PA class and their perceptions of the role of a peer mentor; the impact of a PA training intervention on the behaviour of HCPs in the Maternity and Enablement pathways; the experience of HCPs and patients regarding the promotion of PA on the 'Active Ward' as part of the Renal pathway; HCPs experience of a patient centred PA intervention in the CMU.

\section{Study 2 - Impact of a bespoke Sport and Exercise Medicine led Clinical Champions training programme}

The aims of this study were to i) explore the impact of a bespoke SEM led Clinical Champions training programme (with PA team as recipients) on attitudes, knowledge, confidence, and intentions to promote/engage in a conversation about PA as part of routine practice, and ii) audit the number of subsequent HCPs receiving Clinical Champions training delivered by a PA team member.

Clinical Champions training was originally intended to be delivered by the core SEM pilot team to PA champions within each of the five clinical pathways. The PA champions would then cascade the training down to other members of staff involved in patient care in their respective pathways. The format was intended to be similar to that of the PHE Clinical Champions PA training programme with training delivered to a group using a PowerPoint slide set ${ }^{1}$.

\footnotetext{
${ }^{1}$ This was not the PHE Clinical Champions PowerPoint slide set. Training was delivered with a bespoke set of slides which was not standardised as the different pathways changed the presentations for their respective audiences.
} 


\subsection{Summary of main findings}

The cascade method of training was implemented successfully with staff in the Maternity and Enablement pathways but not in the other 3 pathways. Although this suggests that the structured cascade model of delivering the Clinical Champions PA training is not feasible in all clinical settings there are a number of reasons that help explain the discrepancies observed here. The Maternity and Enablement pathways had dedicated SEM registrars and PA champions from the outset, which facilitated the training. Cardiology also had an SEM registrar but didn't have a PA champion until late in the pilot (January 2019). The other pathways struggled with staff capacity to deliver day-to-day services and so any additional activity simply did not happen. This underlines the importance of dedicated and appropriate resourcing of interventions, as where these are deemed 'nice to have', the reality is that they do not get delivered when resources are stretched.

Data from formal interviews with SEM and pathway leads suggests that within Maternity and Enablement pathways, buy-in from staff was high with some staff even attending training on their days off. On the one hand this presents a positive picture of committed staff, but on the other it points to some of the challenges of implementing training in a resource stretched environment such as OUHFT. Future pilots are wise to acknowledge that where staff do not have protected time to attend training, uptake is likely to be effected. Alternative and potentially more flexible approaches to the face-to-face delivery of training such as drop in sessions, webinars and digital resources (e.g. educational videos) might be more suited to a secondary care context. The SEM core team also suggested that training could be mandated for all HCPs to engage. Whilst this might increase uptake, careful consideration at management level would be required if this type of training was to be implemented in other clinical pathways/Trusts.

Despite variances at an individual pathway level, data from the SEM consultant leads suggested that 18 training sessions were delivered and 249 HCPs were trained across OUHFT during the SEM pilot. Table 3 below provides information about who received the training, what type of training they received (i.e. Clinical Champions PA, motivational interviewing, both or other) and who delivered it. In addition to the face-to-face training, an 8 week online Motivational Interviewing course was delivered to a further 137 OUHFT staff. Staff trained included, but were not limited to Dermatologists, Nutritionists, Physiologists, Physiotherapists, Occupational Therapists, Nurses, Paediatricians, SEM Consultants, Diabetic Medicine staff. This activity has potentially created a critical mass of staff who are on message and have been in receipt of a programme of training on PA. 
Table 3 Details of training delivered in OUHFT as part of the SEM pilot.

\begin{tabular}{llll} 
Pathway & Number of sessions & Number of attendees & Trainer \\
\hline Maternity & 7 & 80 & SEM Registrar \\
Enablement & 4 & 43 & SEM Registrar and Clinical Champion \\
CMU & 2 & 59 & SEM Registrar and Clinical Champion \\
Renal & 2 & 21 & Clinical Champion \\
Other & 3 & 46 & Consultant lead and Clinical Champion \\
TOTAL & $\mathbf{1 8}$ & $\mathbf{2 4 9}$ &
\end{tabular}

\section{HCP survey feedback}

An online survey was distributed to explore the impact of the bespoke SEM led Clinical Champions training programme on attitudes, knowledge, confidence, and intentions to promote/engage in conversations about PA as part of routine practice (see Appendix C.1 for further information). Ten HCPs completed both the baseline and follow-up surveys. At the time of the follow-up survey, all 10 HCPs said they had not completed Clinical Champions training or been involved with any other initiatives as part of this SEM pilot. Given the respondents did not complete the training it is inappropriate to explore the impact of the Clinical Champions PA training on the survey outcomes using this sample. Therefore, we have not presented data in this report. A description of the survey data can be found in Appendix F.2.

\subsection{Implications}

- It is feasible and acceptable to deliver a cascade model of PA training in secondary care, however this appears contingent on having dedicated staff to co-ordinate and deliver the training within clinical pathways (i.e. SEM registrar and Clinical Champion).

- Staff either need dedicated time to attend training or more flexible approaches than face-toface are required (e.g. webinars and digital resources) to overcome resource challenges.

- Data suggests that the training can be delivered by either an SEM consultant, an SEM registrar or a trained Clinical Champion. 


\section{Study 3 - Enablement patients' experience of a physical activity class and their perceptions of the role of a peer mentor}

The aim of this study was to explore Enablement patients' experience of a group PA class ${ }^{2}$ and their perceptions of the role of a peer mentor ${ }^{3}$. Semi-structured interviews took place over the telephone $(n=2)$ or face-to-face $(n=2)$ with 4 patient participants who had attended the Enablement pathway at OUHFT. Details regarding data analysis can be found in Appendix C.8. The topics and themes are described in more detail in Appendix F.3 along with direct quotes to support the themes and provide an example of the point being made.

\subsection{Summary of main findings}

Participants described how much they enjoyed and valued taking part in the Enablement PA class. A consistent reflection reported by all the participants was the universal praise for all staff involved in the delivery of the Enablement PA class and in their patient journey to date. It was evident that the HCPs whom the participants had encountered in the Enablement PA class were particularly skilled in delivering PA based support that was empathetic, motivational and patient focussed.

\footnotetext{
"And they've all been very good to me [healthcare staff]. The whole journey from when I lost my legs has been good. Because one day I had them then I haven't got them. And everybody helped me. The hospital and Nuffield " (S3P04)

"But they do get us moving, get us shifting, encourage us" (S3P02)

"He's allowed me to talk and he's very understanding, empathetic. He's a top bloke really, to be brutally honest" (S3PO2)
}

Participants reflected that the aim of the Enablement PA class was "to get people moving again". This understanding was facilitated by the clear and direct communication style of the HCPs; an approach which was welcomed by all participants. Additionally patients reported a shared responsibility with staff for achieving successful Enablement outcomes.

\footnotetext{
2 These Enablement PA classes did not exist in OUHFT previously but they do exist in some other Trusts. The class was set up by the SEM pilot team with the funding from PHE and is now being continued with Trust funding.

${ }^{3}$ The original aim of this study was to explore patients' experience of a peer-to-peer support programme in two clinical pathways: Enablement and Renal. However only the Enablement pathway provided participants for interview. Furthermore, there were difficulties getting the peer support under way and therefore the focus of the study shifted to the PA class and the perceived role of a peer mentor.
} 
"There's no - how can I put this politely? - BS about them. They're very, very intense with us and they're absolutely brilliant" (S3PO2)

"The ball's in your court, you know" (S3P01)

The contribution of staff to the success of the Enablement PA class cannot be underestimated. Central to the success of the Enablement class was staff whom had the knowledge and the interpersonal skills to create patient rapport and support patient motivation. Staff imparted a sense of professionalism and positivity that in turn gave patients a sense of hope. Patients see several professionals through-out their patient journey and they consistently value their input, professionalism and acknowledge it is the HCPs who help them to move on. Data here suggested that patients perceive that services are under-resourced and that increasing staffing capacity would be beneficial and thus enhance the capacity of future Enablement programmes.

"my answer when it comes to the NHS: there's not enough of them and there isn't enough money, it's as simple as that. The people we have don't need any kind of improvement at all. We just need more of them" (S3P02)

The group-based class format was deemed motivational and it provided the opportunity for tailored patient support yet logistically it accommodated several individuals at once. Despite the current Enablement PA class not having any formal peer mentors the group class was still reported as being meaningful providing patients with the opportunity to share their experiences through informal chats after the class. Building time for coffee and a chat post class seems to be an important feature of the intervention. It seemed implicit for those interviewed that there is more to being in the class than simply taking part for oneself.

\footnotetext{
"Do you know the whole thing is of a value as far as I would say. It's not just one aspect of it. It's the whole group working together and the encouragement of everybody that's there, not just the physios and the doctor. It's everybody else, as patients, helping each other out. And I think it's good we can talk about what happened to us because it is massively life changing " (S3P02)

"And if we can help each other out then that's why we're there" (S3P02)

"We're all in the same boat. We all have the same problems with the amputations. (S3P02)
}

Enablement was described as being more than PA based rehabilitation; it also encompasses learning life skills and learning how to manage post-amputation. This was a key part of the whole Enablement 
approach experienced by the participants and suggests a broad, holistic, integrated approach to Enablement which covers physical, social, psychological and practical needs is valued.

"The best part is, I think has been learning life skills, after an amputation that everything, you know, you have to really plan even the minimum task you have to really plan what you're going to do" (S3P03)

The opportunity for talking and sharing experiences is a key part of the Enablement experience. The desire and intention to support others who have been through something similar and help others was a strong theme. Participants suggested they could offer encouragement and support. Formally sharing their lived experience of amputation and their experience of going through their patient journey in a future peer-to-peer support role was something that was welcomed by two of the participants. However caution should be applied as it was noted...

"There's more to peer-to-peer health than what it sounds like" (S3P02).

Patients were generally willing to give something back and share their experiences. Patients also reported enjoying and benefiting from the camaraderie of their peers and having the opportunity to talk, but it should not be assumed that everyone wants to receive formalised peer support or adopt a peer mentor role. For some patients it was the potential of formally being asked to engage in conversations that might be perceived as personal or uncomfortable that was off putting as opposed to it happening as a natural part of programme engagement. Previous history of other conditions such as mental health conditions, personal preferences, logistical issues (i.e. physical ability to get to venue) also meant some patients did not wish to engage in peer-to-peer support programmes. This is perhaps underlined by the fact that no formal peer mentors were recruited or trained. Mentoring is clearly a complex process and it is likely that it will require the patient mentor to have certain competencies to deliver successful outcomes. Setting, processes, communication skills and mentor characteristics therefore need careful consideration. Moreover, it cannot be assumed that the peerto-peer support model will suit everyone even where these competencies are met. Ultimately, data here suggests that it might be sufficient to create the conditions for patients to informally support one another rather than establish formal structures to achieve what appears to happen naturally. 


\subsection{Implications}

- The implementation of the Enablement PA class was in its infancy, but the findings suggest that it was well received by those attending and had benefits beyond physical rehabilitation.

- The qualities of staff involved in the Enablement PA class were important contributors to its perceived success. Knowledge, interpersonal skills, professionalism and positivity were particularly beneficial.

- The social experience of the Enablement PA class was valued, but this should not be confused for a formal peer mentoring process, which is unlikely to be feasible and moreover desirable for many patients.

- Ongoing monitoring and evaluation is important to fully understand the process of implementation and the potential impact of peer-to-peer support.

- The PA Enablement class is now being funded by the Trust with the existing staff (Clinical Champion and Physiotherapist supervising) as part of the Enablement pathway due to its success during the SEM pilot.

\section{Study 4 - Impact of the Sport and Exercise Medicine intervention on the behaviour of healthcare professionals in the Maternity and Complex Medical Unit pathways}

To explore the impact of the SEM pilot on the behaviour of HCPs in the Maternity and Enablement pathways, OUHFT were asked by the evaluation team to audit electronic patient records prior to and after implementation of the SEM pilot for mention of PA in patients' notes. This intention being to explore whether HCPs were talking to patients about PA more frequently as a result of the intervention. The following case study presents the data that was received from OUHFT in this regard and provides an indication of the impact and reach of the activities taking place in the Maternity and Enablement pathways. The narrative begins with a brief summary of interventions in the Maternity pathway.

\subsection{Maternity}

As part of the Clinical Champions training, nurses within the Maternity pathway were trained to conduct motivational interviewing sessions with the aim of increasing the amount of PA pregnant women with gestational diabetes mellitus (GDM) engaged in. Between 18th May 2018 and 15th February 201948 women were assessed. Women with a diagnosis of GDM were invited to engage in a 20 minute individual motivational interviewing session on PA, delivered by a trained midwife, during their first outpatient appointment as an adjunct to their normal care. Each motivational interviewing session included goal setting and activity planning. A modified version of the exercise 
vital sign (see Appendix E) was used to record self-reported PA levels (moderate intensity or greater) at baseline, and at a two-week telephone follow-up. PA levels were assessed and coded into three categories: Red (<30 min/week), Amber (30-150 min/week), and Green ( $>150 \mathrm{~min} /$ week).

\subsubsection{Summary of main findings}

- There was an increase in PA post-motivational interviewing (see

- Figure 1).

- There was a large decrease in the number of women in the Red category (see

- Figure 1).

- The proportion of women achieving the national PA guidelines increased nearly two-fold and average PA doubled (see Figure 2).
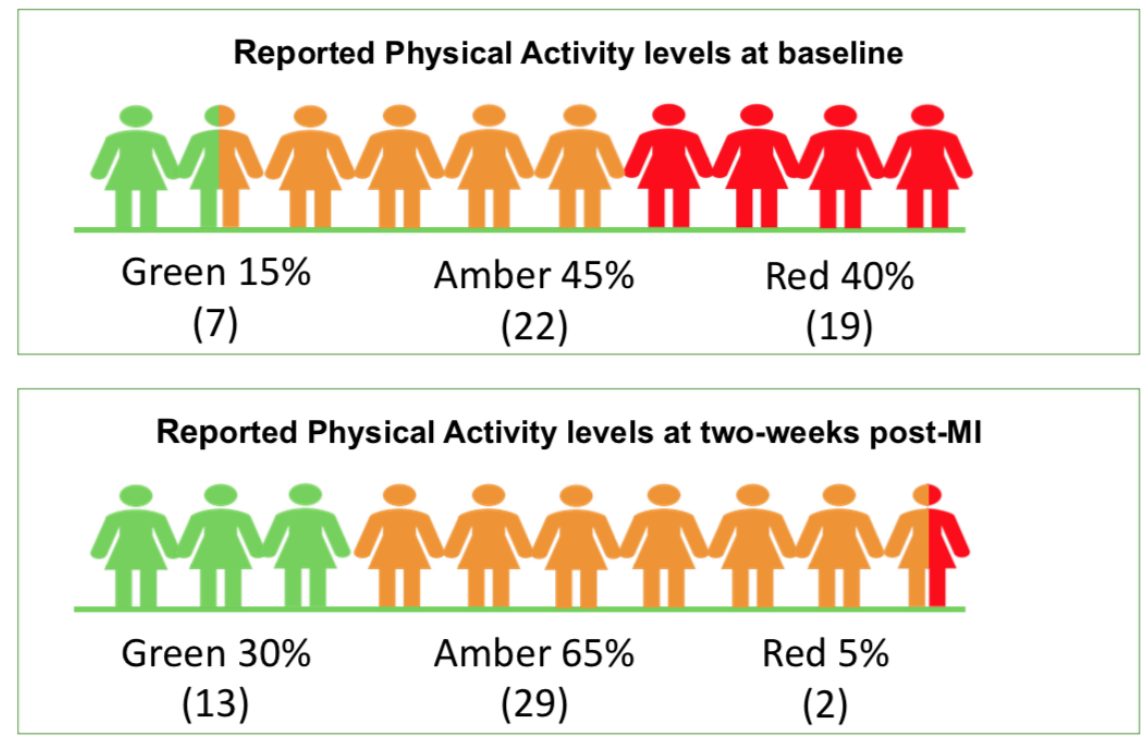

Figure 1 Self-reported PA levels at baseline and two-weeks post-MI (motivational interviewing). 


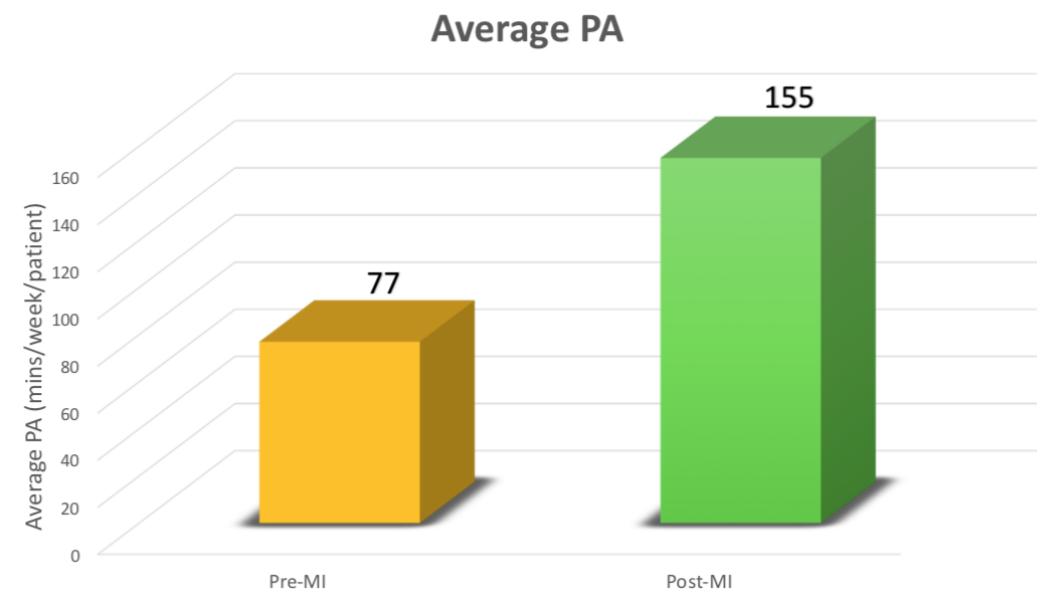

Figure 2 Average self-reported PA levels at baseline and two-weeks post-MI (motivational interviewing).

\subsubsection{Implications}

- It was feasible and acceptable to train HCPs in the Maternity pathway to deliver motivational interviewing to increase the PA levels of pregnant women attending their service.

- It was also possible to embed an exercise vital signs tool within the electronic patient record to record the PA level of every patient at every booking appointment.

- Patients increased their PA as a result of the motivational interviewing they received.

- Whether this type of intervention would be successful in other pathways in not clear and would need testing before any conclusion can be drawn.

\subsection{Complex Medical Unit}

A snapshot audit over a five day period was conducted to identify the number of patients who were suitable to receive a PA intervention (i.e. motivational interviewing, goal setting, exercise advice with bed/seated/or standing leaflet and iCAN tool - see Appendix D) and those who actually received one. Exclusion criteria were as follows; a 'track \& trigger' score greater than one, cognitive impairment, end of life care and patient refused intervention.

\subsubsection{Summary of main findings}

- The SEM consultant lead reported that a total of 20 iCAN documents (developed as part of the SEM pilot) had been used with patients but as the iCAN has been through a series of redesigns since January 2018 its use might not always have been recorded.

- It was not clear how many staff had been trained to deliver the iCAN intervention.

- Following a five day snapshot audit of the CMU pathway it was apparent that the exclusion criteria were sensitive but not specific (excluded suitable patients), see Figure 3. 
- Data demonstrated only the PA champion was encouraging patients to be physically active, see Figure 4. Therefore on days when the designated PA champion was not on the ward, patients were not encouraged to be active.

- This suggests other members of staff think that it is not their job to encourage PA. Creating a culture on the ward whereby the promotion of PA is everyone's business has to be the goal but data here suggests that this is not business as usual.

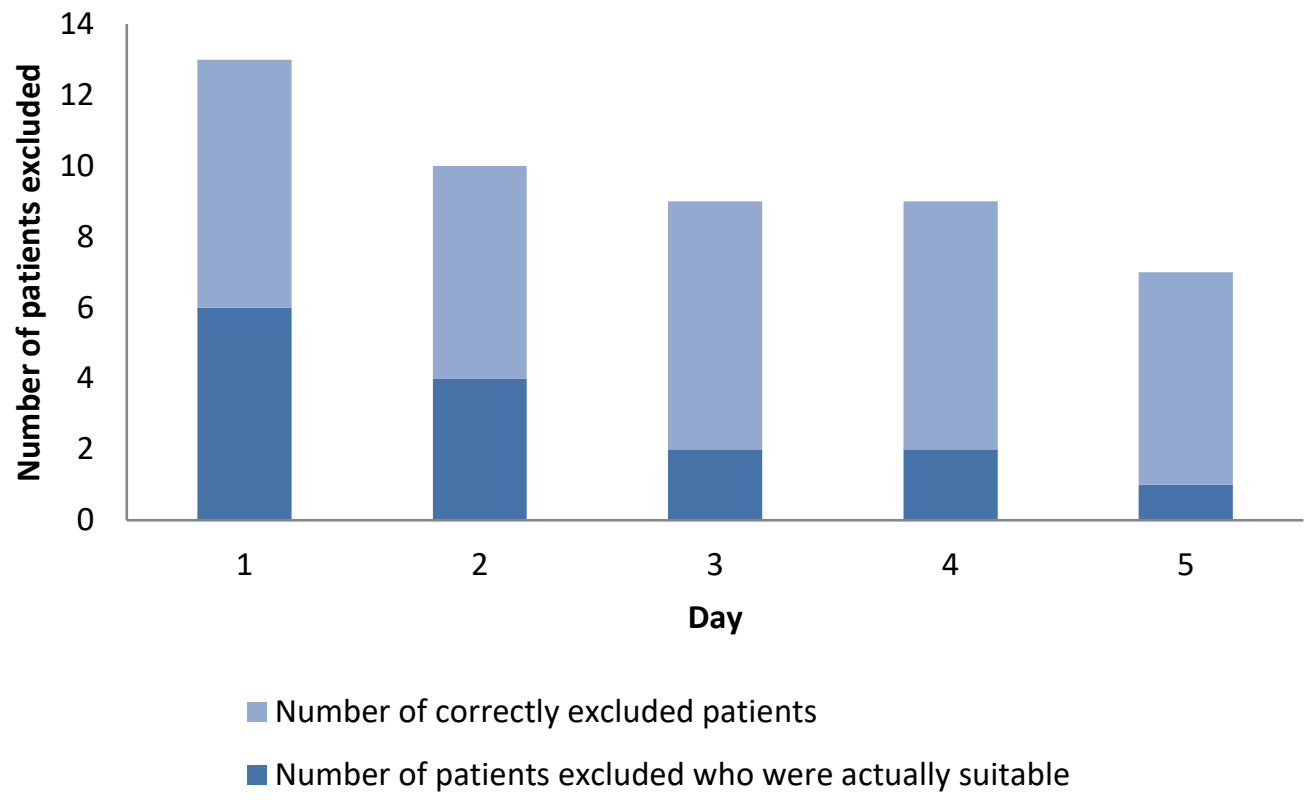

Figure 3 Number of patients correctly and incorrectly excluded from a PA intervention on the CMU ward. 


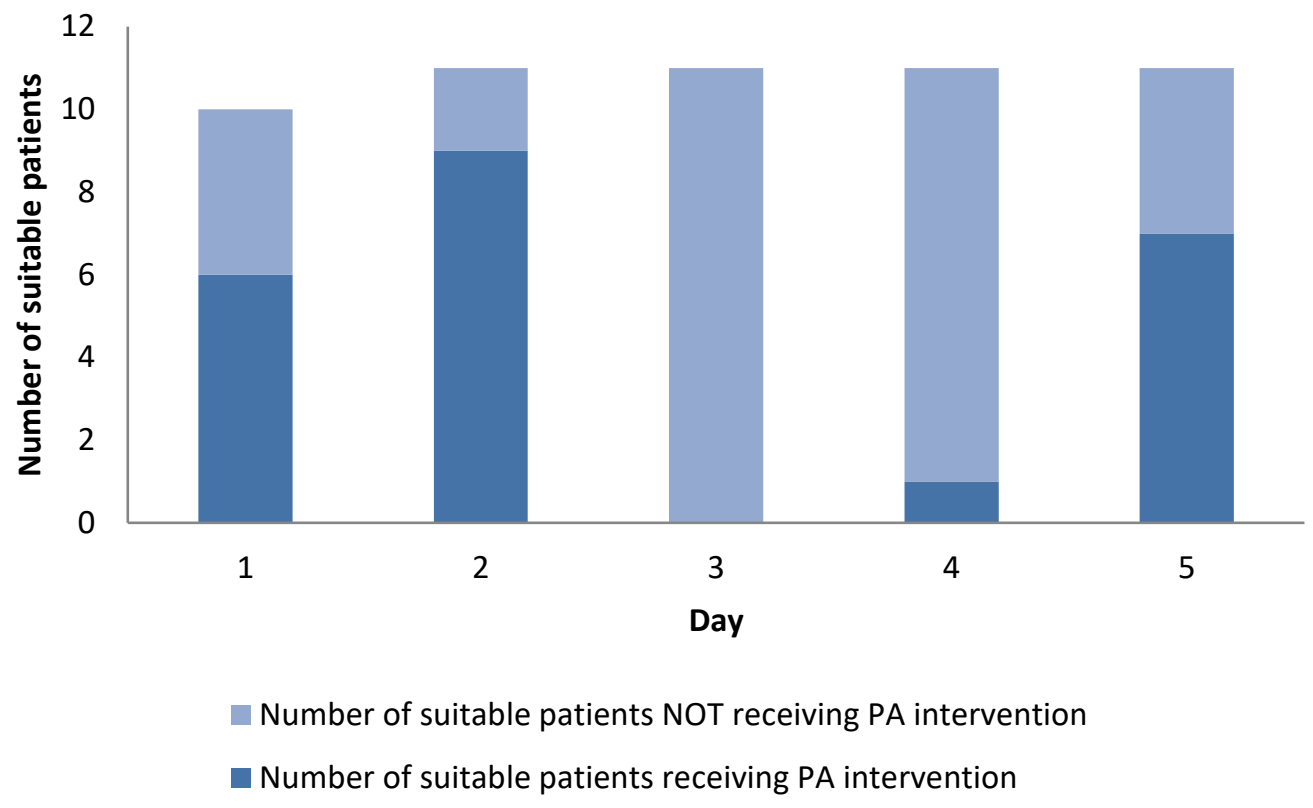

Figure 4 The number of suitable patients who did and did not receive a PA intervention on the CMU ward. The PA champion was not on the ward on day 3. 


\subsubsection{Implications}

- Patients can be encouraged to increase their PA on the CMU ward through a simple intervention such as the iCAN tool. We found little evidence of the impact of this tool in facilitating the transfer of this message to different wards as part of the patient journey.

- Careful consideration needs to be given to the unintended consequences of PA champions, as they might inadvertently limit the spread of a mind-set of 'its everyone's business to promote $\mathrm{PA}^{\prime}$.

- An alternative approach might be for the PA Champion to oversee and coordinate activities on the ward whilst encouraging ward staff to implement the intervention rather than be responsible for actual delivery.

- To improve the consistency of PA promotion and ensure sustainability it is recommended that the core SEM team encourage the wider MDT to engage with and take ownership of the PA intervention on the CMU ward.

- The exclusion criteria should also be refined to ensure all suitable patients receive a PA intervention.

\section{Study 5 - Acceptability of an active ward in the Renal pathway}

The aim of this study was to understand the experience of HCPs and patients regarding the promotion of PA on the 'Active Ward' as part of the Renal pathway at OUHFT4. Two face-to-face semi-structured interviews took place with HCPs working in the Renal pathway at OUHFT. One telephone interview was conducted with a patient receiving treatment in this pathway. Details regarding data analysis can be found in Appendix C.8 and the interviews are described in more detail in Appendix F.4 along with direct quotes taken which help demonstrate the findings and support the researcher's interpretation.

\footnotetext{
${ }^{4}$ One of the intended aims of this study was to explore patients' experience of being part of a peer mentoring scheme. The intention was for patients to have a 'buddy' to encourage PA. This was not possible due to the physical environment of the ward and often short patient stay. Additionally patients are mostly kept in isolation to reduce the risk of infection and there is limited social space. This was not considered when the intervention was developed initially.

Out of 3 possible contacts provided, only one patient responded. Since the peer-mentoring scheme was not implemented the participant was questioned as to whether they would value being part of a peer mentoring scheme, whether they would like to be a mentor and what training they would require to be successful in such a role.
} 


\title{
9.1 Summary of main findings
}

Initially, the SEM consultants at OUHFT planned to trial a peer mentoring scheme on the Renal ward. However, it became apparent that it would not be feasible in this pathway for several reasons including; short admission time, a lack of social space and patients are mostly kept in isolation to reduce the risk of infection. The pathway evolved to include a daily walk round, individualised motivational support, goal setting and posters. The HCPs interviewed highlighted the benefits of having an active ward as well as the need for sustainability. Both HCPs were overwhelmingly positive about the importance of using motivational interviewing with patients and the led walks were deemed to be of value.

\begin{abstract}
"Over the last few months we've been seeing the kidney transplants mainly for motivational interviewing and just getting them talking about PA... So the motivational interviewing sessions have probably been the biggest thing. So I sit down with patients and ask them about PA. How they were before their surgery and if doing a bit more since their surgery is something they want to do". (S5P01)
\end{abstract}

However, the medical equipment Renal patients often require on the ward was a barrier as it proved difficult to mobilise patients and took time to get patients to the walk meeting point. Furthermore, there was a clear difference in the level of ability, fitness and willingness to undertake PA in the Renal patients. This could cause patients to become demotivated, for example, if they do not feel like they are being challenged, or conversely, if they feel they are being left behind during the group walks. To our knowledge no alternative modes of exercise had been trialled at the time of writing this report.

\begin{abstract}
"And also with varying levels of ability among the transplant patients, some people are really active, some people not so much. And I think putting them all in a walking group together was quite difficult...... The patients that haven't been so appropriate tend to be the ones that are fitter already and don't really need our support with that". (S5P01)

"There was also the difficulty of people being at very different levels. From somebody that's very active before they came to hospital to somebody that can only really stand for a few minutes before they came to hospital. So there's those sorts of issues". (S5P02)
\end{abstract}

A staffing crisis on the Renal ward was apparent but there was a clear desire to keep the promotion of PA high on the agenda. Staff were keen to maintain visibility of the programme to ensure sustainability. However, this was difficult without dedicated resource. 
"I think it's been slightly difficult for us in particularly because we're really short staffed. We're missing a couple of band 5s.....so ideally we'd be getting patients up into the gym and getting them doing exercise as soon as possible. But sometimes we're a little bit delayed with that which can't be helped because a nurse needs to be with them at all times". (S5P01)

"On Renal ward they were having a real crisis of staffing when we first started". (S5PO2)

Whilst only one patient agreed to be interviewed they were very complimentary about their experience on the ward as well as the PA education and opportunities they received. They felt that PA should be a part of every patient's treatment but it needs to be tailored to individual patient needs and ability. The patient would have been happy to be a mentor or mentee, but they felt that training would be needed to become a peer mentor.

"I'm not clever enough to know what [exercises] that would be. What would be a good idea is that the part of the pack you get when you come out is, while you are in there some information is given about the local centres". (S5P03)

Based on the three interviews (two HCPs and one patient) it appears to be acceptable to promote PA on the Renal ward. Furthermore, HCPs felt that capitalising on the 'teachable moment' early after surgery might act as a catalyst for positive behaviour change. HCPs were keen to explore the possibility of increasing PA prior to surgery; however, they indicated there could be a risk of overwhelming the patient with too much information. Prehabilitation is becoming more popular for a range of clinical populations - the next phase of the pilot could explore this approach in the Renal population.

\subsection{Implications}

- The feasibility of the peer support programme needs exploring further and for the existing PA provision (led walks, motivational interviewing, goal setting) to be sustainable the ward must be adequately staffed.

- Motivational interviewing was evaluated positively by HCPs.

- PA needs to be tailored to suit the individual needs of patients. 


\title{
10. Study 6 - Patient centred physical activity intervention in the Complex Medical Unit
}

The aim of this study was to understand the experience of the SEM pilot within the CMU pathway from the perspective of $\mathrm{HCPs}^{5}$. Semi-structured interviews took place over the telephone $(n=2)$ or face-to-face ( $n=1)$ with three HCPs working in the CMU pathway at OUHFT. Details regarding data analysis can be found in Appendix C.8 with more detail on the content of the interviews provided in Appendix F.5 along with direct quotes to support the themes and provide an example of the point being made.

\subsection{Summary of main findings}

The HCPs interviewed perceived a clear need for this intervention on their ward. The mobilisation of patients on the CMU ward was a priority, to prevent pressure areas and infections developing through lack of movement. It was regarded a positive move towards a shift in culture for both ward staff and patients.

\begin{abstract}
"Most people that I've come across have been really pleased about doing it. They've enjoyed it. Sometimes they've been surprised about what they've managed and it's generally been well received by patients" (S6P03)

"it's the knock-on effect...it only takes one in the bay and someone else will say tomorrow, well he's walking, Alfie's walking to the toilet, I'd like to do that." (S6P02)
\end{abstract}

The implementation of the SEM pilot in the CMU pathway evolved into the use of exercise booklets and the iCAN tool with patients on the ward. The aim was to change the culture of the ward such that PA and mobilisation were encouraged to all patients (wherever possible) by all staff. The staff identified training needs, changes to practice and the need for a PA champion to facilitate implementation.

"what's made it easier, obviously having people having some dedicated time for this, and having some dedicated champions on the ward that are nurse based" (S6P03)

\footnotetext{
${ }^{5}$ The original aim of this case study was to explore patients' experience of the PA intervention. This was not possible as no patients were identified by staff in the CMU pathway. One HCP working on the ward suggested that telephone interviews were not appropriate for $\mathrm{CMU}$ patients. We did not have ethical approval to conduct home visits. We are aware that a questionnaire for patients has been developed by staff at OUHFT that could be used to evaluate the scheme.
} 
It was apparent that physiotherapists were already well accustomed to the emphasis on mobility and accustomed to mobilising patients, whereas this was not always a priority for nurses. The iCAN tool was praised for facilitating communication between staff, especially staff across different shifts and for its ease of use.

"It's found to be helpful, especially for communication between members of the team when they come to work" (S6P01)

The staff interviewed were hopeful that the iCAN tool would encourage patients to keep mobile and functioning at their pre-hospital level, helping prevent deconditioning. The exercise booklets were also praised for being easy to use.

"can be distributed by any member of staff, they're fairly self-explanatory" (S6P03)

It was important that the intervention fitted easily within the system and existing work practices. An example of this was taking an existing skin integrity assessment tool (SKIN) and placing more emphasis on the 'keep moving' element of this assessment, thus not asking staff to do anything different (i.e. low burden). Anecdotal evidence from the staff suggested that the exercises were well received by those patients who experienced them.

\footnotetext{
"I have seen a nurse doing exercises with a patient. The patient looked very involved and interested and taking it seriously as something good for his health, and as a positive really." (S6P01)
}

Staff noted that that the exercises were not suitable for all patients, for example those with palliative care needs, suggesting that an individualised and case-by-case approach to implementation is needed.

\subsection{Implications}

- The feasibility of the patient-centred PA intervention on the CMU needs exploring further, especially from the viewpoint of the patients receiving the intervention.

- Where an intervention targets the MDT, staff with different training backgrounds may have different training needs. 
- Interventions are received well by staff when they fit within existing systems and work practices.

- Motivational interviewing was evaluated positively by HCPs.

- PA needs to be tailored to suit the individual needs of the patients.

\section{Study 7: Experiences of lead Sport and Exercise Medicine consultants in delivering the Sport and Exercise Medicine pilot}

The SEM pilot at OUHFT was overseen by two SEM consultants. A senior SEM Consultant with over 10 years' experience of working in SEM at OUHFT (one session a week in their job plan allocated to the project), and a newly appointed locum SEM consultant that was funded two days per week to implement the pilot. These posts are here forward referred to as 'lead SEM consultants'. There are other SEM roles aligned to the SEM pilot (i.e. SEM registrar) but they are not considered here.

The primary aim of this study was to explore the experiences of the lead SEM consultants in implementing a broad programme of PA in a hospital Trust. Objectives included exploring:

- The demands placed on the SEM lead consultant during the SEM pilot.

- Barriers and facilitators to implementation of new PA services.

- Lessons for scaling of interventions in other NHS Trusts.

- Leadership qualities required from SEM lead consultants in implementing system wide programmes.

Face-to-face semi-structured interviews were conducted with the lead SEM consultants midway through the implementation of the pilot and post-pilot. Details of data collection and analysis can be found in Appendix C.

\subsection{Leadership that is trusted and enduring}

The ambition and vision of the OUHFT SEM pilot meant that implementation was complex and challenging. The pilot aimed to work across five clinical pathways and deliver multi-component interventions across the physical and cultural environment of the hospital including embedding change within IT systems and different areas of clinical delivery. The importance of strong and committed leadership across the system was highlighted consistently in interviews and this is perhaps where the importance of long-standing relationships of the senior SEM consultant at the Trust was invaluable. The SEM pilot was delivered with a dual consultant model. A senior lead (one session/week) and a locum SEM consultant who was allocated to the programme two days per 
week $^{6}$. The senior lead took overall responsibility for the project with service delivery overseen by the locum. The senior lead made introductions between the locum and key staff across the Trust and ensured that the locum was able to navigate their way around the hospital - culturally and politically, as well as structurally. This 'intuitive' knowledge of the Trust gained through working in the context for over 10 years was a significant advantage when implementing the pilot.

\begin{abstract}
"I think it would be very difficult for a new consultant to come into a Trust and immediately set up a new service like this. I think you need to know people both on the clinical and the managerial side, or it makes it an awful lot easier if you do. I'm not saying it wouldn't be possible, I just think it would take longer. "S7P02
\end{abstract}

The message here was that culture isn't created overnight and it is crucial to recognise this when scaling SEM pilots in other Trusts across the UK. So much of the culture change observed at OUHFT was driven through long-standing and trusted relationships and whilst this can potentially be achieved through force of personality on occasion, we observed the importance of a long history of SEM as a key driver for change here. Future programmes might need to lengthen any 'set-up' phase where these long-standing relationships do not already exist.

\begin{abstract}
"These things generally get driven by influential people with a strong desire for change and so when we're looking to scale this model we need to have things that are going to enable those people to start making changes. "S7P01
\end{abstract}

\title{
11.2 Understand how the NHS system works
}

Within any complex system it is important to understand how the system behaves (Tsasis et al., 2012) and data here suggested that it is important that conversations occur between the same hierarchical 'levels' of professional within the Trust - particularly at the outset of the pilot when making the case for engagement. For example, because the SEM lead was from a 'medicine' background, they were able to have conversations with other consultant leads in other services in a more direct manner than perhaps a HCP might be able to. The model of having a consultant at the top is also consistent with other services in the hospital. Reaching agreements, achieving a mandate for action and working out how interventions could be implemented could be achieved more efficiently (or indeed actually implemented) through a consultant to consultant level approach.

\footnotetext{
${ }^{6}$ The person undertaking this role left after 12 months in post and was subsequently replaced in January 2019.
} 
"Where there's a senior clinician, a consultant who is engaged in driving forward some of these initiatives in a department that makes a huge difference in terms of the impact there and that really impacts upon the speed at which you can make stuff happen."

(STP01)

Moreover, the degree of scepticism about PA and other non-medical interventions amongst some clinicians and managers was perhaps more easily overcome due to the existing trust between longstanding consultants. The experiences described here suggest that it would perhaps be more difficult if these conversations needed to happen across different hierarchical levels and with staff who are new to the Trust. These are key factors to understand when considering scaling and translating the pilot work to other Trusts.

\subsection{Create the team from a coalition of the willing}

Leadership from the lead SEM consultants was a key factor in the acceptability and feasibility of the pilot but data from the interviews highlighted the importance of developing a 'network of champions' within departments and services so that lines of communication could easily be maintained.

\footnotetext{
"The PA champion network works so well because you have someone that's in that service and you're talking to them regularly, and if there's problems in an area you can go and chat to the people in that service a bit higher up the food chain or something like that to see what the barriers are and explore things." (S7P01)
}

One of the roles of the lead SEM consultant(s) was therefore to spot opportunities for collaboration and in essence establish a coalition of the willing. In that regard, the lead SEM consultant(s) needed to have the skills, influence and mandate to 'join the dots' of practice that was already occurring in the Trust. This had the effect of creating momentum across departments that was beyond what was being implemented directly through this pilot.

\footnotetext{
"The more you find people are doing stuff, like one of the vascular surgeons has set up milestones for walking down the ward and things like that. So there are people doing stuff like this and this is where having a central service to support it and share ideas and things like and drive change is so valuable really, because all these small things that people are already working on and doing brilliantly that work in different environments have just never been coordinated." (S7P01)
} 
To achieve this, the lead SEM consultant(s) reported spending a significant amount of time having meetings with a substantial range of people across the Trust, in terms of; engagement, talking about what they can do, what they can offer, how PA and SEM skills can fit into services. Undertaking a mapping exercise at the outset of the pilot to explore the physical and social environment of the hospital, who is working where, what can be fitted in where, what's being done well in the hospital, where things can be augmented and where the key partners are, would be a sensible first step in implementation of future SEM pilots.

\subsection{A flexible approach and a willingness to fail fast}

At the outset the SEM pilot had clearly articulated plans for how and importantly where PA was to be embedded within the Trust. This included exploring the theoretical underpinning for behaviour change using the COM-B model, which was a strength of the approach. The lead SEM consultants also explored the interests of people across different departments, audited what was happening already and subsequently explored what could be augmented to include a greater element of PA. This work was undertaken in addition to the planned pathways of work in this pilot. Over time, it became clear that changes to the implementation process needed to be made, either because services were simply inappropriate for the proposed interventions (i.e. Critical Care) and/or because there were existing activities that could be harnessed to drive forward a change in culture but were not part of the original scope. The SEM lead(s) therefore needed to be sensitive to where these new opportunities existed whilst at the same time not being dogmatic about pre-planned activity but instead looking for opportunities across the system to intervene.

\footnotetext{
"You just shoehorn things in, I don't think it's the best way of doing things but because of the reality of the timelines we've just been just jumping on any opportunity we can and making it happen." (STPO1)
}

The SEM consultants also needed to be able to recognise that the contexts differed significantly between departments and this was facilitated by a baseline understanding of what was currently being delivered in the Trust, where it was being delivered and by whom.

\footnotetext{
"We might be working on general medical wards one ward to the next ward and the routines will be different, the staffing patterns will be different, when they do the drug rounds will be different." (S7P01)
}

These qualities of flexibility also applied to the development of resources. The implementation of activities as a one size fits all approach would not work due to the varying contexts within the Trust 
services. The COM-B approach to intervention mapping helped engender some consistency across the pilot and it is recommended that future programmes follow a similar approach.

\footnotetext{
"It has to be very individualised within [departments], so you work from the core elements, but then the implementation has to be tailored, so there's that difficult balance between making common resources to support everybody, but having flexibility that they can be adapted into whatever the demands of the specific service are." (STP01)
}

It is important to be mindful that this phase of evaluation was about feasibility and acceptability and therefore it was really important to explore the SEM pilot in a number of different pathways. The diversity of work whilst challenging has been a strength of the pilot. The approach here is therefore perhaps best described as 'starting a thousand fires, knowing only a few will keep going'. The risk with this approach is that next time people are less receptive to the 'offer' but data here suggests that getting spread as well as depth across a Trust is important when it comes to increasing the profile and priority of PA. It is likely that future pilots will need to seek out the 'open doors' for interventions but the road map developed here will potentially support the process of this.

"I think it's very easy to create an initial spark, but to build on it and continue to motivate people over a number of years and to progress things is a whole different ballgame." (S7P02)

\subsection{System supporters to drive change and ensure sustainability}

The lead SEM consultant(s) identified that points of contact need to be embedded in pathways and these 'champions' need to be given the freedom and mandate to lead change locally. In addition, ensuring that these roles/people are engaged early in the process is crucial as this prevents the mind-set of:

"there's a new PA team and they're going to be doing some stuff to your patients...".

"Having someone already in the department to be able to be there and initiate, so we've got a therapy assistant working with amputees who was working part-time as a therapy assistant and part-time in research and he was allowed to come out of his research time to deliver this." (S7P01) 
The SEM consultants were also required to develop new leaders of culture change within different services so that once their direct support was withdrawn, the services did not immediately revert back to type.

\begin{abstract}
"So having regular contact with different departments and that's where the PA champion network works so well, because you have someone that's in that service and you're talking to them regularly, you can have team meetings with them and the others, sharing ideas, working on things and if there's problems in an area that something's not happening or there's barriers that you can go and chat to the people in that service a bit higher up the food chain or something like that to see what the barriers are and explore things." (S7P01)
\end{abstract}

It wasn't deemed sufficient to simply appoint the team leads and kick-start the intervention, data here suggested that there needed to be longer-term and planned support and audit of the process.

"I think there has to be core components that are structural just because of the nature of the most essential things will always be done." (S7P01)

One way to achieve this was through establishing policies and structures that aligned to making the new behaviours sustainable. These policies then needed to be bolstered with good governance and follow-up processes.

"if you set it up but leave them and you never go back to them, it might sustain for another year. So, what you need to do is set things up, then leave them, but keep going back and reminding them, do some audits, do the patient feedback, do the health professional feedback, do the 360 appraisals, all those things as part of a really robust governance structure and that will sustain it but that all takes work and it takes leadership." (S7P02)

The lead SEM consultants suggested that they were used to dealing with clinical governance on a regular basis and so this is perhaps an important reason as to why a consultant role is well suited to leading these types of interventions. The system leadership and central co-ordination functions provided by the lead SEM consultants was also essential in the sustainability of the interventions. Throughout the pilot they acted as voices for the change and provided a platform upon which to continue to build. Had the support of this core team been removed, evidence here suggests that the pilot would have potentially collapsed. 
"everyone's getting engaged and they've made a big effort at it, but then the reality is that it's hard to maintain, because to sustain that change takes a lot more than just a good idea and an intervention. They have to be embedded in the day to day practice of that specific department" (STP01)

In addition, interview data suggested that there were a number of practical aspects to the set-up of the pilot that could have enhanced implementation. These included but were not limited to the early employment of staff on the programme, finance systems being established at the outset, and system prompts setup through the Electronic Patient Record. This is the ideal scenario of course and this needs to be tempered with the realities of implementing change within a resource stretched Trust with multiple competing agendas for that resource. Not to labour the point, but this is where the experience, connections and trusted relationships of the senior SEM consultant were perhaps most valuable. Being able to navigate the political climate of a large Trust is challenging and change programmes such as the one described here are potentially at risk of getting swamped by larger agendas without strong senior leadership.

\subsection{More than just physical activity}

The lead SEM consultant(s) were realistic about the stage at which the SEM pilot was in terms of being wholly embedded within the core offer of the Trust. The SEM lead consultant(s) also identified that the sell to commissioners needed to include the contribution that SEM will make to the day to day activity of the Trust and not just on the basis of a culture change programme to promote PA, even where the rationale was that it might save money further down the line. This is important insight when thinking about making the case to scale such interventions to other areas of the UK, and talks to the tangible case that needs to be made to drive forward prevention agendas such as this. If they can be aligned or linked to a resource that can equally contribute to the here and now challenges, as well as the future vision then the view here from the lead SEM consultants was that they are more likely to be accepted.

"I think from a Trust, writing a job plan, doing a VCF and employing somebody, they need to have the easy quick wins. They need to know that you can see 50 patients a week and you can bring in the money that way... we'll do that for three days a week and then for the other two days I'm going to do this PA intervention, I think that's easier" (STP02) 


\section{Conclusions}

The SEM pilot represented a complex system intervention. It therefore required consistent leadership from senior clinical staff with excellent negotiation skills, gravitas and an ability to make connections across system components for it to work. The data captured here also identified that a depth of relationship and pre-existing high levels of trust might also be important in successfully delivering such an ambitious pilot in a large Trust with multiple dynamic relationships and hierarchies. Where a Trust has a lead SEM consultant(s) with these skills and broad networks then a programme similar in size and scale to that delivered in OUHFT could feasibly be replicated with the necessary mandate from Trust executives. Where this is absent then we would suggest a more modest approach is adopted (e.g. identifying one clinical area to work within in to demonstrate success). It is crucial that this is considered in the spread of any learning from this pilot as failure to do so could lead to a significant waste of resource.

\section{Implications}

The results from this evaluation will have direct implications for OUHFT and ongoing implementation of the SEM pilot. There is also the potential for wider implications for practice, with OUHFT sharing its learning with other Trusts across the UK.

- A PA culture isn't created overnight and it is crucial to recognise this when scaling SEM pilots in other Trusts. So much of the culture change observed at OUHFT was driven through longstanding and trusted relationships and whilst this can potentially be achieved through force of personality on occasion, we observed the importance of a long history of SEM as a key driver for change. Future programmes might need to lengthen any 'set-up' (up to 6months) phase where these long standing relationships do not already exist.

- The experience, connections and trusted relationships of the senior SEM consultant are extremely valuable, especially in being able to navigate the political climate of a large Trust with competing agendas and limited resource.

- Undertaking a mapping exercise at the outset of the pilot to explore the physical and social environment of the hospital, who is working where, what can be fitted in where, what's being done well in the hospital, where things can be augmented and where the key partners are, would be a sensible first step in implementation of future SEM pilots.

- New initiatives need a flexible approach to implementation. SEM lead(s) need to be responsive and sensitive to where new opportunities exist, looking for opportunities across the system to intervene.

- The COM-B approach to intervention mapping helped engender some consistency across the pilot and it is recommended that future programmes follow a similar approach. 
- The sell to commissioners needs to include the contribution that SEM will make to the day to day activity of the Trust and not just on the basis of a culture change. If proposed outcomes can be aligned to current challenges, as well as the future vision then they are more likely to be accepted.

\section{Strengths and limitations of this evaluation}

The main strengths of this evaluation relate to its methodological rigour. Using the SHU research team as external evaluators means that the evaluation was independent of OUHFT and PHE. A key strength was the use of mixed methods to collect a range of relevant and in-depth data to aid the evaluation.

The evaluation team identified a number of methodological challenges to this evaluation, which should be considered when interpreting the findings. The sample size at each data collection point varied and some were small. With small samples it is difficult to reach robust conclusions and findings should be interpreted with caution. Larger sample sizes might further support the present findings but might also reveal new insights and potentially contradictory opinions. That said, this was an exploration of acceptability and feasibility and not effectiveness and so the sample sizes are perhaps less of a limitation in this context. It is also possible that self-selection bias resulted in a sample that may be skewed towards reporting outcomes from patients and HCPs who are highly engaged with the pilot.

When considering the potential for SEM pilot to bring about change, it is important to be realistic about the time it may take for change to happen. Embedding SEM into the Trust is likely to require a change in culture and therefore any changes brought about by the SEM pilot might not be expected to manifest as measurable change within the lifespan of this evaluation. 


\section{Acknowledgements}

The evaluation team would like to thank OUHFT for their support and contributions to the evaluation. We greatly appreciate the time and enthusiasm displayed by the patients and staff we worked with.

\section{References}

BRANNAN, M., BERNARDOTTO, M., CLARKE, N., \& VARNEY, J. 2019. Moving healthcare professionals - a whole system approach to embed physical activity in clinical practice. BMC medical education, 19, 84.

FINLAY, I. 2001. UK strategies for palliative care. Journal of the Royal Society of Medicine, 94, 437441.

GAPA 2012. Global Advocacy for Physical Activity (GAPA) the Advocacy Council of the International Society for Physical Activity and Health (ISPAH). NCD Prevention: Investments that Work for Physical Activity. British Journal of Sports Medicine, 46, 709-712.

GLEESON, M., BISHOP, N. C., STENSEL, D. J., LINDLEY, M. R., MASTANA, S. S. \& NIMMO, M. A. 2011. The anti-inflammatory effects of exercise: mechanisms and implications for the prevention and treatment of disease. Nature Reviews Immunology, 11, 607.

KOHL, H. W., CRAIG, C. L., LAMBERT, E. V., INOUE, S., ALKANDARI, J. R., LEETONGIN, G., KAHLMEIER, S. \& GROUP, L.P. A. S. W. 2012. The pandemic of physical inactivity: global action for public health. The Lancet, 380, 294-305.

LEE, I.-M., SHIROMA, E. J., LOBELO, F., PUSKA, P., BLAIR, S. N., KATZMARZYK, P. T. \& GROUP, L. P. A. S. W. 2012. Effect of physical inactivity on major non-communicable diseases worldwide: an analysis of burden of disease and life expectancy. The lancet, 380, 219-229.

MICHIE, S., ATKINS, L. \& WEST, R. 2014. The behaviour change wheel: A guide to designing interventions, Great Britain, Silverback Publishing.

PUBLIC HEALTH ENGLAND 2014. Everybody Active Everyday: National Physical Activity Framework. In: ENGLAND, P. H. (ed.). London: Public Health England.

TSASIS, P., EVANS, J. M. \& OWEN, S. 2012. Reframing the challenges to integrated care: a complexadaptive systems perspective. International journal of integrated care, 12.

WOODCOCK, J., FRANCO, O. H., ORSINI, N. \& ROBERTS, I. 2010. Non-vigorous physical activity and all-cause mortality: systematic review and meta-analysis of cohort studies. International journal of epidemiology, 40, 121-138. 
Evaluation of the Public Health England and Sport England Funded Sport and Exercise Medicine Pilot in Secondary Care

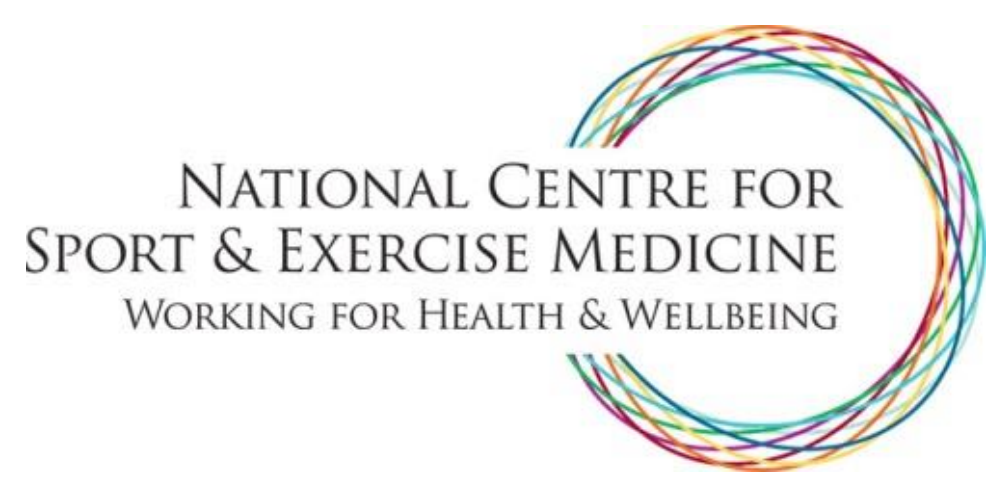

\section{Sheffield | Centre for Sport \\ Hallam and Exercise \\ University $\mid$ Science}

\section{Appendices}




\section{Appendix A - Overview of Sport and Exercise Medicine pilot pathways}

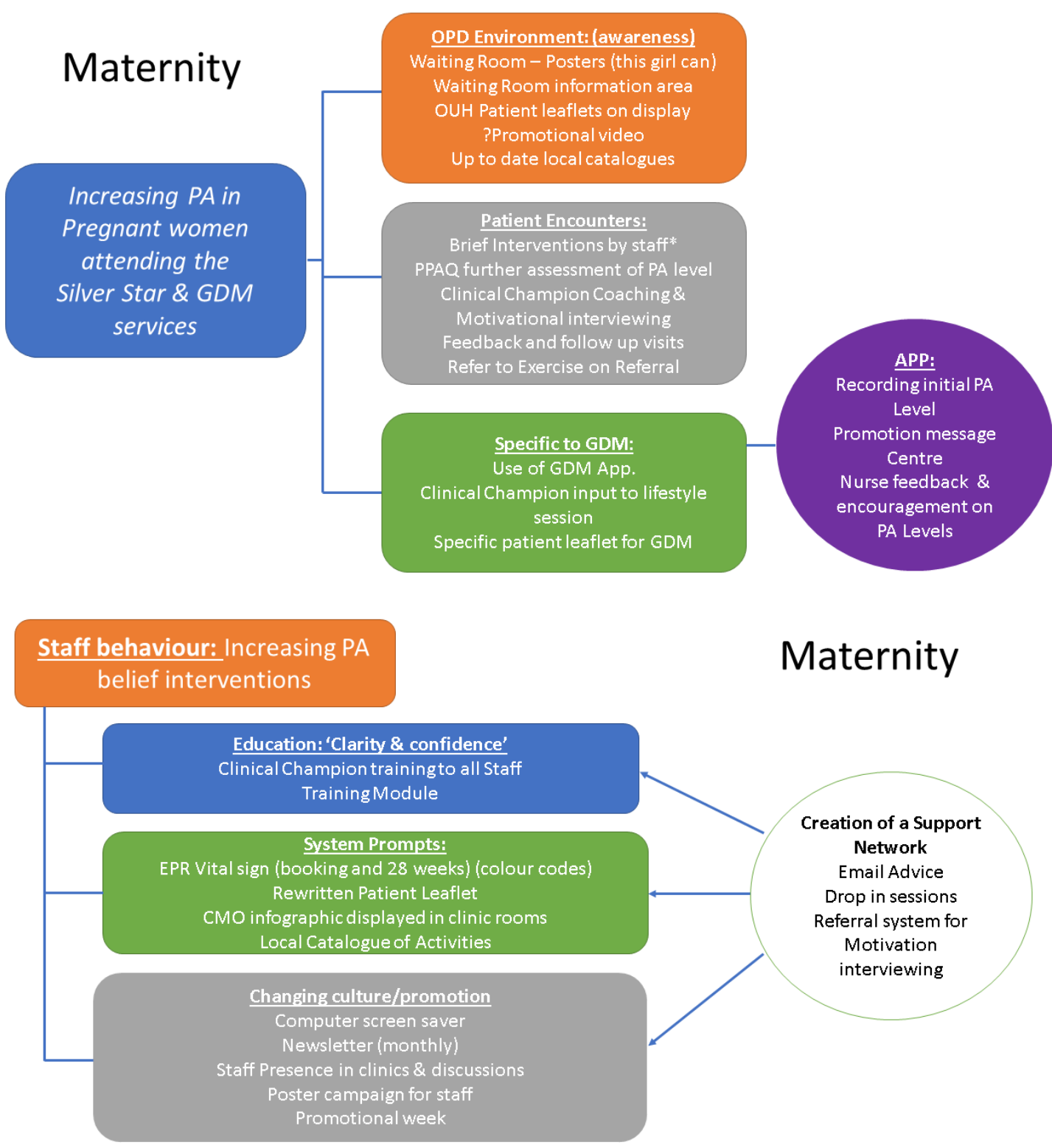




\section{Medical amputees PA}

\section{Circuits class}

- Part of weekly rehabilitation

- Health related PA

- Training to do activities at home

- Starting March

\section{Weekly education component}

Link to community resources that can support ongoing PA

\section{Medical amputees peer support}

\section{Class based model}

- Education sessions around PA class

- Weekly group meeting

- Patient information

Remote support

- Establish network for remote communication

- Utilise Living without limbs network meetings

- Explore social media and other options

\section{Leadership}

- Identify patient leaders 


\section{Transplant - Patients PA on Active Ward}
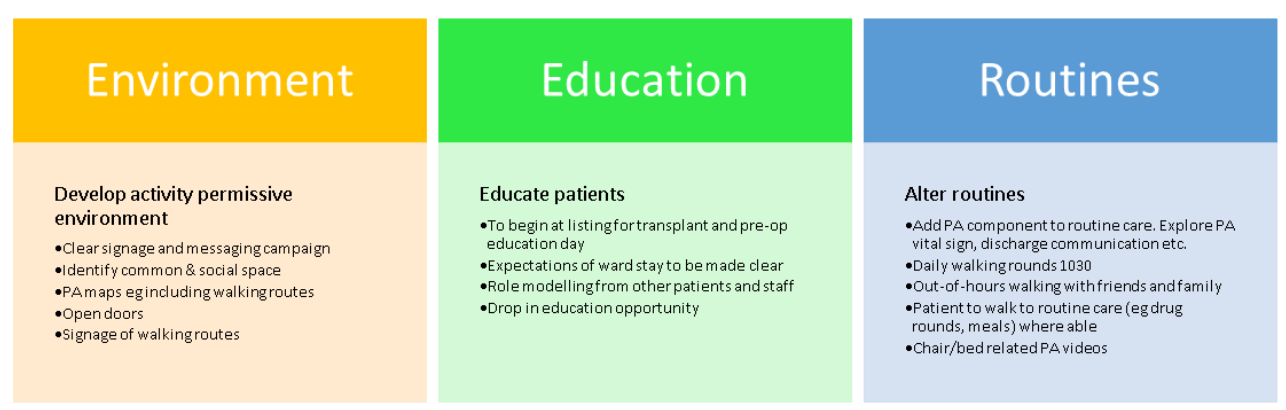

\section{Transplant - staff education}

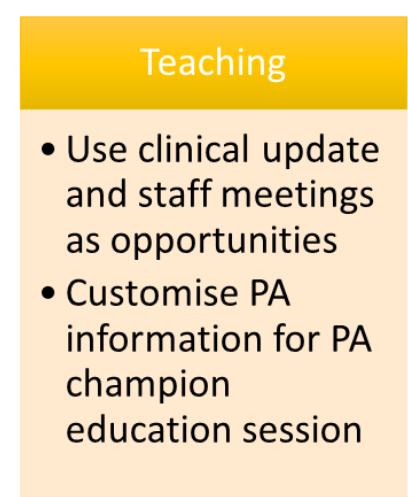

Signage and posters

- Education messages

- Include influential members of staff

- Use screensavers and computer opportunities

\section{Transplant patients peer support}

In pathway
- Contacts at
appointments and
pre-op education day
- Visit ward pre-op
- Focus on contacts
made during walking
rounds during
inpatient stay

\section{Remote support}

- Establish network for remote communication

- Utilise Living without limbs network meetings

- Explore social media and other options

\section{PA advice}

- Contact for advice

- Drop in opportunity 


\section{Critical Care - post ICU discharge patient PA}

PA initiatives to follow patient

- Develop clear PA component of ICU discharge and handover

- Test iCAN concept single page to go with obs chart

- Empower patient to do autonomous movement within capability
PA champion contact on

$$
\text { the ward }
$$

- Customise activity plan to augment physio offer

- Continuity with input from ICU team

- Educate patients and provide information

\section{Leadership}

- Clear message to receiving wards (28 of them) that PA is vitally important for the sickest of patients in the hospital

\section{Critical care - PA behaviour of ward staff}

\section{Patient derived}

- Clear messaging and simple pathway to follow patients

- Education component to this

\section{Education for staff}

- Staff meetings

- Grand rounds

- Routine education opportunities

- Mandatory training 


\section{Cardiology - PA of patients on Day case ward}

Education
- Patient information on
benefits
- Resources to support
activity once home
- Staff reinforcement
- Links to community
providers

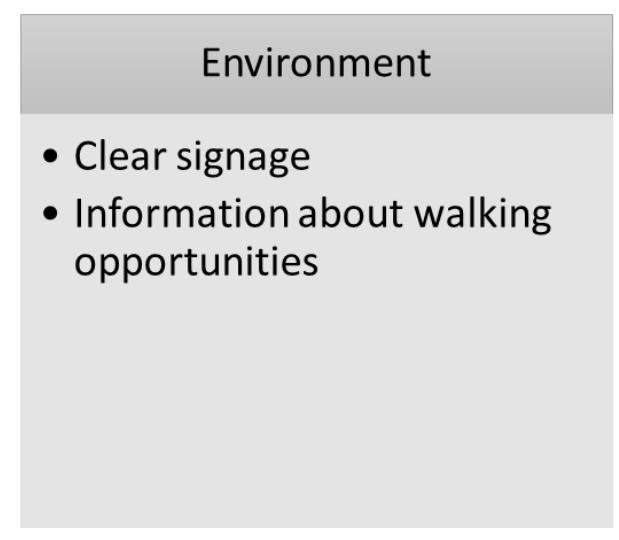

\section{Cardiology - TAVI patients PA}

At MDT assessment
- Education from staff
- PA consultation \&
MI
- Information \&
education materials
- Links to community
offer

Pre-op ( 10 weeks)
- PA champ contact
via phone
- Community
navigator
involvement to
network community
support

Procedure admission

- Early mobilisation

- Explore transferability of iCAN concept

- Regular PA contacts with clinical staff 


\section{Appendix B - Example COM-B framework}

Table 4 Example COM-B framework: Enablement pathway.

\begin{tabular}{|c|c|c|c|c|c|}
\hline $\begin{array}{c}\text { Target } \\
\text { Behaviour that } \\
\text { you are } \\
\text { wanting to } \\
\text { rhanos }\end{array}$ & \multicolumn{2}{|c|}{$\begin{array}{c}\text { Health related physical activity of } \\
\text { medical amputees in rehabilitation } \\
\text { pathway }\end{array}$} & Intervention Overview & \multicolumn{2}{|c|}{ Development of PA class for medical amputees } \\
\hline $\begin{array}{l}\text { COM-B } \\
\text { component }\end{array}$ & $\begin{array}{l}\text { Intervention } \\
\text { function }\end{array}$ & $\begin{array}{l}\text { Intervention } \\
\text { description }\end{array}$ & Policy Category & $\begin{array}{l}\text { Behavioural } \\
\text { change technique }\end{array}$ & Policy Description \\
\hline \multirow{4}{*}{$\begin{array}{l}\text { Capability - } \\
\text { Physical }\end{array}$} & \multirow{4}{*}{ Training } & \multirow{4}{*}{$\begin{array}{l}\text { Teaching patients } \\
\text { how to become } \\
\text { more physically } \\
\text { active through } \\
\text { exercises that can } \\
\text { be performed in } \\
\text { both gym and } \\
\text { home-based } \\
\text { settings }\end{array}$} & Guidelines & $\begin{array}{l}\text { Instruction on } \\
\text { how to perform a } \\
\text { behaviour, } \\
\text { demonstration of } \\
\text { the behaviour, } \\
\text { behavioural } \\
\text { practice/rehearsal }\end{array}$ & $\begin{array}{l}\text { Demonstrate exercises during } \\
\text { PA class. Develop patient } \\
\text { facing resources that include } \\
\text { instructions of how to } \\
\text { perform specific exercises. }\end{array}$ \\
\hline & & & Fiscal & & \\
\hline & & & Regulation & $\begin{array}{l}\text { Feedback on } \\
\text { outcomes of } \\
\text { behaviour }\end{array}$ & $\begin{array}{l}\text { Develop feedback } \\
\text { mechanisms for patients to } \\
\text { provide feedback on the } \\
\text { exercises and training } \\
\text { delivered }\end{array}$ \\
\hline & & & Legislation & & \\
\hline
\end{tabular}




\begin{tabular}{|c|c|c|c|c|}
\hline & & Service Provision & $\begin{array}{l}\text { Behavioural } \\
\text { practice/rehearsal }\end{array}$ & $\begin{array}{l}\text { Develop and deliver a group } \\
\text { PA programme for medical } \\
\text { amputees and their partners } \\
\text { to run weekly }\end{array}$ \\
\hline \multirow{6}{*}{ Enablement } & \multirow{6}{*}{$\begin{array}{l}\text { Develop a PA class } \\
\text { that is open to } \\
\text { medical amputees } \\
\text { and incorporates } \\
\text { exercises that can } \\
\text { be taught in a gym- } \\
\text { based setting and } \\
\text { transferred to a } \\
\text { home-based setting }\end{array}$} & Guidelines & $\begin{array}{l}\text { Adding objects to } \\
\text { the environment }\end{array}$ & $\begin{array}{l}\text { Design exercises that can be } \\
\text { easily incorporated into } \\
\text { everyday life and replicated in } \\
\text { a home or gym-based setting. } \\
\text { Provide necessary equipment } \\
\text { to complete programme at } \\
\text { home }\end{array}$ \\
\hline & & Fiscal & & \\
\hline & & Regulation & & \\
\hline & & Legislation & & \\
\hline & & $\begin{array}{l}\text { Environmental/social } \\
\text { planning }\end{array}$ & $\begin{array}{l}\text { Adding objects to } \\
\text { the environment }\end{array}$ & $\begin{array}{l}\text { Design exercises that can be } \\
\text { easily incorporated into } \\
\text { everyday life and replicated in } \\
\text { a home or gym-based setting. } \\
\text { Provide necessary equipment } \\
\text { to complete programme at } \\
\text { home }\end{array}$ \\
\hline & & Service Provision & Action planning & $\begin{array}{l}\text { Design and deliver a PA class } \\
\text { incorporating exercises that } \\
\text { can be replicated in a gym or } \\
\text { home-based setting }\end{array}$ \\
\hline
\end{tabular}




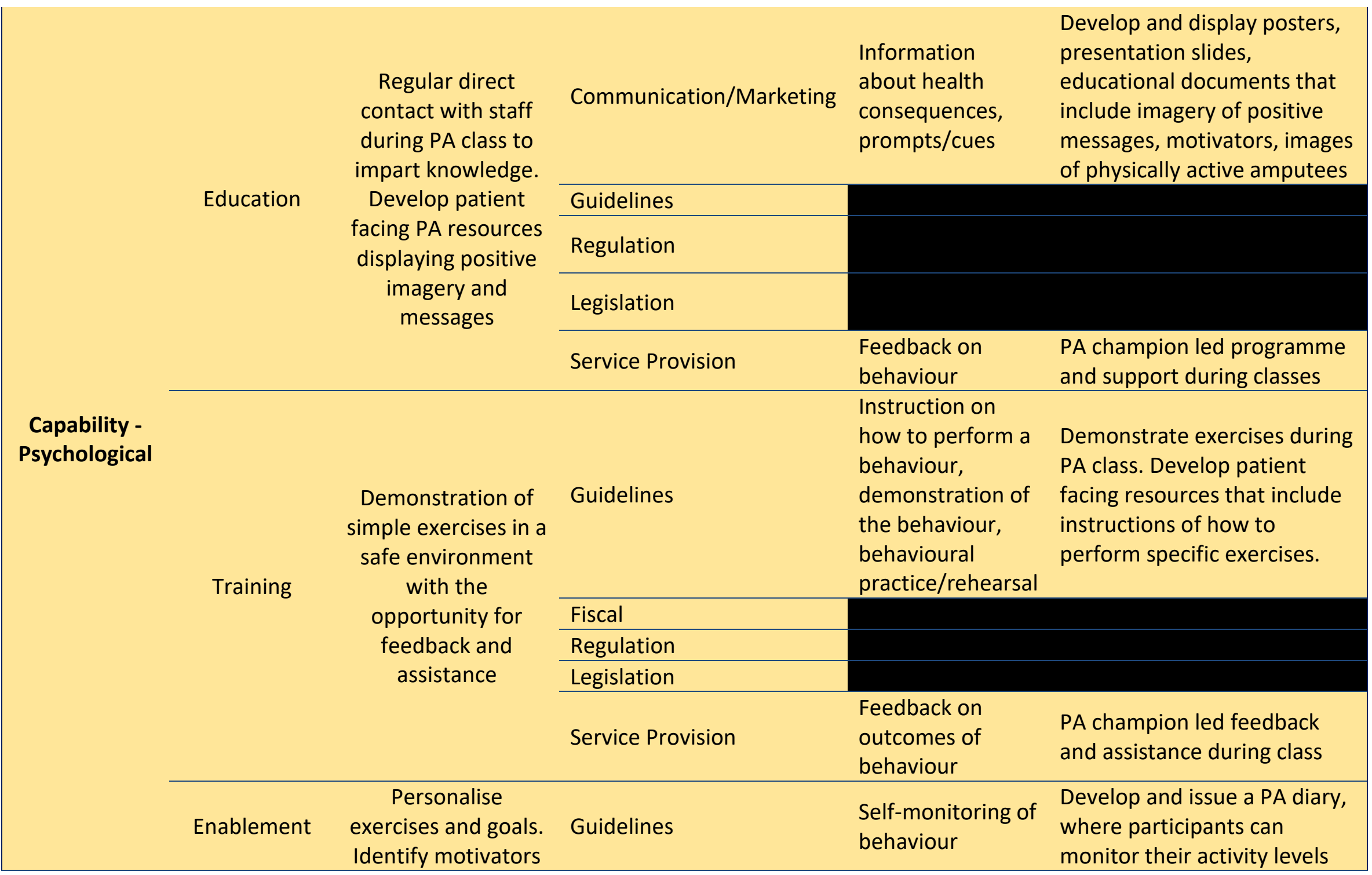


and barriers to PA amongst patients and their partners before, during and after the classes

(a)

Legislation
Environmental/social
planning

Service Provision

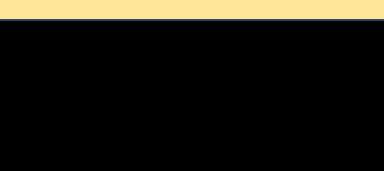

\begin{tabular}{l}
\hline Guidelines \\
\hline Regulation \\
\hline Legislation \\
\hline
\end{tabular}

\section{PA class to}

Opportunity Physical incorporate the use of every day items

Environmental that may act as cues restructuring to patients to

continue to be

physically active at

Fiscal

$\begin{array}{ll}\text { Regulation } & \begin{array}{l}\text { Self-monitoring of } \\ \text { behaviour }\end{array}\end{array}$

behaviour

Social support, restructuring the physical environment

Goal setting, problem solving

and document any positive/negative experiences

Attendance register to be kept to monitor adherence to programme

4-8 participants per class, enabling them to offer support to one another

PA champion to be present during PA classes to provide personalised exercises and goal setting as well as identifying and addressing barriers that arise within or outside of classes

\section{Guidelines}

Adding objects to the environment

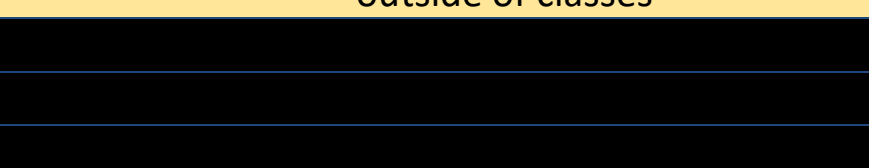

Design exercises that can be easily incorporated into everyday life and replicated in a home or gym-based setting. Provide necessary equipment to complete programme at home

\section{Fiscal}




\begin{tabular}{|c|c|c|c|c|c|}
\hline & & & Regulation & & \\
\hline & & & Legislation & & \\
\hline & & & Service Provision & $\begin{array}{l}\text { Prompt/cues, } \\
\text { adding objects to } \\
\text { the environment }\end{array}$ & $\begin{array}{l}\text { Design exercises that } \\
\text { incorporate everyday items, } \\
\text { such as chairs, and provide all } \\
\text { necessary equipment for PA } \\
\text { class exercises to be } \\
\text { replicated at home }\end{array}$ \\
\hline & & & Guidelines & $\begin{array}{l}\text { Self-monitoring of } \\
\text { behaviour }\end{array}$ & $\begin{array}{l}\text { Develop and issue a PA diary, } \\
\text { where participants can } \\
\text { monitor their activity levels } \\
\text { and document any } \\
\text { positive/negative experiences }\end{array}$ \\
\hline & & & Fiscal & & \\
\hline & & Provide free, open & Regulation & & \\
\hline 0 & & access PA class in an & Legislation & & \\
\hline & Enablement & $\begin{array}{l}\text { environment that } \\
\text { patients are familiar } \\
\text { with. Supply } \\
\text { patients with the } \\
\text { equipment required } \\
\text { to complete the }\end{array}$ & $\begin{array}{l}\text { Environmental/social } \\
\text { planning }\end{array}$ & $\begin{array}{l}\text { Restructuring the } \\
\text { physical } \\
\text { environment, } \\
\text { adding objects to } \\
\text { the environment }\end{array}$ & $\begin{array}{l}\text { Design exercises that } \\
\text { incorporate everyday items, } \\
\text { such as chairs, and provide all } \\
\text { necessary equipment for PA } \\
\text { class exercises to be } \\
\text { replicated at home }\end{array}$ \\
\hline & & class at home & Service Provision & $\begin{array}{l}\text { Goal setting, } \\
\text { problem solving }\end{array}$ & $\begin{array}{l}\text { PA champion to be present } \\
\text { during PA classes to provide } \\
\text { personalised exercises and } \\
\text { goal setting as well as } \\
\text { identifying and addressing } \\
\text { barriers that arise within or } \\
\text { outside of classes }\end{array}$ \\
\hline
\end{tabular}




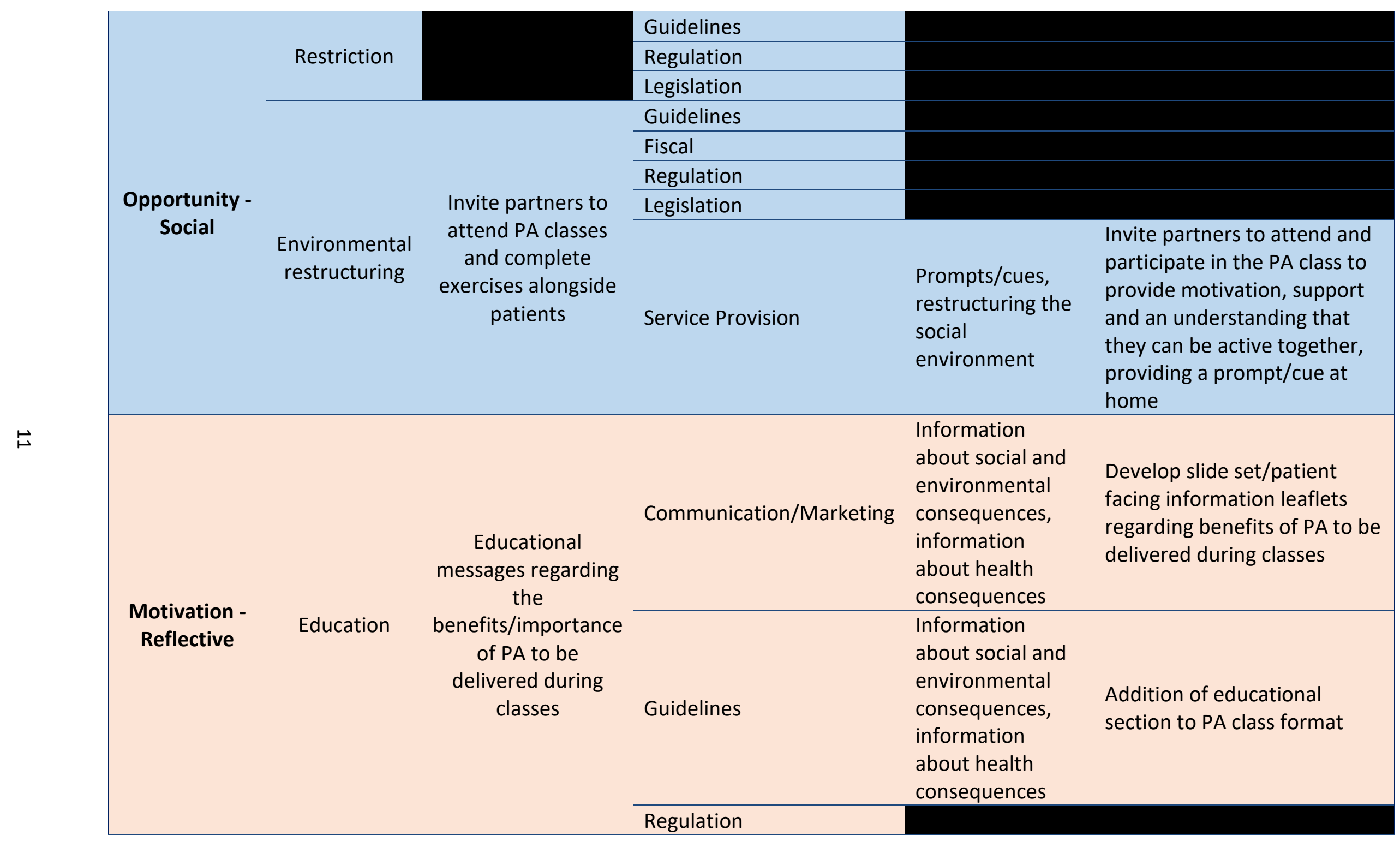




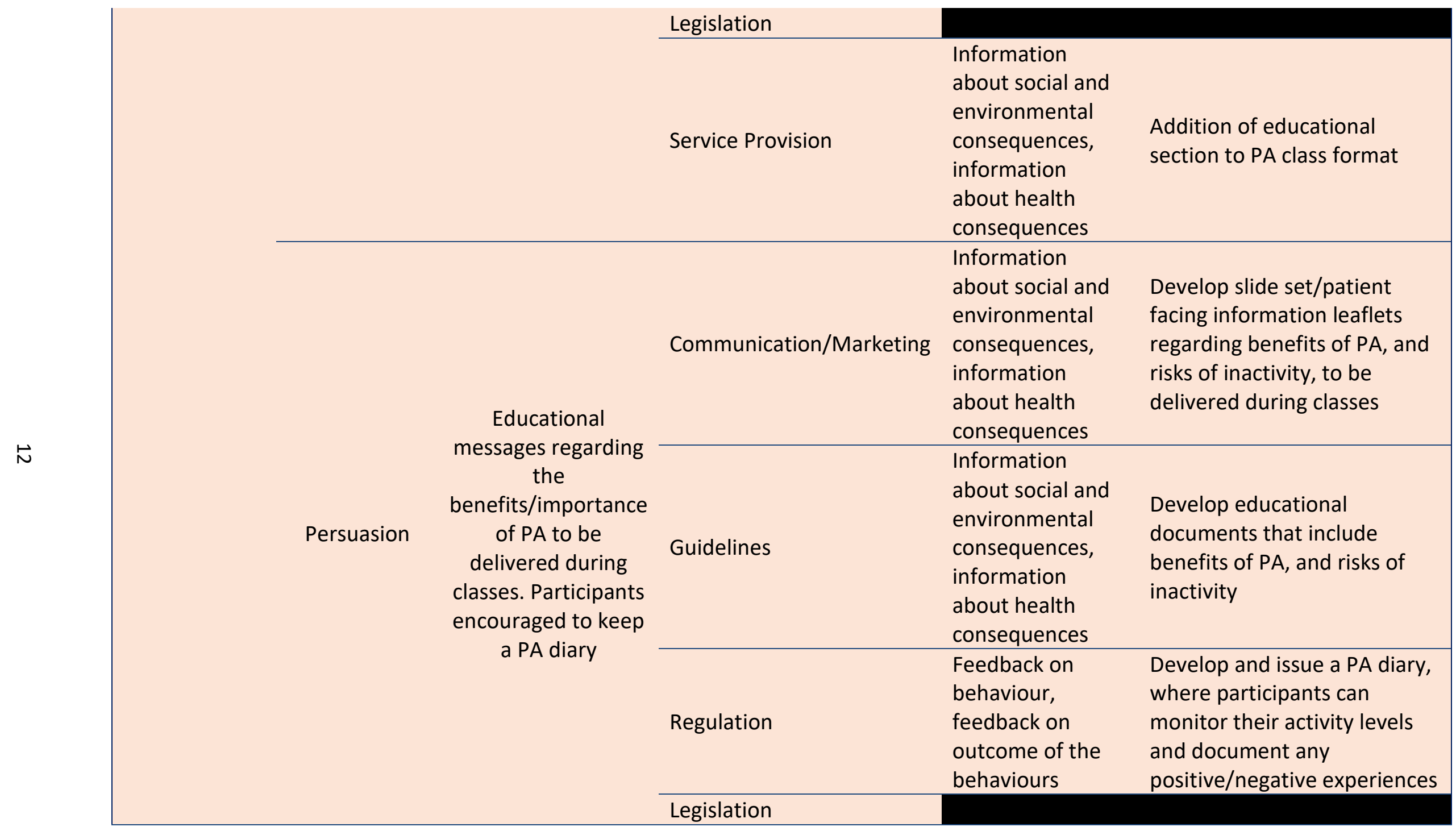


Credible source

feedback on

Service Provision

behaviour,

feedback on

PA champion led PA class,

outcome of the

educational messages and

behaviours

Attendance monitored and participants

Incentivisation encouraged to keep a PA diary

\section{Communication/Marketing}

Guidelines

Fiscal

Regulation
Self monitoring of

behaviour,

monitoring of

behaviour by

others without

evidence of

feedback,

feedback on

behaviour,

feedback on

outcome of the

behaviours

Feedback on

behaviour,

feedback on

outcome of the

behaviours
Attendance register to be kept to monitor adherence to programme. Develop and issue a PA diary, where participants can monitor their activity levels and document any positive/negative experiences

Service Provision

Communication/Marketing

L




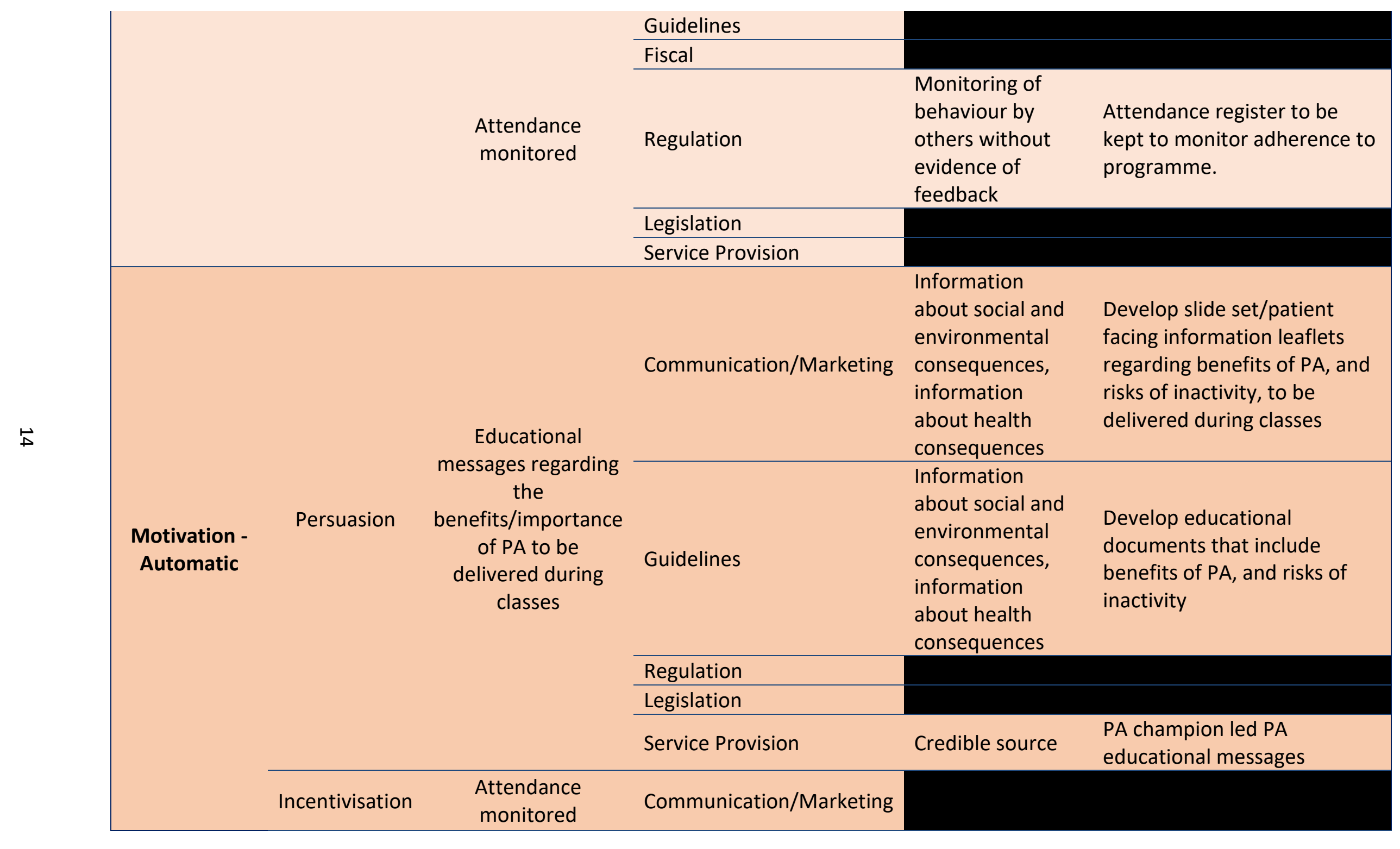




\begin{tabular}{|c|c|c|c|c|c|}
\hline & & & Guidelines & & \\
\hline & & & Fiscal & & \\
\hline & & & Regulation & $\begin{array}{l}\text { Self monitoring of } \\
\text { behaviour, } \\
\text { monitoring of } \\
\text { behaviour by } \\
\text { others without } \\
\text { evidence of } \\
\text { feedback }\end{array}$ & $\begin{array}{l}\text { Attendance register to be } \\
\text { kept to monitor adherence to } \\
\text { programme }\end{array}$ \\
\hline & & & Legislation & & \\
\hline & & & Service Provision & & \\
\hline & & & Communication/Marketing & & \\
\hline & & & Guidelines & & \\
\hline & & & Fiscal & & \\
\hline & Coercion & $\begin{array}{l}\text { Attendance } \\
\text { monitored }\end{array}$ & Regulation & $\begin{array}{l}\text { Monitoring of } \\
\text { behaviour by } \\
\text { others without } \\
\text { evidence of } \\
\text { feedback }\end{array}$ & $\begin{array}{l}\text { Attendance register to be } \\
\text { kept to monitor adherence to } \\
\text { programme. }\end{array}$ \\
\hline & & & Legislation & & \\
\hline & & & Service Provision & & \\
\hline & $\begin{array}{c}\text { Environmental } \\
\text { restructuring }\end{array}$ & $\begin{array}{c}\text { Utilise readily } \\
\text { available/everyday } \\
\text { items to facilitate } \\
\text { PA, e.g. chair based } \\
\text { activities }\end{array}$ & Guidelines & $\begin{array}{l}\text { Adding objects to } \\
\text { the environment }\end{array}$ & $\begin{array}{l}\text { Design exercises that can be } \\
\text { easily incorporated into } \\
\text { everyday life and replicated in } \\
\text { a home or gym-based setting. } \\
\text { Provide necessary equipment } \\
\text { to complete programme at } \\
\text { home }\end{array}$ \\
\hline & & & Fiscal & & \\
\hline
\end{tabular}




\begin{tabular}{|c|c|c|c|c|c|}
\hline & & & Regulation & & \\
\hline & & & Legislation & & \\
\hline & & & $\begin{array}{l}\text { Environmental/social } \\
\text { planning }\end{array}$ & $\begin{array}{l}\text { Restructuring the } \\
\text { physical } \\
\text { environment, } \\
\text { adding objects to } \\
\text { the environment }\end{array}$ & $\begin{array}{l}\text { Design exercises that } \\
\text { incorporate everyday items, } \\
\text { such as chairs, and provide all } \\
\text { necessary equipment for PA } \\
\text { class exercises to be } \\
\text { replicated at home }\end{array}$ \\
\hline & Modelling & $\begin{array}{l}\text { Include case studies } \\
\text { as examples in }\end{array}$ & Communication/Marketing & $\begin{array}{l}\text { Demonstration of } \\
\text { the behaviour }\end{array}$ & $\begin{array}{l}\text { Educational material to } \\
\text { include positive imagery of } \\
\text { physically active amputees }\end{array}$ \\
\hline & Miodelling & $\begin{array}{l}\text { Introductory } \\
\text { documents or } \\
\text { presentation slides }\end{array}$ & Service Provision & $\begin{array}{l}\text { Demonstration of } \\
\text { the behaviour }\end{array}$ & $\begin{array}{l}\text { PA champion led PA class, } \\
\text { including demonstrations, } \\
\text { feedback and assistance }\end{array}$ \\
\hline हे & & $\begin{array}{l}\text { Integrate exercises } \\
\text { involving readily } \\
\text { available/everyday } \\
\text { items to facilitate } \\
\text { PA. Ensure staff are }\end{array}$ & Guidelines & $\begin{array}{l}\text { Adding objects to } \\
\text { the environment }\end{array}$ & $\begin{array}{l}\text { Design exercises that can be } \\
\text { easily incorporated into } \\
\text { everyday life and replicated ir } \\
\text { a home or gym-based setting. } \\
\text { Provide necessary equipment } \\
\text { to complete programme at } \\
\text { home }\end{array}$ \\
\hline & Enablement & available to & Fiscal & & \\
\hline & & troubleshoot any & Regulation & & \\
\hline & & problems that & Legislation & & \\
\hline & & $\begin{array}{l}\text { patients or partners } \\
\text { report during the PA } \\
\text { class or at home }\end{array}$ & $\begin{array}{l}\text { Environmental/social } \\
\text { planning }\end{array}$ & $\begin{array}{l}\text { Adding objects to } \\
\text { the environment }\end{array}$ & $\begin{array}{l}\text { Design exercises that can be } \\
\text { easily incorporated into } \\
\text { everyday life and replicated in } \\
\text { a home or gym-based setting. } \\
\text { Provide necessary equipment }\end{array}$ \\
\hline
\end{tabular}


to complete programme at home

PA Champion led PA class 


\section{Appendix C - Evaluation methodology}

It was apparent after the initial teleconference with the Sport and Exercise Medicine (SEM) pilot delivery team from Oxford University Hospital Foundation Trust (OUHFT) on $23^{\text {rd }}$ November 2017 that the original evaluation framework that was developed based on Public health England's (PHE's) MHPP project specification would need to be amended considerably. The intervention that OUHFT had designed was considerably more complex than the palliative care model proposed in the project specification. The team at OUHFT planned to embed the pilot within five different clinical pathways (Maternity, Enablement, Renal, Complex Medical Unit (CMU) and Cardiology) with a different delivery protocol for each. In order to capture information from as many aspects of the SEM pilot as possible the evaluation team had to amend the original evaluation framework to suit the new delivery model.

Members of the evaluation team met with the SEM pilot leads in London at the Royal College of Physicians on $13^{\text {th }}$ December 2017. The aim of this meeting was to identify the active components of the intervention(s), establish core evaluation outcomes, determine an agreed position for the evaluation and identify the most appropriate data collection methodology. This meeting satisfied step 1 in the original evaluation framework - formative evaluation: discussion with key stakeholders (e.g. SEM consultant leads) to inform the evaluation methods and clarify any assumptions about the implementation of the SEM pilot.

Based on the discussions during that meeting and the nature of the SEM pilot, a number of changes were made to the evaluation framework. The updated evaluation methodology for the SEM pilot was designed to focus on seven discrete studies which are detailed below. The evaluation of the PACAP pilot was conducted using a mixed-methods approach. To meet the aims of the evaluation, the following evaluation activities were completed.

\section{C.1 Impact of a bespoke Sport and Exercise Medicine led Clinical Champions training programme}

Aims:

a) Explore the impact of a bespoke SEM led Clinical Champions training programme (with physical activity (PA) team as recipients) on attitudes, knowledge, confidence, and intentions to promote/engage in conversations about PA as part of routine practice. 
b) Audit ${ }^{1}$ the number of subsequent health care professionals receiving Clinical Champions training programme delivered by a PA team member (target: at least one other healthcare professional (HCP) trained).

\section{Data collection:}

The link to the baseline HCP survey was emailed to the SEM consultant leads on $12^{\text {th }}$ June 2018 . The SEM leads were asked to distribute the survey link to HCPs working in the five clinical pathways involved in the SEM pilot. The SEM leads noted the Maternity and Enablement pathways were already involved in the SEM pilot and therefore responses from staff in these pathways would not reflect a true baseline. The HCP baseline survey link was sent by pathway leads to staff in three of the five pathways (Cardiology, Renal and Maternity). Information about when the survey link was sent and who had received it was difficult to gather as OUHFT lacked administrative support for the project in the early stages. A total of 13 baseline survey responses were received between July and September 2018. HCPs provided their email address for the evaluation team to send a follow-up survey. The follow-up survey was sent to all 13 participants on the 14th January 2019. A first reminder email was then sent on the 30th January, followed by a second reminder email on 7th February. In total 10 follow-up responses were received.

A medical student at OUHFT gathered audit information during February/March 2019 and the SEM pilot leads shared the data with the evaluation team.

\section{C.2 Culture of physical activity within OUHFT}

Aim: Understand the current culture of PA within the hospital from the perspective of operational directors and HCPs. In other words, this strand of the evaluation provides the context within which the pilot is being delivered.

Data collection: Nine face-to-face interviews were conducted with operational directors and HCPs in June/July 2018 to explore the current culture of PA within OUHFT and perceptions of SEM clinical advice.

\section{C.3 Feasibility of a peer-to-peer support programme}

Aim: Investigate the feasibility of a peer-to-peer support programme with patients receiving treatment in the Enablement pathway.

Data collection: Two face-to-face and two telephone interviews were conducted between December 2018 and January 2019 with patients who had received treatment in the Enablement pathway.

\footnotetext{
${ }^{1}$ All audit data was gathered by OUH staff/students and shared with the evaluation team at SHU. All data was anonymised prior to sharing and no identifiable patient data was shared.
} 


\section{C.4 Impact of the Sport and Exercise Medicine intervention on healthcare professional behaviour}

Aim: Explore the impact of the SEM intervention on the behaviour of HCPs in the Enablement and Maternity pathways (was CMU, Cardiology and Renal) by auditing patient's notes for mention of PA in discharge notes.

Data collection: An audit of patient's notes was carried out by an OUHFT medical student in February 2019 to establish the number of patients receiving advice on PA (i.e. mention of PA in discharge notes using the Electronic Patient Record) prior to the SEM pilot and again during the pilot.

\section{C.5 Acceptability of an active ward}

Aim: Explore what an active ward consists of, what works well and what doesn't work so well from the perspective of ward staff (i.e. ward sister, staff nurse, doctor, consultant) and patients. The interviews also explored their perceptions of the active ward.

Data collection: Two face-to-face interviews were conducted in January 2019 with patients who had received treatment in the Renal pathway.

\section{C.6 Patient centred physical activity intervention - iCAN}

Aim: Explore patients experience of a patient centred PA intervention (a PA plan using the iCAN tool) whilst receiving treatment on the $\mathrm{CMU}$ (was originally going to be following discharge from Critical Care). Furthermore, explore the acceptability of this type of intervention with ward staff.

Data collection: One face-to-face and two telephone interviews were conducted in January/February 2019 with staff from the CMU. The evaluation team intended to interview patients who had used the iCAN tool, however, there was difficulty with recruitment and no interviews were undertaken.

An audit was carried out by an OUHFT medical student in February 2019 to establish the number of iCAN plans that had been completed.

\section{C.7 Experiences of lead Sport and Exercise Medicine Consultants in delivering the Sport and Exercise Medicine pilot}

Aim: Understand the experience of lead SEMs implementing a broad programme of PA in a single hospital Trust.

Data Collection: Midway face-to-face interviews were conducted with the two SEM leads in July 2019. Follow-up interviews were then conducted with the SEM leads in February 2019. In addition to the data captured from the interviews, the SEM leads were asked to keep informal notes/diaries to 
document the SEM pilot set-up process, specifically any difficulties that were encountered and how they were overcome. The qualitative enquiries were substantiated with on-site visits from the evaluation teams at 3 time points during the SEM pilot.

\section{C.8 Data analysis}

All interviews were audio-recorded and transcribed verbatim. Interview data was analysed using a qualitative framework guided by a case-study approach (Hartley, 2004). Interviews transcripts were read and re-read several times. In addition, the recordings were listened to ensuring the accuracy of the transcription and to aid interpretation. Data was then organised around the topics, themes and central questions in the aims and objectives outlined in each study. Quotes are used to exemplify key aspects of the lead SEM consultants experience and to make manifest the implementation of the SEM pilot.

\section{References}

Hartley, Jean (2004). Case study research. In Catherine Cassell \& Gillian Symon (Eds.), Essential guide to qualitative methods in organizational research (pp.323-333). London: Sage. 


\section{Appendix D - The iCAN tool}

Date:

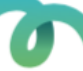

Initials:

\section{Moving}

Medicine
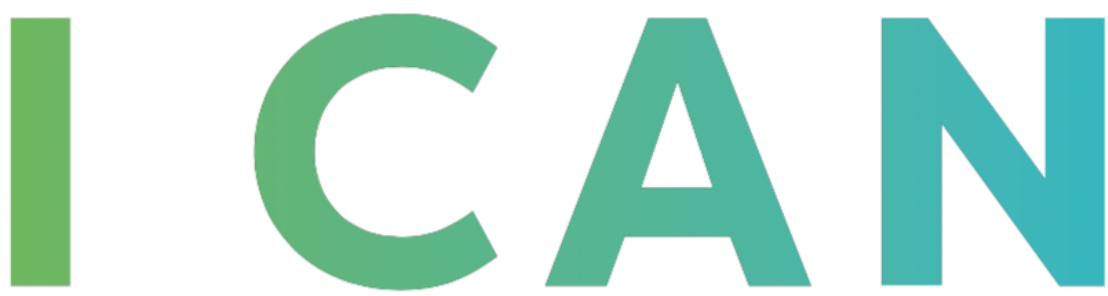

Move around using: $\square$ No aid

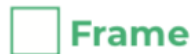

Stick

$\square$ Standing Hoist $\square$ Full hoist $\square$ Rotastand

Other

With:

help of 2

help of 1

independent

And a distance of: $\square$ less than 1m $\square$ 1-5m $\square$ 5-10m $\square$ 10m+

Get washed and dressed:

$\square$ Independently $\square$ Top half only $\square$ With help

Clean teeth: $\square$ With help $\square$ Independently

Practise exercises:

$\square$ Bed exercises $\square$ Chair exercises $\square$ Standing exercises

I use: Hearing Aid Glasses

\#movingmedicine 


\section{Appendix E - Physical Activity Calculator}

\section{Physical Activity Calculator}

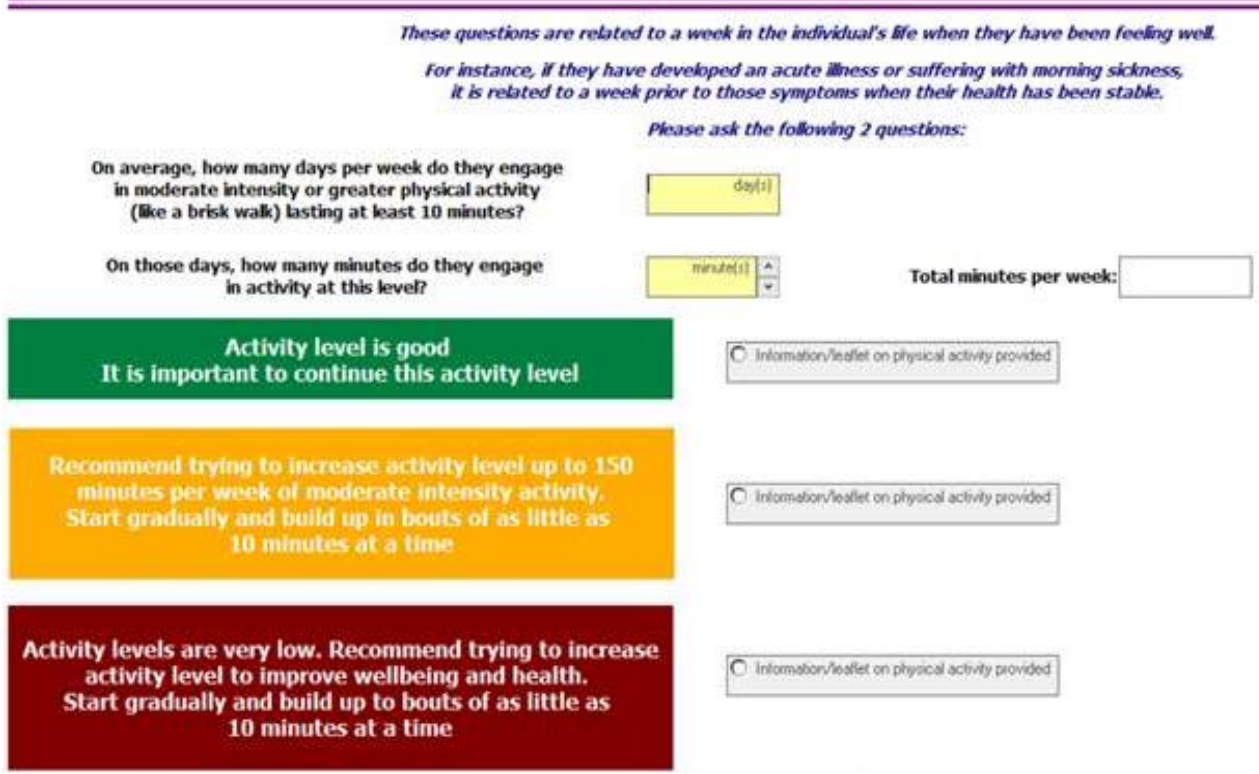

Visit info:

6406417, Churchill, Inpatient, 08/Mar/2019 - 12/Mar/2019

Physical Activity Calculator Entered On: 11/Mar/2019 10:00

Performed On: 11/Mar/2019 10:00 by Barnett. Tracy

Physical Activity Calculator

Days of Physical activity $>10 m: 5$ day(s)

Minutes of Physical Activity: 270 minute(s)

Exercise time in a week: 1.350 minute(s)

Exercise level in pregnancy: Green

Activity 150 or more mins/week: Information/leaflet on physical activity provided

Barnett. Tracy-11/Mar/2019 10:00 


\section{Appendix F}

\section{F.1 Understanding the culture of physical activity within OUHFT}

The tables below contain the main topics and themes that emerged from the analysis of the interviews exploring the current culture of PA within OUHFT and perceptions of SEM clinical advice. A description of theme is given with direct quotes taken from interviews to help demonstrate the findings and support the researcher's interpretation.

Table 5 Topics and themes that capture the context within which the SEM pilot was implemented.

\begin{tabular}{|l|l|l|l|}
\hline Topic & Theme & Quote(s) & Interpretation/implication(s) \\
\hline $\begin{array}{l}\text { What OUHFT is like } \\
\text { as a Trust }\end{array}$ & $\begin{array}{l}\text { OUHFT is an } \\
\text { innovative Trust }\end{array}$ & $\begin{array}{l}\text { "we're using evidence-based medicine approaches, we're at } \\
\text { the forefront of any changes in the way that we manage } \\
\text { patients" S2P02 }\end{array}$ & $\begin{array}{l}\text { Staff described OUHFT as an innovative Trust which } \\
\text { strives to push the boundaries of patient care by } \\
\text { implementing evidence-based practice. The SEM pilot } \\
\text { was seen to fit well with this ethos of innovation as the } \\
\text { aim was to develop new ways of integrating PA into } \\
\text { patient care plans. }\end{array}$ \\
$\begin{array}{ll}\text { "I think they're very keen on innovation and new ideas" } \\
\text { S2P06 }\end{array}$ & $\begin{array}{l}\text { "I do think it's quite a forward thinking trust." S2P07 } \\
\text { "We're constantly looking for new ways to deliver the care } \\
\text { and sort of innovate and bring in new ideas and certainly this } \\
\text { pilot is one of those." S2P01 }\end{array}$ & $\begin{array}{l}\text { "I've also advised them that in some cases their interventions } \\
\text { could be building into the support that we offer for care } \\
\text { pathways with digital tools." S2P01 }\end{array}$ & $\begin{array}{l}\text { Digital technology was perceived to be an integral part } \\
\text { of successully implementing innovative services within } \\
\text { the hospital. }\end{array}$ \\
\hline
\end{tabular}




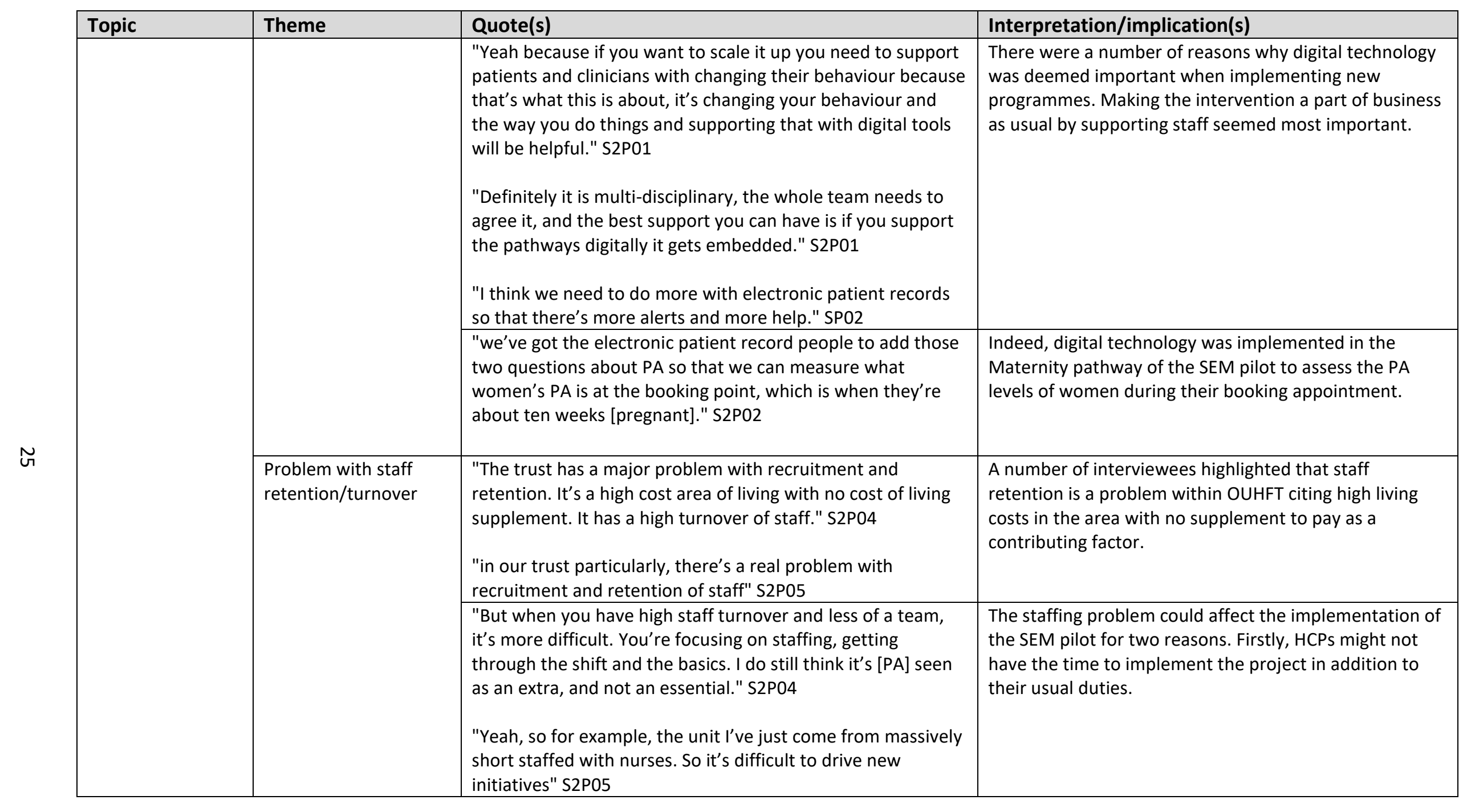




\begin{tabular}{|c|c|c|c|}
\hline Topic & Theme & Quote(s) & Interpretation/implication(s) \\
\hline & & $\begin{array}{l}\text { "Yeah, because you've not got a cohesive team and that's } \\
\text { what you need to get that culture to move forward as a } \\
\text { cohesive team, that when new people come in they join an } \\
\text { already forward-thinking team rather than treading water } \\
\text { team. And there feels like a lot of treading water." S2P05 }\end{array}$ & $\begin{array}{l}\text { And secondly, if staff turnover is high it could prove } \\
\text { problematic to build momentum and change the culture } \\
\text { within the different SEM pilot pathways. }\end{array}$ \\
\hline & $\begin{array}{l}\text { Physical environment } \\
\text { at OUHFT }\end{array}$ & $\begin{array}{l}\text { "Oxford University Hospitals, and we operate on four big } \\
\text { sites and employ about 12,000 staff in those" S2P01 }\end{array}$ & $\begin{array}{l}\text { A reoccurring theme highlighted by the majority of } \\
\text { interviewees was that OUHFT is a very large Trust. }\end{array}$ \\
\hline & & $\begin{array}{l}\text { "I imagine that to be much more difficult just because... it's } \\
\text { got to be quite a big message, so it's got to be pervasive } \\
\text { throughout the whole psyche if you like, rather than be in } \\
\text { sort of the little strands that pop up ad hoc." S2P05 }\end{array}$ & $\begin{array}{l}\text { It could prove difficult to gather traction with the pilot as } \\
\text { there are so many employees and the hospital is spread } \\
\text { over four locations. A coordinated and consistent } \\
\text { approach is necessary if the SEM pilot is to succeed } \\
\text { across the Trust. }\end{array}$ \\
\hline & & $\begin{array}{l}\text { "I think actually if you can implement it in this trust which is } \\
\text { massive, then you can implement it anywhere, because it's } \\
\text { really, the bigger an organisation the more loops you have to } \\
\text { go through, the more people there are to engage with... } \\
\text { We're over four sites so. If you work in a relatively smaller } \\
\text { DGH [district general hospital] you're all on one site... I think } \\
\text { actually if you can do it somewhere like this then I think the } \\
\text { only place that's bigger than this is Bath and London, then } \\
\text { it's proof of concept, you can do it anywhere." S2PO9 }\end{array}$ & $\begin{array}{l}\text { One interviewee suggested that if the SEM pilot is } \\
\text { successful in a Trust as big as OUHFT then the model is } \\
\text { likely to be transferrable to smaller Trusts. This will be } \\
\text { crucial if the SEM pilot is scaled up and rolled out to } \\
\text { other Trusts. }\end{array}$ \\
\hline & & $\begin{array}{l}\text { "I don't have much interaction on a day-to-day basis with the } \\
\text { sport and exercise guys at all." S2P03 } \\
\text { "And I think there is I guess the geographical issue that they } \\
\text { are in a different hospital from the main acute hospital." } \\
\text { S2P02 }\end{array}$ & $\begin{array}{l}\text { The geographical spread of the different SEM pilot } \\
\text { pathways has the potential to hinder the success of the } \\
\text { pilot. One interviewee highlighted there is little } \\
\text { interaction with the lead SEM consultants. This is a } \\
\text { potential obstacle, particularly in the start-up phase of } \\
\text { the pilot when the multi-disciplinary teams are being } \\
\text { formed in the different pathways. Conversely, this } \\
\text { hands-off approach could foster ownership of the } \\
\text { project leading to long term sustainability. }\end{array}$ \\
\hline & $\begin{array}{l}\text { OUHFT is an outcome } \\
\text { driven Trust }\end{array}$ & $\begin{array}{l}\text { "The culture in the NHS is that if you want to have a service } \\
\text { that is continually funded, you have to show the outcome." } \\
\text { S2P04 }\end{array}$ & $\begin{array}{l}\text { A prominent theme highlighted by eight out of the nine } \\
\text { interviewees was that the Trust, and the NHS as a whole } \\
\text { is very outcome driven. Unless a new service or } \\
\text { programme can demonstrate impact through improved }\end{array}$ \\
\hline
\end{tabular}




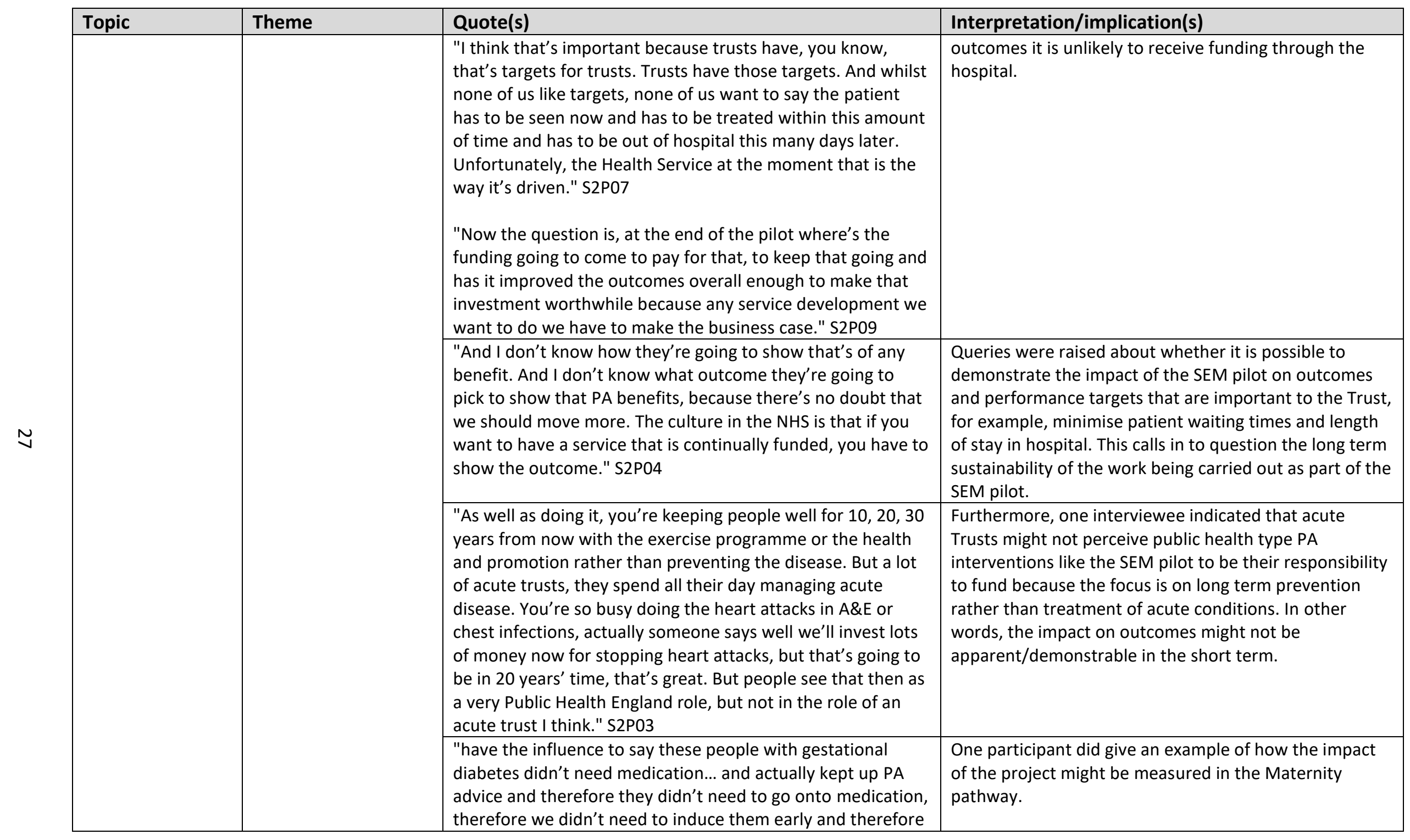




\begin{tabular}{|c|c|c|c|}
\hline Topic & Theme & Quote(s) & Interpretation/implication(s) \\
\hline & & $\begin{array}{l}\text { they had less stay and less. So that's what you've got to do. } \\
\text { So that's what other models, that's how other things worked } \\
\text { in the past, I think, that's how the trust respond best to it." } \\
\text { S2P06 }\end{array}$ & \\
\hline \multirow[t]{5}{*}{ Supportive culture } & \multirow[t]{3}{*}{$\begin{array}{l}\text { Supportive senior } \\
\text { management }\end{array}$} & $\begin{array}{l}\text { "business has always been done in the corridor on first name } \\
\text { terms in a very social and friendly manner." (S2P03) } \\
\text { "I mean the team above me, so the senior team, senior } \\
\text { support I've had have been really good and helpful and } \\
\text { they've guided me through the process which has been } \\
\text { excellent." (S2P07) } \\
\text { "The trust are incredibly supportive." (S2P08) }\end{array}$ & $\begin{array}{l}\text { When interviewees were asked what the Trust was like, } \\
\text { staff described OUHFT as being a friendly, supportive } \\
\text { and nurturing place to work in general. A place where } \\
\text { senior staff support more junior staff. }\end{array}$ \\
\hline & & $\begin{array}{l}\text { "I am in no way dissing this or unsupportive of it, but this is } \\
\text { supportive and, the chief exec signed off on the project and } \\
\text { his is keen on us doing PA" (S2P09) }\end{array}$ & $\begin{array}{l}\text { When asked about the SEM pilot specifically, staff } \\
\text { perceived the SEM pilot to be supported at senior } \\
\text { leadership level. }\end{array}$ \\
\hline & & $\begin{array}{l}\text { "it's [PA] on the trust's strategic priorities, but I can't pretend } \\
\text { it's the top of them." (S2P09) }\end{array}$ & $\begin{array}{l}\text { Despite this senior level buy-in and support for the SEM } \\
\text { pilot it was acknowledged that there are competing } \\
\text { interests and PA is not always top of the Trust's strategic } \\
\text { priorities. }\end{array}$ \\
\hline & \multirow[t]{2}{*}{$\begin{array}{l}\text { The staff wellbeing } \\
\text { offer at OUHFT }\end{array}$} & $\begin{array}{l}\text { "There are gym facilities I think near the site or aligned with } \\
\text { the site. There are various sports groups. So there's five-a- } \\
\text { side football and all of those usual kind of groups. There is } \\
\text { Pilates, yoga." S2P08 }\end{array}$ & $\begin{array}{l}\text { All nine interviewees noted that there are services } \\
\text { available to support staff wellbeing OUHFT. However, } \\
\text { the level of enthusiasm for the staff wellbeing offer } \\
\text { varied. Some staff were enthusiastic about the services } \\
\text { on offer. }\end{array}$ \\
\hline & & $\begin{array}{l}\text { "Yeah that's [staff health and wellbeing], well yes that seems } \\
\text { fairly good actually. Not that I've particularly used any of the } \\
\text { opportunities but weekly, monthly you'll get a newsletter } \\
\text { that comes through." S2P05 } \\
\text { "The trust does a lot to promote health and wellbeing and it } \\
\text { pays a lot of lip service to, go for a walk at lunchtime, do your } \\
\text { mindfulness training for that, you know, it really does, but } \\
\text { actually I think a lot of that is just lip service." S2P03 }\end{array}$ & $\begin{array}{l}\text { Despite some interviewees enthusiasm for what was on } \\
\text { offer to staff, none reported taking up any of the } \\
\text { services available to them and others felt the Trust paid } \\
\text { 'lip service' to staff wellbeing. }\end{array}$ \\
\hline
\end{tabular}




\begin{tabular}{|c|c|c|c|}
\hline Topic & Theme & Quote(s) & Interpretation/implication(s) \\
\hline \multirow[t]{5}{*}{$\begin{array}{l}\text { PA provision and } \\
\text { the role of SEM }\end{array}$} & \multirow[t]{4}{*}{$\begin{array}{l}\text { Shared responsibility } \\
\text { for PA provision within } \\
\text { the Trust }\end{array}$} & $\begin{array}{l}\text { "I think that it's [promoting PA] any opportunity or } \\
\text { interaction with a healthcare professional ideally." (S2P02) } \\
\text { "it's the remit of all of us but maybe the leadership comes } \\
\text { from people who have specialised in sport and exercise } \\
\text { medicine." S2P02 } \\
\text { "it needs to be figure headed by somebody, it may as well be } \\
\text { the exercise medicine people, delivered by anybody." } \\
\text { (S2P04) }\end{array}$ & $\begin{array}{l}\text { The majority of staff believed it was "everyone's } \\
\text { responsibility" (S2P01) to promote PA to patients. } \\
\text { Although most believed there was a shared } \\
\text { responsibility to promote PA, interviewees suggested } \\
\text { that it should be led by Sport and Exercise Medicine } \\
\text { specialist. }\end{array}$ \\
\hline & & $\begin{array}{l}\text { "And in intensive care that would be the physiotherapy } \\
\text { team." (S2P04) } \\
\text { "Physios are in a good place to lead it" (S2P05) }\end{array}$ & $\begin{array}{l}\text { Other interviewees suggested it might be the } \\
\text { responsibility of the physiotherapy team to lead PA } \\
\text { initiatives. }\end{array}$ \\
\hline & & $\begin{array}{l}\text { "That's interesting actually because I don't know if anyone } \\
\text { could take responsibility for it [promote PA]... I suppose the } \\
\text { very naïve simple answer is to say well it's everyone's } \\
\text { responsibility... But if you wanted someone to be an } \\
\text { overarching point of contact to say these are strategies that } \\
\text { the trust want to develop and we want to implement with } \\
\text { our patients, then does that sit with the rheumatology, does } \\
\text { it sit with the orthopaedics, does it sit with SEM, or does it sit } \\
\text { with the chief executive" (S2P03) }\end{array}$ & $\begin{array}{l}\text { It was acknowledged that whilst the promotion of PA in } \\
\text { practice was deemed to be everyone's responsibility, it } \\
\text { was less clear whose responsibility it was to promote PA } \\
\text { on a strategic level. }\end{array}$ \\
\hline & & $\begin{array}{l}\text { " the PA is a bonus in an inpatient ward environment...there } \\
\text { isn't a CQUIN [Commissioning for Quality and Innovation] or } \\
\text { anything in any inpatient pathway that says a patient should, } \\
\text { PA is involved... there is no stick to beat the executive board } \\
\text { with to say if patients aren't physically active" (S2P04) }\end{array}$ & $\begin{array}{l}\text { A key theme that emerged was staff believed that for PA } \\
\text { to sit higher in the Trust's priorities there would need to } \\
\text { be a formal policy making PA a mandatory part of } \\
\text { secondary care. } \\
\text { Staff felt that other areas took priority especially if they } \\
\text { had a formal target or standard to meet, such as the } \\
\text { "four hour wait in A\&E" or "the } 18 \text { week cancer wait" } \\
\text { (S2P04). }\end{array}$ \\
\hline & & $\begin{array}{l}\text { "I think that's where we're trying to figure out as a specialty } \\
\text { what our role is: are we leaders that just overview things and }\end{array}$ & $\begin{array}{l}\text { Sport and Exercise Medicine was recognised as a medical } \\
\text { specialty in 2005. It was clear that the role of a Sport and }\end{array}$ \\
\hline
\end{tabular}




\begin{tabular}{|c|c|c|c|}
\hline \multirow[t]{5}{*}{ Topic } & Theme & Quote(s) & Interpretation/implication(s) \\
\hline & \multirow[t]{4}{*}{$\begin{array}{l}\text { Perceived role of a } \\
\text { Sport and Exercise } \\
\text { Medicine Consultant }\end{array}$} & $\begin{array}{l}\text { try and implement these things and have a knowledge about } \\
\text { what works; or is that public health's actual goal to refer to; } \\
\text { or are we working with them? I think that's still something } \\
\text { that's going to be ironed out in the future." (S2P06) }\end{array}$ & $\begin{array}{l}\text { Exercise Medicine Consultant was not well defined or } \\
\text { clearly understood, perhaps because the specialty is still } \\
\text { in its infancy or because the role can be very varied. }\end{array}$ \\
\hline & & $\begin{array}{l}\text { "looking after elite athletes and people with musculoskeletal } \\
\text { problems and getting them back to activity, that can be } \\
\text { anything from a builder who's injured his ankle playing } \\
\text { football to a footballer who's playing at high level." (S2P06) } \\
\text { "working outside the NHS sector and elite athletes" (S2PO2) }\end{array}$ & $\begin{array}{l}\text { Interviewees tended to highlight musculoskeletal injury } \\
\text { as one of the main areas of work for SEM consultants. }\end{array}$ \\
\hline & & $\begin{array}{l}\text { "looking at sports medicine for those higher performing } \\
\text { athletes and that seems to be a bit of a focus." (S2P04) } \\
\text { "for the more general population is the role of sport and } \\
\text { exercise chaps managing low level tendinopathies, sort of } \\
\text { sprains, strains that where they can bring to bear their } \\
\text { expertise of high end athletes to the average population." } \\
\text { (S2P03) }\end{array}$ & $\begin{array}{l}\text { They also made a distinction between the types of } \\
\text { patients SEM consultants might treat. The first type of } \\
\text { patient identified was the elite athletes after an injury } \\
\text { and the goal of treatment is to bring them back to full } \\
\text { health and regain their pre-injury performance } \\
\text { standards. The second type of patient identified were } \\
\text { the general population receiving treatment in the NHS } \\
\text { for a musculoskeletal injury. }\end{array}$ \\
\hline & & $\begin{array}{l}\text { "NHS time which is presumably about, I don't exercise } \\
\text { prescriptions or working in particular high risk communities } \\
\text { within the hospital." (S2P02) } \\
\text { "there's really a public health role for us to have in } \\
\text { promoting PA and getting people more active now, I think } \\
\text { that's evolving and that's something that hopefully we'll } \\
\text { develop in the future." (S2P06) }\end{array}$ & $\begin{array}{l}\text { There was less emphasis placed on the role of the SEM } \\
\text { consultant in promoting PA within the NHS in the } \\
\text { interest of public health, but this was discussed. It } \\
\text { seemed like this preventative public health role was a } \\
\text { new area or work for the SEM specialism and more of } \\
\text { this type of work might be seen in the future. }\end{array}$ \\
\hline $\begin{array}{l}\text { Barriers to the } \\
\text { implementation of } \\
\text { the SEM pilot }\end{array}$ & Competing priorities & $\begin{array}{l}\text { "So yeah, it's not a priority, it's not a trust priority, and PA } \\
\text { isn't a trust priority." (S2P04) } \\
\text { "I think the trust is very, it's definitely, high on their agenda is } \\
\text { PA in preventative medicine" (S2P06) }\end{array}$ & $\begin{array}{l}\text { Interviewees said that the Trust has numerous priorities } \\
\text { and targets to meet and PA is not currently one of them. } \\
\text { Although PA might not be a Trusts priority, others } \\
\text { thought it was still high on the Trust's agenda. }\end{array}$ \\
\hline
\end{tabular}




\begin{tabular}{|c|c|c|c|}
\hline Topic & Theme & Quote(s) & Interpretation/implication(s) \\
\hline & & $\begin{array}{l}\text { "I do still think it's seen as an extra, and not an essential." } \\
\text { (S2PO4) } \\
\text { "And by the time they've done all that and they've gone } \\
\text { through all this big booking form and they're doing the damn } \\
\text { thing, the PA has really fallen off the end" (S2P02) }\end{array}$ & $\begin{array}{l}\text { Because of these competing demands PA is seen as an } \\
\text { extra and is the first thing to go if time or resources are } \\
\text { tight. }\end{array}$ \\
\hline & $\begin{array}{l}\text { Inter-pathway } \\
\text { differences }\end{array}$ & $\begin{array}{l}\text { "It's not easy getting information from other units and it's } \\
\text { not easy to have, compare like for like because all units work } \\
\text { in a slightly different way." (S2P05) }\end{array}$ & $\begin{array}{l}\text { Differences between how care is delivered across the } \\
\text { different pathways might prove problematic for a Trust } \\
\text { wide intervention such as the SEM pilot. Something that } \\
\text { works in one pathway might not necessarily work in } \\
\text { another. }\end{array}$ \\
\hline & & $\begin{array}{l}\text { "Well it's different in different areas, what will be important } \\
\text { both to the patients and to the staff and accepted as is really } \\
\text { worth investing in in terms of time and other resources in } \\
\text { Maternity will be very different to what is important in the } \\
\text { dialysis unit to what is important in the amputee unit. And so } \\
\text { it's having it localised enough that it carries on, not just } \\
\text { having a sort of one size fits all model." (S2PO9) }\end{array}$ & $\begin{array}{l}\text { These differences mean it is extremely important that } \\
\text { the pilot is developed in collaboration with staff who } \\
\text { work within the different pathways. Furthermore, it } \\
\text { needs to be delivered with enough flexibility that the } \\
\text { interventions can be adapted to specific pathways. }\end{array}$ \\
\hline & $\begin{array}{l}\text { Limited time and } \\
\text { resources }\end{array}$ & $\begin{array}{l}\text { "I don't think there's been a pushback in terms of a worry } \\
\text { that it's not important or that it's dangerous or any of those } \\
\text { things, it really has just been about time and, well mostly } \\
\text { time I suppose and money I suppose." (S2PO2) } \\
\text { "I think the challenges are it was a short period of time to try } \\
\text { and deliver something and to spend longer doing more and } \\
\text { to get the sustainability element together into a field that it's } \\
\text { something that will continue to benefit." (S2PO2) }\end{array}$ & $\begin{array}{l}\text { Regardless of whether promoting PA is a Trust priority or } \\
\text { not, it was clear from the interviews that resources } \\
\text { (money and time) are a major determining factor as to } \\
\text { whether an intervention like the SEM pilitot is successful } \\
\text { in the short-term and sustainable going forward. }\end{array}$ \\
\hline & & $\begin{array}{l}\text { "There is significant financial problems within the trust, and } \\
\text { that spirals down into difficulties." (S2PO4) }\end{array}$ & $\begin{array}{l}\text { External funding is often required to support innovative } \\
\text { projects like the SEM pilot as the Trust does not have the } \\
\text { resource. }\end{array}$ \\
\hline & & $\begin{array}{l}\text { "But yeah I'm not sure to be brutallly honest what would } \\
\text { happen if they said like there's no money for this, what we } \\
\text { going to do? I think they'd say OK we'll just use the leaflet } \\
\text { because that's what they may have done." (S2P06) }\end{array}$ & $\begin{array}{l}\text { The external funding is required to cover the cost of } \\
\text { things like staff time to focus on delivering the project } \\
\text { which wouldn't otherwise be possible. The problem with } \\
\text { external funding is it is often short-term which means }\end{array}$ \\
\hline
\end{tabular}




\begin{tabular}{|c|c|c|c|}
\hline Topic & Theme & Quote(s) & Interpretation/implication(s) \\
\hline & & $\begin{array}{l}\text { "I think what they've achieved is huge in that short } \\
\text { timeframe and what we need is a bit longer to then start to } \\
\text { do the next bit." (S2P02) }\end{array}$ & $\begin{array}{l}\text { there is a short timeframe to deliver the project. Longer } \\
\text { term funding would help ensure sustainability of } \\
\text { projects after the initial implementation phase. }\end{array}$ \\
\hline & Safety concerns & $\begin{array}{l}\text { "So I guess lifestyle intervention has been something that's } \\
\text { been on our radar for a long time. I would probably say that } \\
\text { the dietetic element of it has taken precedence over the PA } \\
\text { element. Often because people just, you know, again it's } \\
\text { about the safety issues and worried about it [PA]" (S2P02) } \\
\text { "Am I going to break this person, yeah I think so." (S2P05) } \\
\text { "we also need to be careful of is that by promoting more PA } \\
\text { we're also not putting patients at risk of falls and that of } \\
\text { course, that's another thing that is perhaps a bit or a barrier } \\
\text { is this patient safety" (S2P05) }\end{array}$ & $\begin{array}{l}\text { Safety concerns were raised abound encouraging } \\
\text { patients to be more physically active. Some interviewees } \\
\text { worried that by encouraging patients to be more active } \\
\text { they might increase the risk of injury. This was perceived } \\
\text { to be a barrier to promoting PA within the hospital and } \\
\text { potentially why other lifestyle factors are targeted more } \\
\text { readily. }\end{array}$ \\
\hline \multirow[t]{2}{*}{$\begin{array}{l}\text { Facilitators of the } \\
\text { implementation of } \\
\text { the SEM pilot }\end{array}$} & \multirow[t]{2}{*}{$\begin{array}{l}\text { Buy-in and } \\
\text { engagement with the } \\
\text { project from key } \\
\text { stakeholders }\end{array}$} & $\begin{array}{l}\text { "the practical barrier of making a service change and the } \\
\text { inertia that you face with a large organisation to influence an } \\
\text { effect, getting buy-in from senior management" (S2P03) } \\
\text { "I think you need buy-in and I think, it's almost like you need } \\
\text { to go and prove a business model, as in proving it's effective } \\
\text { and then they'll buy onto it." (S2P06) }\end{array}$ & $\begin{array}{l}\text { Interviewees reported that buy-in from senior } \\
\text { management was crucial for the success of a project like } \\
\text { the SEM pilot. }\end{array}$ \\
\hline & & $\begin{array}{l}\text { "there's been a hugely positive response to the work that the } \\
\text { sport and exercise team have been doing to promote PA in } \\
\text { pregnancy. There have been very few barriers to educating } \\
\text { staff and all the rest of it and given the fact that we're asking } \\
\text { staff to come on their days off or whatever who haven't been } \\
\text { able to take out of their time in order to come to education } \\
\text { sessions we've had a really good uptake." (S2P02) } \\
\text { "I think at a management level, all the managers have been } \\
\text { very positive about it." (S2P02) }\end{array}$ & $\begin{array}{l}\text { Early engagement with and ownership of the SEM pilot } \\
\text { was evident among the interviewees. Staff at all levels } \\
\text { across the hospital, from ward staff to senior } \\
\text { management, were supportive of the project. A number } \\
\text { of interviewees reported that the SEM pilot had been } \\
\text { well received and some staff had even completed } \\
\text { training related to the pilot on their days off. }\end{array}$ \\
\hline
\end{tabular}




\begin{tabular}{|c|c|c|c|}
\hline Topic & Theme & Quote(s) & Interpretation/implication(s) \\
\hline & & $\begin{array}{l}\text { "the trust are really behind it, they do endorse it and they } \\
\text { are keen on it" (S2P06) } \\
\text { "I mean the team above me, so the senior team, senior } \\
\text { support I've had have been really good" (S2P07) }\end{array}$ & \\
\hline & & $\begin{array}{l}\text { "I mean it felt a little bit as though there was some resistance } \\
\text { from above, initially, but I think that was not fully } \\
\text { understanding the aims of the project, what we were trying } \\
\text { to do. But the moment that was discussed and we'd had that } \\
\text { conversation it became very very easy." (S2P07) } \\
\text { "So initially they said they wanted to do pre-op, which isn't } \\
\text { necessarily intensive care. And I don't think, I think they got } \\
\text { quite a frosty reception from preadmission clinic, so then } \\
\text { they moved to inpatients." (S2P04) }\end{array}$ & $\begin{array}{l}\text { However, there were exceptions and some aspects of } \\
\text { the SEM pilot were met with resistance. One } \\
\text { interviewee suggested that the reason for the resistance } \\
\text { from senior staff was because they did not fully } \\
\text { understand the purpose of the project. Another } \\
\text { interviewee believed that a lack of understanding on the } \\
\text { part of the SEM leads around how individual wards work } \\
\text { could hinder its success in certain pathways. }\end{array}$ \\
\hline & & $\begin{array}{l}\text { "I think the setup would have been significantly more } \\
\text { successful if they'd have contacted the stakeholders of the } \\
\text { five areas prior, because they probably would have been able } \\
\text { to focus more and foreseen some of the problems that have } \\
\text { come up in the different areas, and would have probably } \\
\text { been a better tailored intervention." (S2PO4) } \\
\text { "Yeah I'm not really sure what I was expecting to be honest. I } \\
\text { mean it hasn't surprised me that they've come to us and } \\
\text { asked these questions over there because they've been very } \\
\text { engaged from the beginning." (S2P07) }\end{array}$ & $\begin{array}{l}\text { There were mixed opinions about whether the SEM pilot } \\
\text { leads had engaged with key stakeholders early in the } \\
\text { project. One interviewee felt the pilot would have been } \\
\text { more successful if the SEM leads had engaged with } \\
\text { stakeholders in each of the five pathways. However, } \\
\text { another interviewee felt the central team had engaged } \\
\text { with them early on. }\end{array}$ \\
\hline & $\begin{array}{l}\text { The Trust and staff } \\
\text { value PA }\end{array}$ & $\begin{array}{l}\text { "I suppose the first thing what helps is if they've had, if they } \\
\text { understand the value of it [PA] and understand why they } \\
\text { should be doing it" (S2PO6) } \\
\text { "I think they tried to implement an active ward previously } \\
\text { over at the Churchill before we'd been doing that sort of } \\
\text { thing. So I don't think we're coming into a group of people }\end{array}$ & $\begin{array}{l}\text { Some interviewees indicated they had an interest in PA } \\
\text { prior to the SEM pilot. If staff value PA, a PA intervention } \\
\text { like the SEM pilot is more likely to be met with } \\
\text { enthusiasm which in turn will facilitate the } \\
\text { implementation of the pilot. Furthermore, the Trust staff } \\
\text { are more likely to buy-in to something they think is of } \\
\text { value to the patient. Interviewees also said there have } \\
\text { been other PA initiatives within the Trust prior to the }\end{array}$ \\
\hline
\end{tabular}




\begin{tabular}{|l|l|l|l|}
\hline Topic & Theme & Quote(s) & Interpretation/implication(s) \\
\hline & & $\begin{array}{l}\text { that have never, the doors have been closed and this has } \\
\text { never been entertained before." (S2P07) }\end{array}$ & $\begin{array}{l}\text { SEM pilot. This may have 'warmed up' the hospital (or } \\
\text { localised areas) to PA interventions making them more } \\
\text { susceptible to change. }\end{array}$ \\
\hline
\end{tabular}




\section{F.2 HCP survey results}

\section{F.2.1 Demographics}

Thirteen HCPs completed the baseline survey and $10 \mathrm{HCPs}$ completed the follow-up survey.

Therefore 10 participants were identified as having completed both the baseline and follow-up surveys, allowing their data to be matched and analysed. Of these individuals, $80 \%$ were female and $20 \%$ male, whilst the average age of respondents was 40 years.

In terms of profession, $60 \%$ were doctors and the remaining $40 \%$ were nurses, working across a range of departments including transplant (40\%), obstetrics and gynaecology (30\%), Cardiology $(20 \%)$ and anaesthesia (10\%). The average number of years experience in their respective roles was 11.2 years, ranging from 1 year to 29 years. From a patient interaction perspective, $50 \%$ of the sample stated they spend $>20$ minutes engaging with each patient, $30 \%$ spend $16-20$ minutes with each patient, whilst the remaining $20 \%$ stated they spend $11-15$ minutes with each patient. These results did not differ between baseline and follow-up stages.

At the time of the follow-up survey, all ten respondents reported they had not completed Clinical Champions training or been involved with any other initiatives as part of this SEM pilot.

\section{F.2.2 Attitudes, knowledge, confidence and intentions to promote/engage in a conversation about physical activity in routine practice}

Respondents were asked to rate a series of statements that focused on their views of promotion/engagement in PA, the results of which can be seen in Table 6.

Table 6 Perceived importance of PA promotion.

\begin{tabular}{|l|c|c|c|}
\hline Factor & $\begin{array}{c}\text { Baseline } \\
\text { (average } \\
\text { score) }\end{array}$ & $\begin{array}{c}\text { Follow-up } \\
\text { (average } \\
\text { score) }\end{array}$ & $\begin{array}{c}\% \\
\text { change }\end{array}$ \\
\hline $\begin{array}{l}\text { Promoting/engaging in a conversation about PA in routine practice } \\
\text { would be... (1 = Bad to 7 = Good) }\end{array}$ & 6 & 5.8 & $-3.3 \%$ \\
\hline $\begin{array}{l}\text { Promoting/engaging in a conversation about PA in routine practice } \\
\text { would be... (1 = Unpleasant to 7 = Pleasant) }\end{array}$ & 5 & 4.8 & $-4.0 \%$ \\
\hline $\begin{array}{l}\text { Most healthcare professionals promote/engage in conversations } \\
\text { about PA in routine practice... (1 = Unlikely to 7 = Likely) }\end{array}$ & 3.4 & 4 & $17.6 \%$ \\
\hline $\begin{array}{l}\text { How confident or unconfident would you describe yourself in terms } \\
\text { of discussing PA with your patients in routine practice? (1 = } \\
\text { Unconfident to 7 = Confident) }\end{array}$ & 5.4 & 5.4 & $0.0 \%$ \\
\hline $\begin{array}{l}\text { Promoting/engaging in a conversation about PA in routine practice } \\
\text { is up to me... (1 = Disagree to 7 = Agree) }\end{array}$ & 3.9 & 5.4 & $38.5 \%$ \\
\hline $\begin{array}{l}\text { I intend to promote/engage in conversations about PA in routine } \\
\text { practice... (1 = Unlikely to 7 = Likely) }\end{array}$ & 5.4 & 5.5 & $1.9 \%$ \\
\hline
\end{tabular}


Additionally, respondents were asked to state whether they had promoted/engaged in conversations about PA in their routine practice in the 3 months prior to completing the survey. At the baseline stage, $90 \%$ said they had and this increased to $100 \%$ at follow-up.

\section{F.2.3 Knowledge of Chief Medical Officers' guidelines for physical activity}

At both the baseline and follow-up stages, all 10 respondents stated that they were aware of the health benefits of regular PA. As Figure 5 shows, at baseline only $50 \%$ of respondents stated that they had heard of PA guidelines; this had increased to $70 \%$ at follow-up.

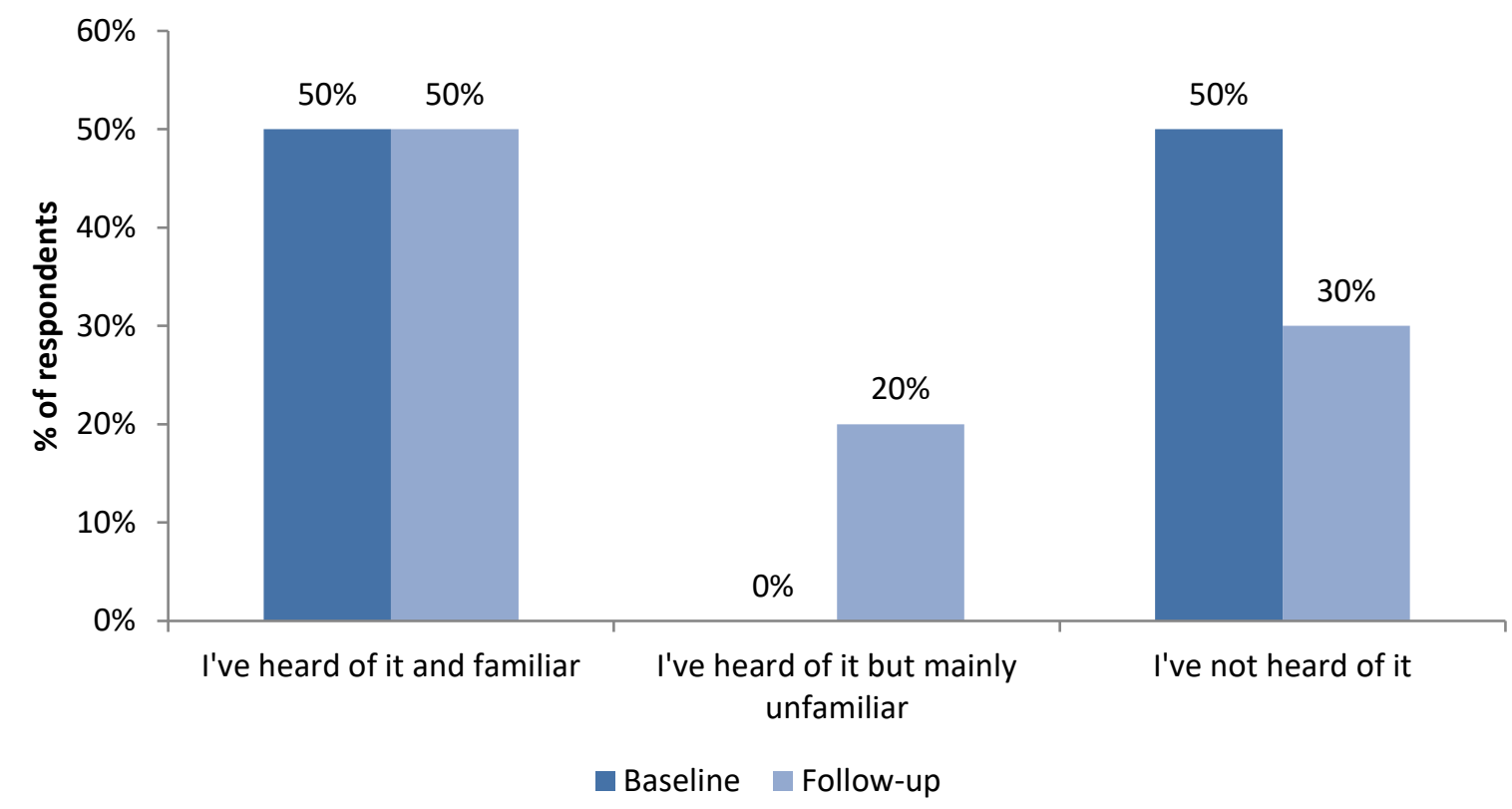

Figure 5 Respondents' familiarity with the Chief Medical Officers' PA guidelines.

\section{F.2.4 Training on brief physical activity advice}

Participants were asked which, if any, training sessions they had undertaken with respect to encouraging PA (see Figure 6). At the baseline stage, only $20 \%$ stated they had undertaken training relating to PA. This doubled to $40 \%$ at the follow-up stage. Of this $40 \%$, the greatest increases were seen across two types of training; delivering brief interventions to encourage PA ( $30 \%$ had undertaken this training at follow-up in comparison to $10 \%$ at baseline) and use of PA assessment tools (20\% had undertaken this training at follow-up in comparison to no respondents at baseline). No respondents reported completing the PA Clinical Champions Programme training or the BMJ PA Module. 


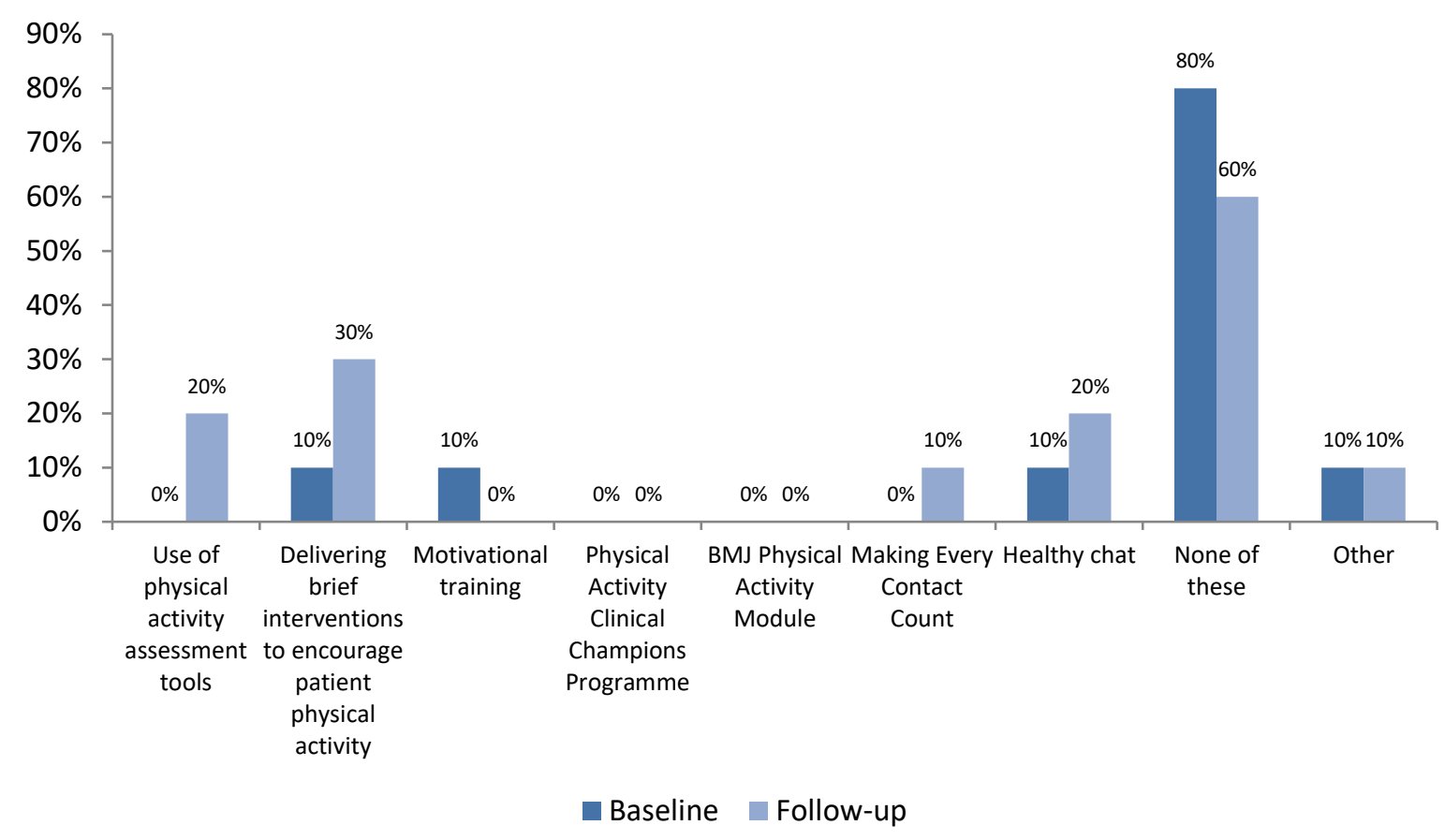

Figure 6 PA training sessions undertaken by respondents.

In terms of self-reported confidence in raising the subject of PA with their patients, there was no change, with $70 \%$ of respondents at both baseline and follow-up reporting they felt very $(20 \%)$ or somewhat $(50 \%)$ confident discussing the topic with their patients.

None of the participants reported completing any modules on PA during their training, however two individuals (20\%) stated that PA training was delivered in other modules, which were outlined as health and wellbeing modules (working in partnership with patients module) and a regional teaching session by physiotherapists that work in Maternity.

\section{F.2.5 Referrals to physical activity opportunities}

At both baseline and the follow-up respondents were asked whether they had the opportunity to refer patients to a PA pathway from their service. Figure 7 shows that only one individual $(10 \%)$ stated they had such an opportunity at baseline; however this increased to $50 \%$ at follow-up. 


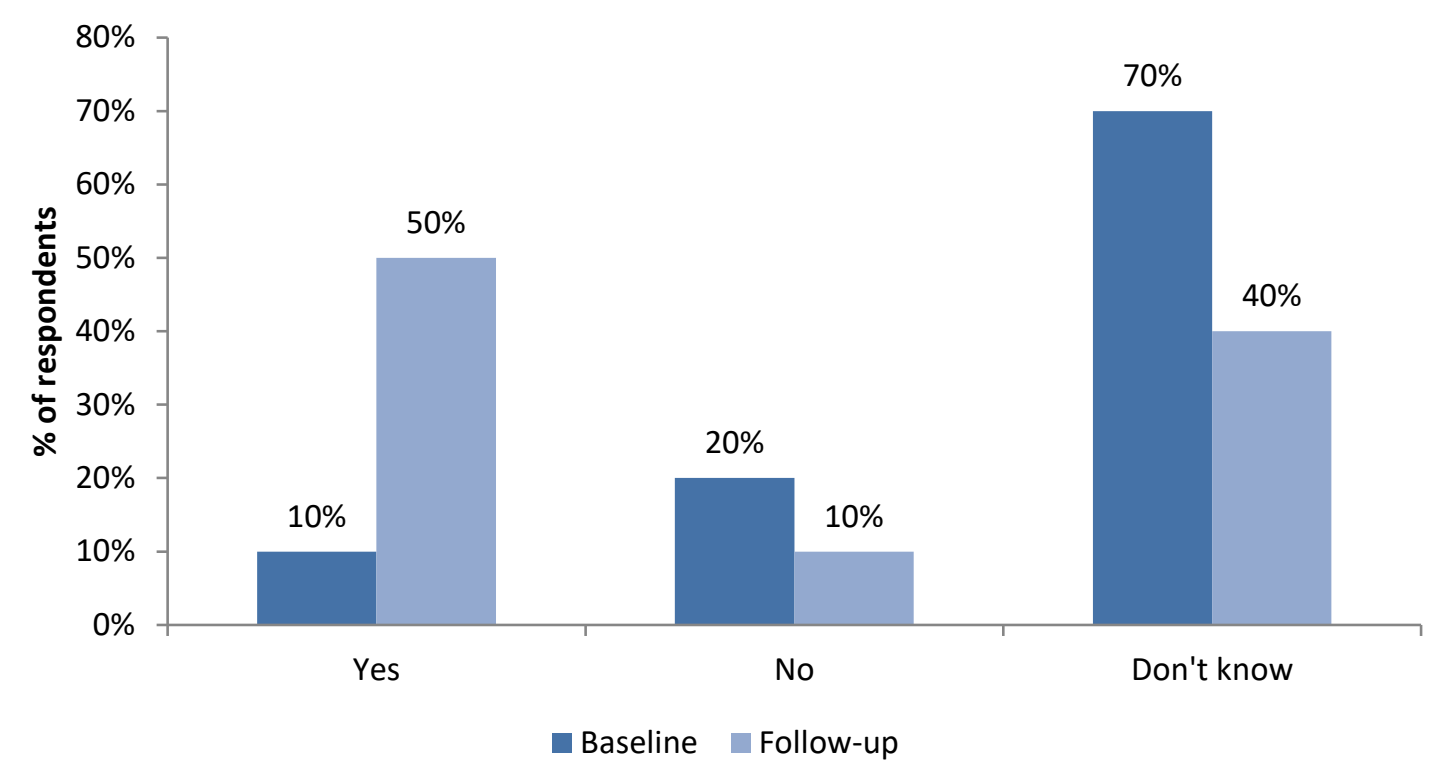

Figure 7 HCP perceived opportunity to refer patients to a PA pathway from their service.

Only one individual at baseline and follow-up stated that they knew what the PA pathway consists of. At baseline, only one individual knew how to refer patients to the PA pathway; however this increased to two individuals at follow-up. Only one of which had referred a patient to a PA pathway in the past 6 months, which was detailed by the respondent as "a local physio led PA" pathway.

\section{F.2.6 Physical activity resources, use of social marketing materials/leaflets and incentives}

At both baseline and follow-up, $70 \%$ of respondents stated that they were aware of websites or smartphone apps that promote PA. At follow-up 43\% stated they recommend/signpost their patients to these websites/smartphone apps "occasionally/often", as opposed to only $14 \%$ at baseline. In terms of which websites/smartphone apps respondents said they recommended to their patients, the most common responses were Couch to $5 \mathrm{k}$ and the NHS website, in which $71 \%$ and $57 \%$ recommended these respectively.

Only one respondent said that they distribute leaflets or other social marketing materials to patients to encourage them to become more physically active; this was stated as a "prevention of Deep Vein Thrombosis leaflet".

Lastly, only one respondent suggested that there is an incentive (financial or other) for the time they spend promoting PA in routine practice. A respondent from obstetrics and gynaecology stated that there are health benefits to be gained, including potential increase in maternal wellbeing/less weight gain during a pregnancy. 


\section{Enablement patients' experience of a physical activity class and their perceptions of the role of a peer mentor}

The tables below contain the main topics and themes that emerged from the analysis of the Enablement patient interviews. A description of each theme is given with direct quotes taken from interviews to help demonstrate the findings and support the researcher's interpretation.

\section{Table 7 Describes participants' experiences of taking part in an Enablement PA class.}

\begin{tabular}{|c|c|c|c|}
\hline \multicolumn{4}{|c|}{ Experience of PA based Enablement class/pathway } \\
\hline Topic & Theme & Quote(s) & Interpretation/implication(s) \\
\hline $\begin{array}{l}\text { Requirement for } \\
\text { enabling clinical } \\
\text { support }\end{array}$ & $\begin{array}{l}\text { Patients physical and } \\
\text { psychological needs post } \\
\text { amputation require } \\
\text { professional support }\end{array}$ & $\begin{array}{l}\text { "we have got the best surgeons in the world probably, but it } \\
\text { takes somebody to pick up the pieces after the surgery which, } \\
\text { you know, so physiotherapists to me are my, you know, my } \\
\text { absolute go to. You know, they're the people to turn to" (S3P03) }\end{array}$ & $\begin{array}{l}\text { MDT teams of HCPs are required to meet the needs of } \\
\text { patients in the Enablement pathway. }\end{array}$ \\
\hline $\begin{array}{l}\text { Patients } \\
\text { perception of PA }\end{array}$ & $\begin{array}{l}\text { The meaning of PA to } \\
\text { patients }\end{array}$ & $\begin{array}{l}\text { "To me, PA means simply moving, being able to walk. Anything } \\
\text { on top of that is a bonus for me, to be brutally honest. It's } \\
\text { literally as simple as that and being actually able to get out of a } \\
\text { wheelchair, which I was in for seven months, to get off a bed, to } \\
\text { get off a chair, and walk under my own power" (S3P02) } \\
\text { "Freedom! ...my hobby is cooking. I love to cook. Some guys love } \\
\text { football, cricket, tennis, whatever, or golf. I like cooking. When I } \\
\text { can walk around the kitchen initially, just to be able to do that, } \\
\text { I'll do it. Sometimes I get a lot of chafing, but if I can do it and I'm } \\
\text { pain free or more or less pain free, then that gives me a lot of } \\
\text { freedom" (S3P01) } \\
\text { "The PA side of things I find is what keeps me motivated. It's too } \\
\text { easy to accept what's happened and just switch off from the real } \\
\text { world" (S3P03) }\end{array}$ & $\begin{array}{l}\text { The perceived understanding of the term PA needs to be } \\
\text { acknowledged for each patient - in order to design } \\
\text { interventions that will be appropriate and meaningful to } \\
\text { patients. } \\
\text { PA means different things to different people in the context } \\
\text { of Enablement - it is often associated with activities of daily } \\
\text { living rather than a specific sport or recreational type of } \\
\text { activity. In itself taking part in PA is a metaphorical and literal } \\
\text { vehicle for moving on after amputation. }\end{array}$ \\
\hline $\begin{array}{l}\text { Perceived aim of } \\
\text { the Enablement }\end{array}$ & $\begin{array}{l}\text { The medical care team's } \\
\text { aim is to get people } \\
\text { moving again }\end{array}$ & $\begin{array}{l}\text { "It isn't about the gym. It's about exercise. That's where their } \\
\text { focus is" (S3P01) }\end{array}$ & $\begin{array}{l}\text { Patients and staff have clear expectations of what the } \\
\text { programme is trying to achieve- namely Enablement } \\
\text { underpinned by regaining mobility and getting moving again. }\end{array}$ \\
\hline
\end{tabular}




\begin{tabular}{|c|c|c|c|}
\hline \multicolumn{4}{|c|}{ Experience of PA based Enablement class/pathway } \\
\hline Topic & Theme & Quote(s) & Interpretation/implication(s) \\
\hline $\begin{array}{l}\text { class - to get } \\
\text { moving }\end{array}$ & & $\begin{array}{l}\text { "They want to get us all moving" "There's no - how can I put this } \\
\text { politely? - BS about them. They're very, very intense with us and } \\
\text { they're absolutely brilliant" (S3P02) } \\
\text { "I've had a meeting with Dr James and James where they set you } \\
\text { a programme and so, for example, the exercise programme you } \\
\text { do, they want to get you out and about and you get stronger as } \\
\text { you follow the programme" (S3P01) } \\
\text { "I suppose the best thing is they've not written me off. A lot of } \\
\text { people say you're } 78 \text { years old, you just get in a wheelchair and } \\
\text { that's where you stay. But they said no. We can get you further } \\
\text { than that. And they have" (S3P04) }\end{array}$ & $\begin{array}{l}\text { The aim of the programme is holistic - to support daily } \\
\text { activities. Aligning personal aims with the aims and outcomes } \\
\text { of the programme may assist patient motivation and } \\
\text { adherence. Staff have imparted a sense of positivity that has } \\
\text { in turn given patients a sense of hope. }\end{array}$ \\
\hline $\begin{array}{l}\text { Specific features } \\
\text { of the PA based } \\
\text { Enablement class }\end{array}$ & $\begin{array}{l}\text { Class provision - A } \\
\text { bespoke class with HCPs } \\
\text { in attendance }\end{array}$ & $\begin{array}{l}\text { "Well, we do it in a class. There's usually about three or four, } \\
\text { maybe five of us at one time and the three physios are there. It's } \\
\text { like a rotational class. We go from exercise to exercise to } \\
\text { exercise" (S3P02) } \\
\text { So I'm on a programme and you get evaluated on the } \\
\text { programme, by phone or whatever, and you can go back. And } \\
\text { also, I can go back up there at any time. So for example, when I } \\
\text { do that mobility, if I want to go to a class up there every week, I } \\
\text { can just ring James. You're discharged, but you're not discharged, } \\
\text { if you know what I mean?" (S3P01) } \\
\text { "It's a two-hour slot when you do the physio and then you do the } \\
\text { like a keep fit. And usually they're all present thereabouts and } \\
\text { whatnot and that's where you get your training and they teach } \\
\text { you how to walk again and give you encouragement and } \\
\text { everything" (S3P02) } \\
\text { "I wasn't really that bothered about gym or anything like that. } \\
\text { But then of course once you go to the OCE (Oxford Centre for }\end{array}$ & $\begin{array}{l}\text { Having a structured class means patients have something to } \\
\text { adhere to, it makes the goal of doing PA easier, it assists } \\
\text { motivation. It can be difficult to engage with the exercises at } \\
\text { home. The group class means there is support on hand to } \\
\text { learn the correct techniques of the activity. } \\
\text { The experiences of patients reported that it is possible to } \\
\text { combine a group-based class and still also receive a } \\
\text { personalised approach thus meeting patients' specific needs. } \\
\text { Central to this is the input of trained staff who have the } \\
\text { knowledge and the interpersonal skills to create patient } \\
\text { rapport and support patient motivation. } \\
\text { Activities within the class or programme are tailored to } \\
\text { support the individual patient progress their rehabilitation } \\
\text { and be able to resume activities of daily living in due course. } \\
\text { The professionals supporting the class have a very positive } \\
\text { impact upon the patient and their motivation to sustain their } \\
\text { PA. }\end{array}$ \\
\hline
\end{tabular}




\begin{tabular}{|c|c|c|c|}
\hline \multicolumn{4}{|c|}{ Experience of PA based Enablement class/pathway } \\
\hline Topic & Theme & Quote(s) & Interpretation/implication(s) \\
\hline & & $\begin{array}{l}\text { Enablement), then when you've had your physio, so you've had } \\
\text { an hour physio, then you have an hour of physical exercises and } \\
\text { you have to do like circuit training basically around these like, } \\
\text { but the interesting thing about that is that everything you do is } \\
\text { actually geared towards not just your wellbeing, but the way } \\
\text { they've set it up is very clever because it's geared towards giving } \\
\text { you strength, giving you balance, and all the things that you need } \\
\text { as an amputee" (S3P01) } \\
\text { "it's [PA] been very much just laid on for me, and all I have to do } \\
\text { is turn up and the expertise is there" (S3P03) } \\
\text { "you're given a set of skills which you can take away and use at } \\
\text { home, but you're also given the motivation to do these exercises } \\
\text { as well. Whereas I mean, a gym instructor will say well do this at } \\
\text { home, do this at home and you wouldn't. But this, the exercises } \\
\text { that I'm given to do, I find the benefit is absolutely fantastic. I } \\
\text { mean you really do notice" (S3P03) } \\
\text { "Well you do the exercises they give you, properly really I } \\
\text { suppose. Whereas at home you probably, now and again you're } \\
\text { oh I don't feel like doing it today. You cut corners. (S3P03) } \\
\text { "Here you don't, you have to do them. So it is important. And I } \\
\text { think that the classes are very good" (S3P04) }\end{array}$ & \\
\hline & $\begin{array}{l}\text { Group format is } \\
\text { therapeutic in itself }\end{array}$ & $\begin{array}{l}\text { "well we see each other every week and at one point it's starting } \\
\text { to evolve into like a club, can I say a club? Where we all know } \\
\text { each other, we all know because we've spent, we've gone } \\
\text { through so much together. We're all bonded if that's the right } \\
\text { word " (S3P03) }\end{array}$ & $\begin{array}{l}\text { Despite not having any formal mentors the group class was } \\
\text { reported as being meaningful. Of note the patient remarks } \\
\text { the group has "evolved" - this suggests that the process of } \\
\text { Enablement with peers is a dynamic experience and the } \\
\text { future set up of any peer support programmes might want to } \\
\text { consider being reactive to the groups changing needs over } \\
\text { time. }\end{array}$ \\
\hline
\end{tabular}




\begin{tabular}{|c|c|c|c|}
\hline \multicolumn{4}{|c|}{ Experience of PA based Enablement class/pathway } \\
\hline Topic & Theme & Quote(s) & Interpretation/implication(s) \\
\hline & $\begin{array}{l}\text { Gradual paced } \\
\text { progression of exercise }\end{array}$ & $\begin{array}{l}\text { "So for example, like bench presses I might only achieve three } \\
\text { initially when I first started; now I can probably do around 200" } \\
\text { (S3P03) } \\
\text { "And it's just the right amount of exercise" (S3P03) } \\
\text { "Initially I thought oh this is going to be really gruelling, really } \\
\text { know you're going to come out pouring with sweat and really } \\
\text { aching and tired, but it's just a gradual build up. So he's gradually } \\
\text { building it up. But doing it really carefully and really nicely. I've } \\
\text { never pulled any muscles or had any real serious..." (S3P03) }\end{array}$ & $\begin{array}{l}\text { Patients appreciate having their PA plan mapped out for } \\
\text { them, knowing it has been designed by someone with } \\
\text { professional knowledge and that it offers gradual } \\
\text { progression. }\end{array}$ \\
\hline & $\begin{array}{l}\text { More than exercise - } \\
\text { learning life skills }\end{array}$ & $\begin{array}{l}\text { "The best part is, I think has been learning life skills, after an } \\
\text { amputation that everything, you know, you have to really plan } \\
\text { even the minimum task you have to really plan what you're } \\
\text { going to do" (S3P03) }\end{array}$ & $\begin{array}{l}\text { Enablement is more than rehabilitation exercise, it also } \\
\text { encompasses planning and managing life skills. }\end{array}$ \\
\hline & $\begin{array}{l}\text { There is a clear patient- } \\
\text { centred approach }\end{array}$ & $\begin{array}{l}\text { "The big thing I'd say is if you want to say one thing about the } \\
\text { people that have dealt with me from Bob Sharpe, Henderson } \\
\text { Slater, or Nurse Tina, she's the amputee nurse for the prosthetics } \\
\text { for the physio, there's no stars up there (referring to HCPs), they } \\
\text { don't see themselves as stars; if anything, they make you the } \\
\text { star" (S3P01) } \\
\text { "The ball's in your court, you know" (S3P01) } \\
\text { "You get a lot of care - a better word. You get all of that and you } \\
\text { get as much of it as you want. It's not overpowering, but you can } \\
\text { get what you want " (S3P01) } \\
\text { "And so you constantly given a progress update which I find } \\
\text { encouraging" (S3P03) }\end{array}$ & $\begin{array}{l}\text { The style in which staff interact with patients can be } \\
\text { empowering for the patients. The empowering style of } \\
\text { interaction encountered by patients across the MDT team of } \\
\text { doctors, surgeons, nurses, physiotherapists and occupational } \\
\text { therapists was warmly received. } \\
\text { It is important to help patients have a sense of ownership of } \\
\text { their engagement in the class or programme. Facilitating } \\
\text { ownership has come about through skilful communication } \\
\text { from the healthcare staff and by having clear programme } \\
\text { aims. }\end{array}$ \\
\hline & $\begin{array}{l}\text { Information giving and } \\
\text { signposting are given }\end{array}$ & $\begin{array}{l}\text { "Giving us information about outside activities, sports like golf } \\
\text { and archery and stuff like that. Yeah, they're all very good" } \\
\text { (S3P02) }\end{array}$ & $\begin{array}{l}\text { Providing options for continuity of PA beyond the hospital is } \\
\text { necessary. Meeting the needs of patients in terms of } \\
\text { Enablement will mean connecting with other agencies }\end{array}$ \\
\hline
\end{tabular}




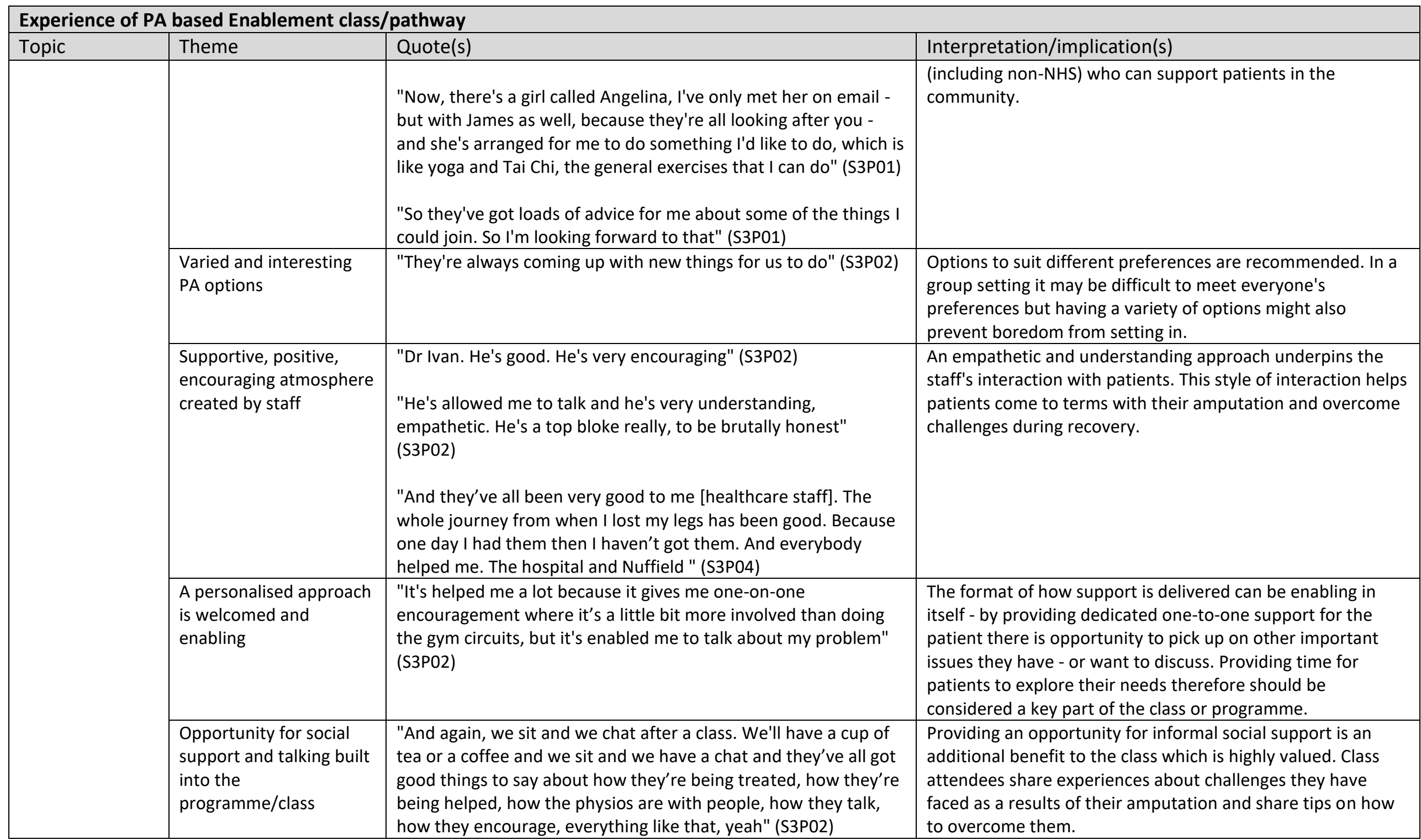




\begin{tabular}{|c|c|c|c|}
\hline \multicolumn{4}{|c|}{ Experience of PA based Enablement class/pathway } \\
\hline Topic & Theme & Quote(s) & Interpretation/implication(s) \\
\hline & & $\begin{array}{l}\text { "But I find also being with other amputees is a good source of } \\
\text { information because whereas upon the particular task I might } \\
\text { find difficult so then I will discuss it with another amputee and } \\
\text { they'll say why don't you try it this way?" (S3P03) } \\
\text { "Well I've learnt exercises to do and how to keep fit. And I've } \\
\text { seen other people and talked to them with the same problems as } \\
\text { you've got, helps you" (S3P04) }\end{array}$ & \\
\hline \multirow[t]{4}{*}{$\begin{array}{l}\text { Perceived } \\
\text { benefits of taking } \\
\text { part in an } \\
\text { enablement class }\end{array}$} & $\begin{array}{l}\text { Perceived physiological } \\
\text { benefits of taking part in } \\
\text { the class }\end{array}$ & $\begin{array}{l}\text { "The things like the breathing, cardiovascular-type exercises I } \\
\text { find help me because it tends to give me energy" (S3P03) } \\
\text { "Well I think I'm fitter. I'm quite fit for someone who's, I'm } 79 \\
\text { next week. For somebody who's } 79 \text { in a wheelchair with no legs. } \\
\text { And I think I'm quite fit. In fact I know I am because by what the } \\
\text { physios tell me" (S3P04) }\end{array}$ & $\begin{array}{l}\text { Physical benefits are "felt" - such as having more energy but } \\
\text { also directly hearing the message from professionals that the } \\
\text { patient is getting fitter is reassuring. }\end{array}$ \\
\hline & $\begin{array}{l}\text { Informally supporting } \\
\text { others is perceived as } \\
\text { valuable }\end{array}$ & $\begin{array}{l}\text { "And if we can help each other out then that's why we're there" } \\
\text { (S3P02) }\end{array}$ & $\begin{array}{l}\text { In the absence of a formal peer-to peer-support programme } \\
\text { patients still recognise and report that helping others is } \\
\text { linked to their involvement in the class. It seems implicit for } \\
\text { those interviewed that there is more to being in the class } \\
\text { than simply taking part for oneself. Patients are generally } \\
\text { willing to give something back and share their experiences - } \\
\text { but it should not be assumed that everyone wants to receive } \\
\text { peer support or adopt a formal peer mentor/or peer-to-peer } \\
\text { support role - see later entry receiving peer support and/or } \\
\text { being a peer mentor isn't for everyone. }\end{array}$ \\
\hline & $\begin{array}{l}\text { Supporting others also } \\
\text { helps yourself }\end{array}$ & $\begin{array}{l}\text { "but who knows what other people are going through? And if I } \\
\text { can help support them a little bit, it helps me as well" (S3P02) } \\
\text { "I've got other problems involved in it, but if I can help } \\
\text { somebody else, it does me good" (S3P02) }\end{array}$ & $\begin{array}{l}\text { Patients reported feeling good as a result of helping others. } \\
\text { Being able to offer peer support may also be therapeutic for } \\
\text { the individual providing the support. }\end{array}$ \\
\hline & $\begin{array}{l}\text { Enablement class } \\
\text { supports other condition }\end{array}$ & $\begin{array}{l}\text { "To be honest, since my amputation my mental health problems } \\
\text { have got worse" (S3P02) }\end{array}$ & $\begin{array}{l}\text { The setup of any programme needs to recognise that patients } \\
\text { could also have mental health concerns arising from their }\end{array}$ \\
\hline
\end{tabular}




\begin{tabular}{|c|c|c|c|}
\hline \multicolumn{4}{|c|}{ Experience of PA based Enablement class/pathway } \\
\hline Topic & Theme & Quote(s) & Interpretation/implication(s) \\
\hline & $\begin{array}{l}\text { management - mental } \\
\text { health }\end{array}$ & $\begin{array}{l}\text { "Initially, from the amputation, above knee amputation I found } \\
\text { myself quite deep in to depression" (S3P03) } \\
\text { "Low points, you get lots of them. Because you get depression" } \\
\text { (S3P04) }\end{array}$ & $\begin{array}{l}\text { amputation or an already existing mental health condition } \\
\text { being exacerbated. }\end{array}$ \\
\hline & Peers have similar needs & $\begin{array}{l}\text { "We're all in the same boat. We all have the same problems with } \\
\text { the amputations. Maybe not so much with mental health-wise, } \\
\text { but who knows what other people are going through?" (S3P02) }\end{array}$ & $\begin{array}{l}\text { Patients feel they have similar needs to other patients } \\
\text { receiving treatment in the Enablement pathway which aligns } \\
\text { well with a group exercise class and peer support } \\
\text { programme. }\end{array}$ \\
\hline
\end{tabular}

Table 8 Participants thoughts about what makes a successful Enablement PA class and patients perceptions of key features of future peer-to-peer support programmes.

ज $\quad$ What makes a successful Enablement PA class and future peer-to-peer support programme?

\begin{tabular}{|c|c|c|c|}
\hline Topic & Theme & Quote(s) & Interpretation/implication(s) \\
\hline \multirow[t]{3}{*}{$\begin{array}{l}\text { Individual } \\
\text { experience and } \\
\text { characteristics of } \\
\text { the peer mentor }\end{array}$} & $\begin{array}{l}\text { Patients previous } \\
\text { experience of mentoring } \\
\text { or supporting others } \\
\text { may influence outcomes }\end{array}$ & $\begin{array}{l}\text { "I've always been a trainer. Always through my working life, I've } \\
\text { always helped people to get along and to train them and to give } \\
\text { them the benefit of my experience if I possibly can. And I believe } \\
\text { that one-on-one training works the best. So one-on-one, working } \\
\text { with somebody at the same level, or even somebody above you, } \\
\text { is one of the easiest ways to learn and get on" (S3P02) }\end{array}$ & $\begin{array}{l}\text { For a peer-to-peer support programme to be successful it } \\
\text { may be necessary to consider patient's previous experience } \\
\text { of mentoring, their suitability to become a mentor, their } \\
\text { competencies as a listener and their ability to be empathetic. } \\
\text { Not everyone will have the requisite experience or desire to } \\
\text { be a mentor - additional training may be required. }\end{array}$ \\
\hline & $\begin{array}{l}\text { Having the right } \\
\text { competencies and } \\
\text { experiences to be a } \\
\text { mentor }\end{array}$ & $\begin{array}{l}\text { "There's more to peer-to-peer health than what it sounds like" } \\
\text { (S3P02) }\end{array}$ & $\begin{array}{l}\text { Mentoring was reported as complex and therefore it may } \\
\text { require the patient mentor to have certain competencies to } \\
\text { deliver successful outcomes. Setting, processes, } \\
\text { communication skills and mentor characteristics need careful } \\
\text { consideration. }\end{array}$ \\
\hline & $\begin{array}{l}\text { Know your limitations as } \\
\text { a mentor }\end{array}$ & $\begin{array}{l}\text { "you've got to follow through afterwards with information if that } \\
\text { person needs information or if you can't help them, to pass them } \\
\text { onto somebody else" (SP302) }\end{array}$ & $\begin{array}{l}\text { Self-discipline is needed to know your limitations as a mentor } \\
\text { and knowledge of how to refer to other services/experts. }\end{array}$ \\
\hline
\end{tabular}




\begin{tabular}{|c|c|c|c|}
\hline \multirow[t]{4}{*}{ Topic } & Theme & Quote(s) & Interpretation/implication(s) \\
\hline & $\begin{array}{l}\text { Being an empathetic } \\
\text { mentor }\end{array}$ & $\begin{array}{l}\text { Sympathy isn't enough. It's empathy that they need" (S3P02) } \\
\text { "But to be able to listen and talk to somebody about what's } \\
\text { going on and what happened sensibly and intelligently is } \\
\text { difficult" (S3P02) } \\
\text { "Trying to understand people, I think. That's one of the things. } \\
\text { And help them if they want help. You can't help somebody if } \\
\text { they don't want help...What you should do? Understand them. } \\
\text { Both physically and mentally really" (S3P04) }\end{array}$ & $\begin{array}{l}\text { Patients recognise there is a distinction between listening or } \\
\text { offering sympathy and being able to mentor a fellow patient. } \\
\text { Mentoring is thought to be a shared process - between the } \\
\text { mentor and the mentee. Peer mentoring requires a sound, } \\
\text { balanced appreciation of fellow peers mental and physical } \\
\text { needs. As such this may require upskilling patients to become } \\
\text { peer mentors. }\end{array}$ \\
\hline & $\begin{array}{l}\text { Being a good listener is } \\
\text { part of being a good } \\
\text { mentor }\end{array}$ & $\begin{array}{l}\text { "A listener, but they also need to be able to talk about what } \\
\text { they're hearing, not make assumptions how people feel. Because } \\
\text { the worst thing anybody can say to any of us: yeah, I know how } \\
\text { you feel. No, you don't. You've no idea. Take your leg off. Let me } \\
\text { take your leg off and see how you feel. I've had it said to me a } \\
\text { couple of times, unfortunately, I know how you feel. No, you } \\
\text { don't. You haven't got a clue. They need to be a listener, a talker, } \\
\text { an empath really" (S3P02) }\end{array}$ & $\begin{array}{l}\text { Future peer mentors need to adopt a non-judgemental } \\
\text { approach, and be capable of asking questions and listening } \\
\text { well this is a complex set of skills - training may be required. }\end{array}$ \\
\hline & $\begin{array}{l}\text { Receiving peer } \\
\text { mentoring and/or being } \\
\text { a peer mentor is not for } \\
\text { everyone }\end{array}$ & $\begin{array}{l}\text { Have you been involved in what we call a peer-to-peer support } \\
\text { programme where you're mentored by a fellow patient? } \\
\text { "No, I haven't. And to be truthful with you, it wouldn't have been } \\
\text { something that I'd have been comfortable with. I'll chat away } \\
\text { with you on the phone, but I'm quite a private guy. I don't make } \\
\text { friends as such and I sometimes with people, if I think that } \\
\text { people are asking me questions for their own benefit or for their } \\
\text { own, I don't know. It's hard to explain the type of person I am" } \\
\text { (SP301) } \\
\text { "I don't mind sharing the experience and whatnot. What I dislike } \\
\text { is do you know when somebody says poor me and they're feeling } \\
\text { sorry for themselves and everything else? The good thing about } \\
\text { the staff up there is nobody feels sorry for you. You're not }\end{array}$ & $\begin{array}{l}\text { Although patients report enjoying and benefiting from the } \\
\text { camaraderie of their peers and the opportunity to talk, for } \\
\text { some patients they do not wish to formally engage in peer- } \\
\text { to-peer support - either receiving peer support or engaging in } \\
\text { conversations that might be perceived as personal or } \\
\text { uncomfortable. Previous history of other conditions such as } \\
\text { mental health conditions may mean some patients do not } \\
\text { wish to engage in peer-to-peer support programmes. It } \\
\text { cannot be assumed that the peer-to-peer support model will } \\
\text { suit everyone and the group based format that developed } \\
\text { authentically during the pilot phase of the pathway is } \\
\text { potentially more suited to Enablement patients. }\end{array}$ \\
\hline
\end{tabular}




\begin{tabular}{|c|c|c|c|}
\hline Topic & Theme & Quote(s) & Interpretation/implication(s) \\
\hline & & $\begin{array}{l}\text { unique. They're very caring. They're very loving, they're } \\
\text { exceptional people. But they don't make you feel like that" } \\
\text { (S3P01) } \\
\text { "I don't mind helping other people, but I don't like this one-on- } \\
\text { one thing because people can get personal" (S3P01) }\end{array}$ & \\
\hline & $\begin{array}{l}\text { Personal characteristics } \\
\text { of the patient can } \\
\text { influence the success of } \\
\text { outcomes }\end{array}$ & $\begin{array}{l}\text { "So I went in with the attitude that I had to work to wearing a } \\
\text { leg. And I did work. And I'm very focused. That comes from my } \\
\text { previous life. I don't give up" (S3P01) }\end{array}$ & $\begin{array}{l}\text { Previous life experiences and personality may account for } \\
\text { how well some patients engage with the class or programme. } \\
\text { If patients don't have the ability to draw upon previous } \\
\text { experiences then building up psychological resilience and } \\
\text { focus may need to be considered as part of the programme. }\end{array}$ \\
\hline \multirow[t]{3}{*}{$\begin{array}{l}\text { Features of the } \\
\text { Enablement class }\end{array}$} & $\begin{array}{l}\text { The whole approach } \\
\text { adds value }\end{array}$ & $\begin{array}{l}\text { "Do you know the whole thing is of a value as far as I would say. } \\
\text { It's not just one aspect of it. It's the whole group working } \\
\text { together and the encouragement of everybody that's there, not } \\
\text { just the physios and the doctor. It's everybody else, as patients, } \\
\text { helping each other out. And I think it's good we can talk about } \\
\text { what happened to us because it is massively life changing " } \\
\text { (S3P02) }\end{array}$ & $\begin{array}{l}\text { Creating Enablement via PA involves numerous factors, } \\
\text { having a programme or class that can address multiple needs } \\
\text { - physical, social, psychological and emotional seems to be of } \\
\text { value to patients. }\end{array}$ \\
\hline & Facilitated access & $\begin{array}{l}\text { "They provided hospital transport because obviously I couldn't } \\
\text { drive and my wife, she couldn't take time off work" (S3P01) } \\
\text { "I come to the fitness class on a Tuesday, I've also been } \\
\text { introduced to horse riding which I do now through the } \\
\text { physiotherapist. That was all organised. All I had to do was turn } \\
\text { up and now I go horse riding on Thursday" (S3P03) }\end{array}$ & $\begin{array}{l}\text { Supported access to class or support programme might be } \\
\text { needed for some depending on mobility status, personal } \\
\text { circumstances. This could also be a challenge for the } \\
\text { sustainability of the activities as patient transportation } \\
\text { requires additional resources. }\end{array}$ \\
\hline & Face-to-face format & $\begin{array}{l}\text { "You have to be able to sit with someone because you can see in } \\
\text { their face what. You can't hide your facial expressions and you } \\
\text { do need to be able to see, I think you need to be able to see in } \\
\text { the other person's face that they do understand and they are } \\
\text { listening and they are willing to help in any way they can" } \\
\text { (S3P02) }\end{array}$ & $\begin{array}{l}\text { There should be opportunity to observe non-verbal } \\
\text { communication within the peer support approach. }\end{array}$ \\
\hline Staffing & $\begin{array}{l}\text { Encouraging/motivation } \\
\text { al support from staff }\end{array}$ & $\begin{array}{l}\text { "But they do get us moving, get us shifting, encourage us" } \\
\text { (S3P02) }\end{array}$ & $\begin{array}{l}\text { Encouragement is received in various formats - verbal } \\
\text { communication and in the form of monitoring and progress }\end{array}$ \\
\hline
\end{tabular}




\begin{tabular}{|c|c|c|c|}
\hline \multicolumn{4}{|c|}{ What makes a successful Enablement PA class and future peer-to-peer support programme? } \\
\hline Topic & Theme & Quote(s) & Interpretation/implication(s) \\
\hline & & $\begin{array}{l}\text { "And so you constantly given a progress update which I find } \\
\text { encouraging" (S3P03) }\end{array}$ & $\begin{array}{l}\text { reports. Both types of encouragement reportedly assist } \\
\text { motivation. }\end{array}$ \\
\hline & $\begin{array}{l}\text { Clear and direct } \\
\text { communication }\end{array}$ & $\begin{array}{l}\text { "There's no - how can I put this politely? - BS about them. } \\
\text { They're very, very intense with us and they're absolutely } \\
\text { brilliant" (S3P02) }\end{array}$ & $\begin{array}{l}\text { Clear communication from staff about the expectations they } \\
\text { have for patients in terms of their rehabilitation and } \\
\text { Enablement is valued by patients. For some a direct approach } \\
\text { is valued. }\end{array}$ \\
\hline \multirow[t]{2}{*}{$\begin{array}{l}\text { Enhancing the } \\
\text { Enablement PA } \\
\text { class or a peer- } \\
\text { to-peer support } \\
\text { programme in } \\
\text { the future }\end{array}$} & $\begin{array}{l}\text { Increasing staff capacity } \\
\text { to deliver Enablement } \\
\text { pathway }\end{array}$ & $\begin{array}{l}\text { "my answer when it comes to the NHS: there's not enough of } \\
\text { them and there isn't enough money, it's as simple as that. The } \\
\text { people we have don't need any kind of improvement at all. We } \\
\text { just need more of them" (S3P02) } \\
\text { "I think there's a limit to how many patients that could be, that } \\
\text { the physiotherapist could encounter at any one single time } \\
\text { because a) there's always people, people will always fall I've } \\
\text { found and so if I were to become a mentor for example it would } \\
\text { take some pressure of the physiotherapist and give more } \\
\text { patients the opportunity to be able to come in and be involved" } \\
\text { (S3P03) } \\
\text { "Physios are very important. Very important. And even the } \\
\text { young ones that come in and help the head ones are good. They } \\
\text { help you. They're all good, they're all important. } \\
\text { And you need hospital staff, nurses and the physios to encourage } \\
\text { them to get out of bed and do some exercises and do } \\
\text { something" (S3P04) }\end{array}$ & $\begin{array}{l}\text { Patient perceived the service to be under-resourced and } \\
\text { suggested increasing staffing capacity would be beneficial. } \\
\text { Patients see several professionals throughout the journey } \\
\text { and they consistently value their input and professionalism } \\
\text { and acknowledge it is the professional who help them to } \\
\text { progress post amputation. }\end{array}$ \\
\hline & $\begin{array}{l}\text { Peer-to-peer } \\
\text { encouragement } \\
\text { important from an } \\
\text { expert patient } \\
\text { perspective }\end{array}$ & $\begin{array}{l}\text { "I would certainly be encouraging... encouragement and support } \\
\text { is massive " (S3P03) } \\
\text { "Encouragement and help. It depends on what their disability is } \\
\text { doesn't it? I mean if they've lost legs then even talking to them } \\
\text { can help them. It can be done" (S3P04) }\end{array}$ & $\begin{array}{l}\text { Giving encouragement to peers is recognised as being one of } \\
\text { the main roles of a peer mentor. It was the first thing that } \\
\text { was mentioned by these two patients when asked what they } \\
\text { could offer as a peer mentor. }\end{array}$ \\
\hline
\end{tabular}




\begin{tabular}{|c|c|c|c|}
\hline \multicolumn{4}{|c|}{ What makes a successful Enablement PA class and future peer-to-peer support programme? } \\
\hline Topic & Theme & Quote(s) & Interpretation/implication(s) \\
\hline & $\begin{array}{l}\text { Sharing and learning } \\
\text { from the lived } \\
\text { experience of } \\
\text { amputation }\end{array}$ & $\begin{array}{l}\text { "Well the obvious, the friendly and the understanding and } \\
\text { because I've been there and I know. I know about the phantom } \\
\text { pain and I know about all the little things. I know the shock you } \\
\text { go through when you fall, even though you're not hurt, it's just a } \\
\text { shock" (S3P03) }\end{array}$ & $\begin{array}{l}\text { Offering education to fellow patients by virtue of sharing } \\
\text { one's own experience could be of value. The mentee could be } \\
\text { more responsive and accepting of support from the peer } \\
\text { mentor if they feel they have lived similar experiences. }\end{array}$ \\
\hline & $\begin{array}{l}\text { Peer mentors need } \\
\text { training }\end{array}$ & $\begin{array}{l}\text { "First aid training I think would be and also blood sugar level they } \\
\text { check. That can be quite scary can't it, just a couple of guys have } \\
\text { sobbed when they've gone over. That would worry me" (S3P03) } \\
\text { "You do need a bit of training because training is important. You } \\
\text { can't just throw people in the deep end and say this is what } \\
\text { you've got to do. They need training" (S3P04) }\end{array}$ & $\begin{array}{l}\text { First Aid training and specific practical skills training might be } \\
\text { needed if patients are expected to deliver peer-to-peer } \\
\text { support formally. A potential requirement in the future might } \\
\text { be to audit patient skills and knowledge. Motivational } \\
\text { interviewing training could be a useful training aid. }\end{array}$ \\
\hline & $\begin{array}{l}\text { Reasonable expectations } \\
\text { of peer mentors }\end{array}$ & $\begin{array}{l}\text { "I probably would. It depends where they were. I mean I'd } \\
\text { support anybody outside if I could. But it's one of those things. } \\
\text { It's where they live, where they are. I certainly wouldn't want to } \\
\text { be able to get to them because that means my wife's got to take } \\
\text { me. And I can't get her doing any more than she does now" } \\
\text { (S3P04) }\end{array}$ & $\begin{array}{l}\text { For some patients their own restricted mobility or ability to } \\
\text { travel to others will limit what they can feasibly offer. }\end{array}$ \\
\hline
\end{tabular}


The tables below contain the main topics and themes that emerged from the analysis of the Renal ward HCP interviews. A description of each theme is given with direct quotes taken from interviews to help demonstrate the findings and support the researcher's interpretation.

Table 9 Describes what worked well with regards to the SEM pilot in the Renal ward.

\begin{tabular}{|c|c|c|c|}
\hline \multicolumn{4}{|c|}{ What worked well on the Active Ward } \\
\hline Topic & Theme & Quote(s) & Interpretation/implication(s) \\
\hline \multirow[t]{3}{*}{$\begin{array}{l}\text { Related to the } \\
\text { intervention }\end{array}$} & $\begin{array}{l}\text { Using motivational } \\
\text { interviewing }\end{array}$ & $\begin{array}{l}\text { "Over the last few months we've been seeing the kidney } \\
\text { transplants mainly for motivational interviewing and just getting } \\
\text { them talking about PA... So the motivational interviewing } \\
\text { sessions have probably been the biggest thing. So I sit down with } \\
\text { patients and ask them about PA. How they were before their } \\
\text { surgery and if doing a bit more since their surgery is something } \\
\text { they want to do". (S5P01) } \\
\text { "So motivational interviewing from the Renal side of things the } \\
\text { motivational interviewing's goal setting conversation has worked } \\
\text { really well..... they have enjoyed the opportunity to talk about } \\
\text { their activity, again getting that permission to do something". } \\
\text { (S5P01) }\end{array}$ & $\begin{array}{l}\text { Both HCPs discussed motivational interviewing multiple } \\
\text { times. The patients seemed to respond and staff who } \\
\text { received training had commented on the value in it. } \\
\text { Relevant staff should receive training in motivational } \\
\text { interviewing and all patients should have the opportunity to } \\
\text { receive motivational interviewing if possible. }\end{array}$ \\
\hline & $\begin{array}{l}\text { Raising awareness of } \\
\text { the PA guidelines }\end{array}$ & $\begin{array}{l}\text { "So the NHS Guidelines and what they're recommending and } \\
\text { whether we're sort of matching up to those..... A lot of patients } \\
\text { aren't actually aware of what the guidelines are and most of the } \\
\text { patients that I come in contact with want to do a little bit more } \\
\text { than they have". (S5P01) }\end{array}$ & $\begin{array}{l}\text { There was a clear need to educate both staff and patients } \\
\text { about the PA recommendations and there was a desire from } \\
\text { patients to do more. } \\
\text { Social marketing is needed to inform about the guidelines. }\end{array}$ \\
\hline & Making the case for PA & $\begin{array}{l}\text { "PA is something that's not really been focused on really. So it's } \\
\text { been really nice to be part of the project and putting the posters } \\
\text { up and shouting about what we do, wearing the lanyard. Getting } \\
\text { patients thinking about PA which again is not something that } \\
\text { they've really been, had to stop and think about before". (S5P01) }\end{array}$ & $\begin{array}{l}\text { The pilot has increased the importance of promoting PA with } \\
\text { ward and senior staff. Staff are making a conscious effort to } \\
\text { ask about PA. }\end{array}$ \\
\hline
\end{tabular}




\begin{tabular}{|c|c|c|c|}
\hline \multicolumn{4}{|c|}{ What worked well on the Active Ward } \\
\hline Topic & Theme & Quote(s) & Interpretation/implication(s) \\
\hline & & $\begin{array}{l}\text { "I think it's the sort of conversation that's historically been fairly } \\
\text { low on the agenda, so patients do get asked about smoking and } \\
\text { they do get asked about drinking and they I think have quite a lot } \\
\text { of conversations about diet. The PA question hasn't routinely } \\
\text { been one that's been asked". (S5P02) }\end{array}$ & \\
\hline & $\begin{array}{l}\text { Educating patients and } \\
\text { staff }\end{array}$ & $\begin{array}{l}\text { "I think education is one of the most important things. So as long } \\
\text { as everybody knows why we're doing what we're doing it can } \\
\text { have a positive effect". (S5P01) }\end{array}$ & $\begin{array}{l}\text { It is important to not only educate the patients about } \\
\text { benefits of PA but also to communicate clearly to staff why } \\
\text { the interventions are being implemented. }\end{array}$ \\
\hline & $\begin{array}{l}\text { Capitalising on } \\
\text { opportunity early on }\end{array}$ & $\begin{array}{l}\text { "I think the patients really appreciate the opportunity to speak } \\
\text { about activity. They're always a little bit surprised when I come } \\
\text { quite so soon after the surgery". (S5P01) } \\
\text { "We've now got on that platform a PA calculator. And there is a } \\
\text { space on there for PA to be part of the conversation that all } \\
\text { patients have when they come into the hospital". (S5P02) }\end{array}$ & $\begin{array}{l}\text { Patients were surprised to be having conversations about } \\
\text { moving and mobility so soon after surgery but both HCPs } \\
\text { stressed the need to get them moving the next day. }\end{array}$ \\
\hline & Goal Setting & $\begin{array}{l}\text { "I would say when you have a really good conversation with a } \\
\text { patient about PA and you're doing the goal setting, that's really } \\
\text { nice. I think being able to just, you know, even influence a couple } \\
\text { of people makes it worthwhile". (S5P01) }\end{array}$ & $\begin{array}{l}\text { Setting clear goals is important for the patients. The staff feel } \\
\text { they have achieved something if they are supporting their } \\
\text { patients to make positive lifestyle changes. }\end{array}$ \\
\hline & Simplicity is key & $\begin{array}{l}\text { "Talk to your patients. Just talk to your patients about PA. It's as } \\
\text { simple as that really. I don't know how many other people would } \\
\text { normally do that". (S5P01) }\end{array}$ & $\begin{array}{l}\text { This supports NICE guidance that brief advice can have an } \\
\text { impact. Simply talking to them and starting a conversation } \\
\text { around PA can make a difference. }\end{array}$ \\
\hline & $\begin{array}{l}\text { The right time to } \\
\text { promote PA }\end{array}$ & $\begin{array}{l}\text { "I just think the feedback we've had from patients has been } \\
\text { overwhelmingly positive. And particularly one of the questions in } \\
\text { the questionnaire we give is, is this the right time to be talking } \\
\text { about PA? And I believe the majority of people have said that it } \\
\text { is". (S5P01) } \\
\text { "I was interested to know whether they thought that } \\
\text { conversation was too soon because it's very early days after } \\
\text { surgery. But actually from the feedback that I've had from the } \\
\text { few patients I've asked that question, they felt it was just right". } \\
\text { (S5P02) }\end{array}$ & $\begin{array}{l}\text { Whilst a day after surgery seemed early on both HCPs } \\
\text { commented that patients have had a life changing event } \\
\text { representing a 'teachable moment' which could be the } \\
\text { catalyst for behaviour change. } \\
\text { Data suggests patients thought it was acceptable to begin to } \\
\text { discuss PA the day following surgery. }\end{array}$ \\
\hline
\end{tabular}




\begin{tabular}{|c|c|c|c|}
\hline \multicolumn{4}{|c|}{ What worked well on the Active Ward } \\
\hline Topic & Theme & Quote(s) & Interpretation/implication(s) \\
\hline & Role modelling & $\begin{array}{l}\text { "I've watched you do that, I could do with something... So that } \\
\text { role modelling of people wanting to be part of what other people } \\
\text { are doing, so I think that's very powerful, yes". (S5P02) }\end{array}$ & $\begin{array}{l}\text { Patients on the ward would see other patients being } \\
\text { supported to be active or moving around which encouraged } \\
\text { them to do the same. }\end{array}$ \\
\hline & $\begin{array}{l}\text { Increasing interaction } \\
\text { with patients }\end{array}$ & $\begin{array}{l}\text { "So physios will have that interaction and occupational therapists } \\
\text { might be doing some activity with a more functional approach. } \\
\text { And then very varied as to how much interaction you'll get from } \\
\text { nursing staff". (S5P02) }\end{array}$ & $\begin{array}{l}\text { Increasing interaction was deemed important which links } \\
\text { clearly to the making every contact count initiative. }\end{array}$ \\
\hline & Positive outcomes & $\begin{array}{l}\text { "When I've spoken to them on the phone they're definitely, } \\
\text { some of them like I say would have been active anyway. But } \\
\text { when I've spoken to them on the phone they are thinking about } \\
\text { what their activity might look like and they're thinking about } \\
\text { what they're trying to achieve as part of their recovery process". } \\
\text { (S5P02) }\end{array}$ & $\begin{array}{l}\text { Whilst specific impact evaluation measures were not } \\
\text { measured or recorded both HCPs were confident it had } \\
\text { increased the patient's PA levels. } \\
\text { Future work should evaluate the impact of the intervention } \\
\text { on behavioural outcomes. For example, measure PA levels } \\
\text { pre and post intervention. }\end{array}$ \\
\hline & Sustainability & $\begin{array}{l}\text { "Well I think that's very sustainable.... That's what we've been } \\
\text { trying to look at is how it would run without too much extra } \\
\text { resource..... if you've got other members staff that are able to } \\
\text { have those conversations and work through that workbook then } \\
\text { that becomes easier and it's not just the physio's job, it would be } \\
\text { nice for that to be anybody's job. (S5P02) }\end{array}$ & $\begin{array}{l}\text { For activities to be sustainable it is important they do not } \\
\text { require too much additional resource in an already stretched } \\
\text { NHS environment. }\end{array}$ \\
\hline $\begin{array}{l}\text { Related to the } \\
\text { staff involved }\end{array}$ & $\begin{array}{l}\text { All staff should be } \\
\text { involved }\end{array}$ & $\begin{array}{l}\text { "I think anybody that has any contact with patients at all should } \\
\text { be broaching the subject..... Having the whole MDT involved and } \\
\text { sharing the same vision about what we're trying to achieve with } \\
\text { an active ward". (S5P01) } \\
\text { "I think that's the overall perception for staff is that if it's } \\
\text { something related to that then it's their role". (S5P02) } \\
\text { "I think medical team are very keen for PA and from the work } \\
\text { that we've been doing we've got a good engagement with } \\
\text { them". (S5P02) }\end{array}$ & $\begin{array}{l}\text { Both HCPs felt strongly that all staff have a responsibility to } \\
\text { promote PA. It should be embedded across all wards and } \\
\text { treatment pathways. }\end{array}$ \\
\hline
\end{tabular}




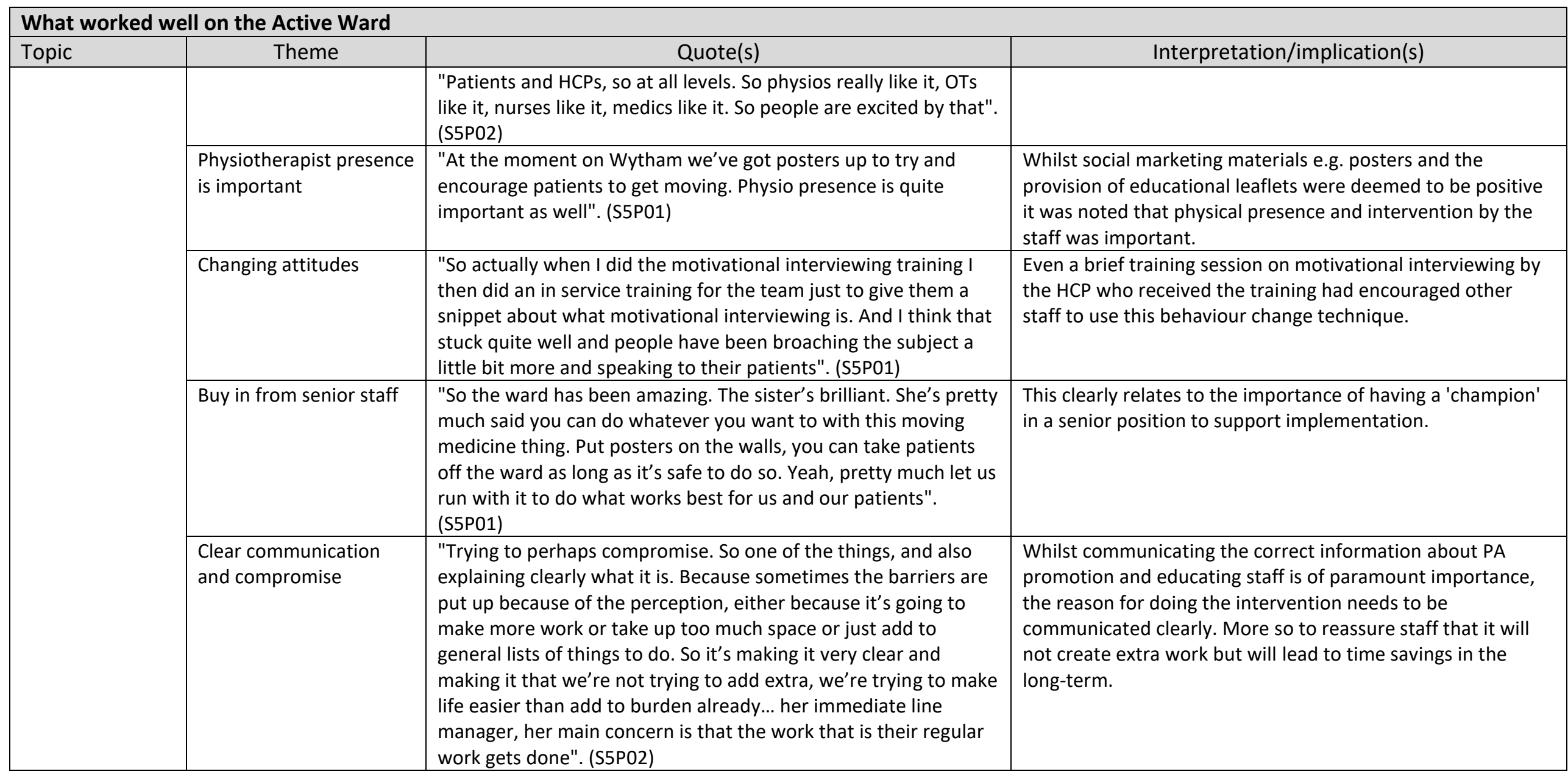




\begin{tabular}{|c|c|c|c|}
\hline \multicolumn{4}{|c|}{ What worked well on the Active Ward } \\
\hline Topic & Theme & Quote(s) & Interpretation/implication(s) \\
\hline $\begin{array}{l}\text { Related to the } \\
\text { environment }\end{array}$ & $\begin{array}{l}\text { Other wards } \\
\text { involvement }\end{array}$ & $\begin{array}{l}\text { "And yes, so with patients over on the medical ward the physios } \\
\text { particularly were really interested in the exercise programmes } \\
\text { and things that I've written for that. So that informed their } \\
\text { practice as well which is quite interesting, they were routinely } \\
\text { with the elderly people doing exercises with patients. So they've } \\
\text { now got the exercise programmes and it's something that they } \\
\text { are beginning to build into their pathway". (S5P01) }\end{array}$ & $\begin{array}{l}\text { The promotion of PA on the Renal ward is having an impact } \\
\text { on staff on other wards who were visiting. They were keen to } \\
\text { know what was happening on the Renal ward and change } \\
\text { their own practice. }\end{array}$ \\
\hline
\end{tabular}

Table 10 Describes the challenges that were faced with regards to the SEM pilot in the Renal ward.

\begin{tabular}{|c|c|c|c|}
\hline \multicolumn{4}{|c|}{ The challenges on the Active Ward } \\
\hline Topic & Theme & Quote(s) & Interpretation/implication(s) \\
\hline \multirow[t]{3}{*}{$\begin{array}{l}\text { Related to the } \\
\text { intervention }\end{array}$} & $\begin{array}{l}\text { No peer mentoring } \\
\text { scheme }\end{array}$ & $\begin{array}{l}\text { "That's not happened as yet. We've investigated about meeting } \\
\text { up with patients in their pre-transplant seminar, but that's a } \\
\text { really information intensive afternoon. So it's perhaps not } \\
\text { appropriate at that time, but we're still looking at ways that we } \\
\text { might have to engage with people before they come in to } \\
\text { hospital and start a short conversation before then" (S5P02) }\end{array}$ & $\begin{array}{l}\text { The intention of the lead SEM consultants was to develop a } \\
\text { peer mentoring scheme within the Renal pathway, however } \\
\text { this did not happen. The patients largely being in isolation, } \\
\text { limited social space and admission time was an oversight. } \\
\text { Whilst this was not transcribed verbatim it appears that } \\
\text { patients were developing camaraderie from the group } \\
\text { exercise sessions anyway. }\end{array}$ \\
\hline & Short admission time & $\begin{array}{l}\text { "One of the things from a peer mentoring side of things would be } \\
\text { if the peer mentoring is going to be taking place on the ward is } \\
\text { the really short admission time for people who are having Renal } \\
\text { transplants". (S5P02) }\end{array}$ & $\begin{array}{l}\text { Patients were only on the ward for a couple of days either } \\
\text { side of surgery restricting the time to establish rapport with } \\
\text { other patients and form peer mentoring relationships. }\end{array}$ \\
\hline & Pre-op not available & $\begin{array}{l}\text { "So pre-op education is not something that we're involved in at } \\
\text { the moment. It's something that we would like to be. But I think } \\
\text { there's been some difficulties with information overload with } \\
\text { patients coming for education days and things. But yeah, I think } \\
\text { the pre-op side would be a really good thing to focus on as well". } \\
\text { (S5P01) }\end{array}$ & $\begin{array}{l}\text { Research regarding the importance of prehabilitation is } \\
\text { burgeoning and there is a demand that Renal patients are } \\
\text { offered prehabilitation or at least educated about the } \\
\text { importance of PA. } \\
\text { However, information overload is a concern and PA is not } \\
\text { necessarily a high up on the agenda. }\end{array}$ \\
\hline
\end{tabular}




\begin{tabular}{|c|c|c|c|}
\hline \multicolumn{4}{|c|}{ The challenges on the Active Ward } \\
\hline Topic & Theme & Quote(s) & Interpretation/implication(s) \\
\hline & & $\begin{array}{l}\text { "So I'd like to see that we start that conversation before } \\
\text { transplant and find a way of getting at least a bit of a flyer into } \\
\text { the system before we get to the ward situation". (S5P02) } \\
\text { "It'd be great if people were building up their PA before they had } \\
\text { their surgery that'd be even better. So we haven't done anything } \\
\text { there. (S5P02) }\end{array}$ & \\
\hline & $\begin{array}{l}\text { Impact of pilot on } \\
\text { outcomes is unclear }\end{array}$ & $\begin{array}{l}\text { (Referring to discharge times, mood or attitude).... Not that I am } \\
\text { able to observe.... From the medical wards we've not been } \\
\text { through enough patients to see that sort of impact, it's been nice } \\
\text { to think that by getting people generally more active, up, } \\
\text { dressed, exercising, moving about it'd be nice to think that we } \\
\text { reduce the length the stay and prevent deterioration. That'll be } \\
\text { really difficult to show in this very short term". (S5P02) }\end{array}$ & $\begin{array}{l}\text { More objective measures are needed to record any changes } \\
\text { to outcomes such as average discharge time. An evaluation } \\
\text { team should be formed to measure and capture these } \\
\text { impacts over a longer period of time (minimum } 2 \text { years). }\end{array}$ \\
\hline & Visibility & $\begin{array}{l}\text { "Keeping visibility of the project and keeping visibility of the } \\
\text { message". (S5P02) }\end{array}$ & $\begin{array}{l}\text { Messages need to continually be reinforced, social marketing } \\
\text { and poster boards updated frequently and action taking place } \\
\text { on the ward daily. }\end{array}$ \\
\hline \multirow[t]{3}{*}{$\begin{array}{l}\text { Related to the } \\
\text { staff involved }\end{array}$} & Lack of time & $\begin{array}{l}\text { "I think some difficulties that we've had potentially are to do } \\
\text { with staffing and time. We were initially doing a walking group } \\
\text { with our kidney transplant patients which was a great idea. But } \\
\text { in reality it didn't sort of play out the way we wanted it to... not } \\
\text { all the patients are always ready. So from a time perspective } \\
\text { having to go and get the patients was quite difficult".... So } \\
\text { ideally we'd be getting patients up into the gym and getting } \\
\text { them doing exercise as soon as possible. But sometimes we're a } \\
\text { little bit delayed with that which can't be helped because a nurse } \\
\text { needs to be with them at all times". (S5P01) }\end{array}$ & $\begin{array}{l}\text { Time is the greatest barrier to a physically active lifestyle and } \\
\text { was reported here in its promotion on the wards. This lack of } \\
\text { time is mostly due to lack of staff at present and many } \\
\text { competing priorities. Despite this it was very clear every } \\
\text { effort was being made to make time. }\end{array}$ \\
\hline & Other priorities & $\begin{array}{l}\text { "And obviously there's other important things going on, drugs } \\
\text { need to be done, obs need to be done". (S5P01) }\end{array}$ & $\begin{array}{l}\text { The other priorities are reducing the time available to } \\
\text { promote PA as highlighted directly above. }\end{array}$ \\
\hline & Lack of staff & $\begin{array}{l}\text { "I think it's been slightly difficult for us in particularly because } \\
\text { we're really short staffed. We're missing a couple of band } \\
5 \text { s.....so ideally we'd be getting patients up into the gym and } \\
\text { getting them doing exercise as soon as possible. But sometimes }\end{array}$ & $\begin{array}{l}\text { Low staff reducing time to promote PA which has been raised } \\
\text { previously. }\end{array}$ \\
\hline
\end{tabular}


The challenges on the Active Ward

\begin{tabular}{|c|c|c|c|}
\hline Topic & Theme & Quote(s) & Interpretation/implication(s) \\
\hline & & $\begin{array}{l}\text { we're a little bit delayed with that which can't be helped because } \\
\text { a nurse needs to be with them at all times". (S5P01) } \\
\text { "On Renal ward they were having a real crisis of staffing when } \\
\text { we first started". (S5P02) }\end{array}$ & \\
\hline & $\begin{array}{l}\text { Building relationships } \\
\text { with wards }\end{array}$ & $\begin{array}{l}\text { "But what was very clear straightaway was that we might go up } \\
\text { there and do an exercise intervention for example, but unless } \\
\text { you've got a relationship with that ward it was difficult for that } \\
\text { to be carried over beyond that window of time that you're with } \\
\text { the patient. So it became very clear that it was the whole ward } \\
\text { environment that was that was more important to work with, } \\
\text { yes". (S5P02) }\end{array}$ & $\begin{array}{l}\text { Pre-existing relationships between SEM team and ward staff } \\
\text { made it easier to implement PA interventions. } \\
\text { At the start of any intervention connections need to be made } \\
\text { so rapport can be established and relationships built. }\end{array}$ \\
\hline & $\begin{array}{l}\text { Lack of knowledge about } \\
\text { the PA guidelines }\end{array}$ & $\begin{array}{l}\text { "I've done a little bit of work looking at knowledge and often } \\
\text { staff don't have good knowledge of, for example government } \\
\text { guidelines of what's expected, so that's difficult". (S5P02) }\end{array}$ & $\begin{array}{l}\text { Some staff did not know the PA recommendations so } \\
\text { education is needed and they should be signposted to the } \\
\text { 'start active, stay active' document. }\end{array}$ \\
\hline & Lack of training & $\begin{array}{l}\text { "People feel that they either haven't got enough time to have } \\
\text { these sorts of conversations or they don't feel that they're } \\
\text { adequately trained to have those conversations". (S5P02) }\end{array}$ & $\begin{array}{l}\text { There is a clear need for training in those that require it. } \\
\text { What training is needed could be gleaned during meetings or } \\
\text { appraisals with line management. }\end{array}$ \\
\hline \multirow[t]{2}{*}{$\begin{array}{l}\text { Related to } \\
\text { patients }\end{array}$} & $\begin{array}{l}\text { Different levels of fitness } \\
\text { and ability }\end{array}$ & $\begin{array}{l}\text { "And also with varying levels of ability among the transplant } \\
\text { patients, some people are really active, some people not so } \\
\text { much. And I think putting them all in a walking group together } \\
\text { was quite difficult..... The patients that haven't been so } \\
\text { appropriate tend to be the ones that are fitter already and don't } \\
\text { really need our support with that". (S5P01) } \\
\text { "There was also the difficulty of people being at very different } \\
\text { levels. From somebody that's very active before they came to } \\
\text { hospital to somebody that can only really stand for a few } \\
\text { minutes before they came to hospital. So there's those sorts of } \\
\text { issues". (S5P02) }\end{array}$ & $\begin{array}{l}\text { There was a clear difference in the level of ability, fitness and } \\
\text { willingness to undertake PA in the Renal patients. This could } \\
\text { cause patients to become demotivated, for example, if they } \\
\text { do not feel like they are being challenged, or conversely, if } \\
\text { they feel they are being left behind. }\end{array}$ \\
\hline & $\begin{array}{l}\text { Limited access and scope } \\
\text { for improvement }\end{array}$ & $\begin{array}{l}\text { "I think, I see them for such a short period of time on the ward I } \\
\text { probably haven't seen a huge amount personally". (S5P01) }\end{array}$ & $\begin{array}{l}\text { Staff did not anticipate a huge change in such a short time } \\
\text { frame. This also links to the short time scale that the patients } \\
\text { are on the ward pre, during and post-surgery. }\end{array}$ \\
\hline
\end{tabular}




\begin{tabular}{|c|c|c|c|}
\hline \multicolumn{4}{|c|}{ The challenges on the Active Ward } \\
\hline Topic & Theme & Quote(s) & Interpretation/implication(s) \\
\hline \multirow[t]{2}{*}{$\begin{array}{l}\text { Related to the } \\
\text { environment }\end{array}$} & $\begin{array}{l}\text { Patients being in } \\
\text { individual rooms and } \\
\text { lack of social space }\end{array}$ & $\begin{array}{l}\text { "Unfortunately we haven't got a day room, having some reason } \\
\text { for the patients to move around and to get out of their side } \\
\text { room. So a day room, you know, activities happening together as } \\
\text { a group might be quite positive". (S5P01) } \\
\text { "The other thing is on the Renal ward all the patients have } \\
\text { individual rooms, so that doesn't naturally facilitate cross } \\
\text { conversation. And there isn't an area on that ward for a space for } \\
\text { them to go and chat together, so there isn't a communal area on } \\
\text { that ward, so the environment does not facilitate that easily". } \\
\text { (S5P02) }\end{array}$ & $\begin{array}{l}\text { The environment on the Renal ward would need to change to } \\
\text { encourage more interaction between patients for a peer } \\
\text { mentoring scheme to be successful. A dedicated space to } \\
\text { socialise would lend itself to a peer mentoring programme. }\end{array}$ \\
\hline & $\begin{array}{l}\text { Reliance on medical } \\
\text { equipment }\end{array}$ & $\begin{array}{l}\text { (Regarding a led walk).... "So there was a three p.m. meet. Now } \\
\text { the difficulty with that is you've got then there's the requirement } \\
\text { for patients to be ready for that. Which when people are all } \\
\text { connected up to all sorts of manner of equipment that can be } \\
\text { tricky". (S5P02) }\end{array}$ & $\begin{array}{l}\text { Whilst led walks were organised daily for a certain time many } \\
\text { patients were late due to their reliance on medical } \\
\text { equipment which made it difficult to move about. }\end{array}$ \\
\hline
\end{tabular}

The table below presents pertinent topics identified from the interview conducted with a Renal ward patient.

Table 11 Feedback from a patient who received treatment in the Renal pathway.

\begin{tabular}{|l|l|}
\hline \multicolumn{1}{|c|}{ Topic } & \multicolumn{1}{c|}{ Quote } \\
\hline $\begin{array}{l}\text { People at the hub are } \\
\text { professional }\end{array}$ & $\begin{array}{l}\text { "People in the hub are very professional in what they are doing, they know what they are doing and everything that was explained } \\
\text { to me happened". }\end{array}$ \\
\hline Surprise at being in isolation & $\begin{array}{l}\text { "I was surprised at being in a single room on the ward itself. But then again I can understand it as they are trying to reduce any } \\
\text { chance of infection. So that is the reason why you are in an individual room". }\end{array}$ \\
\hline $\begin{array}{l}\text { Early mobilisation (exercise } \\
\text { booklet was provided - Assume } \\
\text { Moving Medicine) }\end{array}$ & $\begin{array}{l}\text { "What happened } 2 \text { days before I came out a physiotherapist or nurse came round and said that I need to think about doing some } \\
\text { exercise. They were very simple exercises, they gave me a booklet. So you sit up and get down, but obviously because you have got } \\
\text { a wound it's trying to not put too much strain on it, but to get it so you can manoeuvre rather than sit in one position. That's a good } \\
\text { idea". }\end{array}$ \\
\hline
\end{tabular}




\begin{tabular}{|c|c|}
\hline Topic & Quote \\
\hline $\begin{array}{l}\text { Patient's condition influences } \\
\text { whether they undertake PA }\end{array}$ & $\begin{array}{l}\text { "Undertaking PA... Depends on the patient and the condition they are in obviously. I mean, the physio team are quite clever in } \\
\text { devising a series of exercises depending on the actual condition of the patient and what their illness may be. So they can't put them } \\
\text { on an athletes regime but do something simple that makes them manoeuvre their joints if you know what I mean". }\end{array}$ \\
\hline $\begin{array}{l}\text { Unclear whether PA is part of the } \\
\text { treatment pathway }\end{array}$ & $\begin{array}{l}\text { "I just don't know if it's officially part of their treatment. Personally I think it should be. After day } 3 \text { out of the op there was a } \\
\text { physiotherapist intervention where a lady tried to help me to walk. But it depends on the condition of the patient. It would have to } \\
\text { be the medical team make that decision". }\end{array}$ \\
\hline $\begin{array}{l}\text { No offer of peer mentoring } \\
\text { opportunities }\end{array}$ & "No I wasn't offered, but then again I'm motivated anyway. I couldn't wait to get back to swimming" \\
\hline $\begin{array}{l}\text { A peer mentoring scheme would } \\
\text { be worthwhile }\end{array}$ & $\begin{array}{l}\text { "Yes that would be an idea to motivate. People might be feeling a bit low after the operation when there is a chance to meet other } \\
\text { patients have gone through it". }\end{array}$ \\
\hline $\begin{array}{l}\text { Must have experienced surgery } \\
\text { /the procedure to be a good peer } \\
\text { mentor }\end{array}$ & $\begin{array}{l}\text { "What type of person, uh I guess a patient who has gone through the same treatment. They would be very good and actually make } \\
\text { the patient who is just going through it more relaxed... Encourage them to go their local sport centre and see what facilities are } \\
\text { available". }\end{array}$ \\
\hline $\begin{array}{l}\text { Training would be needed to be a } \\
\text { peer mentor }\end{array}$ & $\begin{array}{l}\text { "I'm not clever enough to know what [exercises] that would be. What would be a good idea is that the part of the pack you get } \\
\text { when you come out is, while you are in there some information is given about the local centres". }\end{array}$ \\
\hline $\begin{array}{l}\text { Peer mentors should answer } \\
\text { questions }\end{array}$ & $\begin{array}{l}\text { "I think first of all somebody who is able to answer any questions that somebody might have after coming out of the operational } \\
\text { stage and going into recovery mode. What they expect and what they can do. I was basically mobile after day } 1 \text { but I'm sure others } \\
\text { aren't". }\end{array}$ \\
\hline $\begin{array}{l}\text { If given the opportunity would } \\
\text { become a peer mentor }\end{array}$ & "Yes I would. If they are asking for financial support no chance, but I can give encouragement or lifts to the centre". \\
\hline
\end{tabular}


The tables below contains the main topics and themes that emerged from the analysis of the CMU HCP interviews. A description of each theme is given with direct quotes taken from interviews to help demonstrate the findings and support the researcher's interpretation.

Table 12 Describes what worked well with regards to the SEM pilot in the CMU.

\begin{tabular}{|c|c|c|c|}
\hline \multicolumn{4}{|c|}{ What worked well in the CMU pathway } \\
\hline Topic & Theme & Quote(s) & Interpretation/implication(s) \\
\hline \multirow[t]{4}{*}{$\begin{array}{l}\text { Related to the } \\
\text { intervention }\end{array}$} & $\begin{array}{l}\text { Being adaptable and } \\
\text { allowing the intervention } \\
\text { to evolve over time }\end{array}$ & $\begin{array}{l}\text { "It was very quickly clear that whilst she was doing a } \\
\text { lovely intervention with people, that was only a } \\
\text { snapshot in time, and [the patients] were actually } \\
\text { sitting in a very inactive ward environment. So the } \\
\text { strand has evolved to try and address a little bit } \\
\text { more the whole ward environment" (S6P03) }\end{array}$ & $\begin{array}{l}\text { Taking a trial and error approach to the pilot was beneficial. It } \\
\text { enabled staff to learn from their experiences and develop ideas. } \\
\text { An implication of this for the evaluation team is that they had to } \\
\text { react to unplanned changes in the implementation plan. }\end{array}$ \\
\hline & $\begin{array}{l}\text { iCAN tool is easy and } \\
\text { quick to use and } \\
\text { facilitates } \\
\text { communication among } \\
\text { staff }\end{array}$ & $\begin{array}{l}\text { "I certainly have found it nice to use, because it's } \\
\text { quick. You don't have to freestyle; it's all there for } \\
\text { you" (S6P03) } \\
\text { "an instant visual about somebody's current ability" } \\
\text { (S6P03) } \\
\text { "It's found to be helpful, especially for } \\
\text { communication between members of the team } \\
\text { when they come to work" (S6P01) }\end{array}$ & $\begin{array}{l}\text { Change was welcomed among staff on the ward but it had to be } \\
\text { easy to embed within existing systems and quick to use/refer to on } \\
\text { the job. The iCAN tool was praised for facilitating communication } \\
\text { between staff, especially between staff on different shifts. It's } \\
\text { primary purpose was to document the level of mobility/physical } \\
\text { ability of each patient on the ward. There was some optimism that } \\
\text { tools like this could help reduce 'pyjama paralysis' often } \\
\text { experienced by patients in hospital. }\end{array}$ \\
\hline & $\begin{array}{l}\text { Exercise booklets are } \\
\text { self-explanatory and can } \\
\text { be used by any member } \\
\text { of staff }\end{array}$ & $\begin{array}{l}\text { "can be distributed by any member of staff, they're } \\
\text { fairly self-explanatory" (S6P03) }\end{array}$ & $\begin{array}{l}\text { Having access to easy-to-use resources was important for staff (for } \\
\text { example, it could act as a prompt or source of information). }\end{array}$ \\
\hline & $\begin{array}{l}\text { Exercise booklets can be } \\
\text { used by patients and } \\
\text { their relatives }\end{array}$ & $\begin{array}{l}\text { "[the patient's] nephew was there and he said oh } \\
\text { yes he's been showing me the leaflet with the }\end{array}$ & $\begin{array}{l}\text { Having access to easy-to-use resources is important for patients } \\
\text { and relatives too. }\end{array}$ \\
\hline
\end{tabular}




\begin{tabular}{|c|c|c|c|}
\hline \multicolumn{4}{|c|}{ What worked well in the CMU pathway } \\
\hline Topic & Theme & Quote(s) & Interpretation/implication(s) \\
\hline & & $\begin{array}{l}\text { exercises and we've been doing some. So relatives } \\
\text { are a big help." (S6P02) }\end{array}$ & \\
\hline & $\begin{array}{l}\text { Response/reaction from } \\
\text { patients who have } \\
\text { engaged has been } \\
\text { positive }\end{array}$ & $\begin{array}{l}\text { "Most people that I've come across have been really } \\
\text { pleased about doing it. They've enjoyed it. } \\
\text { Sometimes they've been surprised about what } \\
\text { they've managed and it's generally been well } \\
\text { received by patients" (S6P03) } \\
\text { "Not all patients but some patients, I mean they're } \\
\text { on the ward; they've not necessarily got much to } \\
\text { entertain themselves, so actually having some } \\
\text { exercises to do is good. But also people have } \\
\text { ambitions to progress and get home. And so } \\
\text { conversations that I've had, so I know I need to be } \\
\text { able to do this to be able to home. So they can see } \\
\text { that being more active helps towards that." } \\
\text { "I have seen a nurse doing exercises with a patient. } \\
\text { The patient looked very involved and interested and } \\
\text { taking it seriously as something good for his health, } \\
\text { and as a positive really." (S6P01) } \\
\text { "they're more vocal. They look more alive, they look } \\
\text { more engaged, they talk to you; all that because of a } \\
\text { personal touch." (S6P02) }\end{array}$ & $\begin{array}{l}\text { The initiative was received well by patients. Anecdotal evidence } \\
\text { could be supported by more formal evaluation. } \\
\text { Important to frame the intervention to suit the individual goals of } \\
\text { the patient i.e., using the exercises as an incentive to get home. } \\
\text { This requires that staff have time to understand the individual } \\
\text { goals of each patient. This was facilitated by motivational } \\
\text { interviewing, but not all staff had received training yet. }\end{array}$ \\
\hline & $\begin{array}{l}\text { The resources are } \\
\text { transferrable across } \\
\text { pathways }\end{array}$ & $\begin{array}{l}\text { "The resources are transferrable. The resources that } \\
\text { we're developing will be on a website, and so they'll } \\
\text { be downloadable and hopefully usable in all } \\
\text { pathways. And already the exercise booklet that I'm } \\
\text { using, people are picking up and saying oh actually } \\
\text { l'd quite like to use it here and here and here, so } \\
\text { definitely transferrable in that respect." (S6P03) }\end{array}$ & Suggests that the resources are transferrable to other contexts. \\
\hline
\end{tabular}




\begin{tabular}{|c|c|c|c|}
\hline \multicolumn{4}{|c|}{ What worked well in the CMU pathway } \\
\hline \multirow[t]{2}{*}{ Topic } & Theme & Quote(s) & Interpretation/implication(s) \\
\hline & $\begin{array}{l}\text { Implementing this at the } \\
\text { ward level means that } \\
\text { patients can learn from } \\
\text { each other }\end{array}$ & $\begin{array}{l}\text { "it's the knock-on effect...it only takes one in the bay } \\
\text { and someone else will say tomorrow, well he's } \\
\text { walking, Alfie's walking to the toilet, l'd like to do } \\
\text { that." (S6P02) }\end{array}$ & $\begin{array}{l}\text { Implementation at the ward level encourages a change in culture } \\
\text { or what's 'normal' for people on the CMU ward. A shift from the } \\
\text { norm being 'pyjama paralysis' to being physically active. }\end{array}$ \\
\hline \multirow[t]{4}{*}{$\begin{array}{l}\text { Related to the } \\
\text { staff involved }\end{array}$} & $\begin{array}{l}\text { Having an ambitious PA } \\
\text { champion based on the } \\
\text { ward with dedicated } \\
\text { time to give }\end{array}$ & $\begin{array}{l}\text { "what's made it easier, obviously having people } \\
\text { having some dedicated time for this, and having } \\
\text { some dedicated champions on the ward that are } \\
\text { nurse based" (S6P03) }\end{array}$ & $\begin{array}{l}\text { Important that the champion is present on the ward and } \\
\text { embedded within the system. The champion needs to be the right } \\
\text { person with the right qualities. On the other hand, having a } \\
\text { dedicated member of staff might take the onus off other ward staff } \\
\text { to promote PA. }\end{array}$ \\
\hline & $\begin{array}{l}\text { Staff who are keen to } \\
\text { change the culture of the } \\
\text { ward }\end{array}$ & $\begin{array}{l}\text { "[the ward manager] is from a rehab background, } \\
\text { and is very keen to change the culture on the ward } \\
\text { as well" (S6P03) }\end{array}$ & $\begin{array}{l}\text { Important to have enthusiastic and supportive staff to get behind } \\
\text { the initiative. Important to find the staff members who are } \\
\text { particularly 'bought into' it and keen. }\end{array}$ \\
\hline & $\begin{array}{l}\text { Shadowing and } \\
\text { modelling among staff on } \\
\text { the ward }\end{array}$ & $\begin{array}{l}\text { "having shadowed me for a little while and watched } \\
\text { the way that I've interacted with people with the MI } \\
\text { style, she can see the difference that that makes. } \\
\text { And so she can see that that's quite a powerful } \\
\text { tool." (S6P03) } \\
\text { "Hopefully the colleagues can role model each } \\
\text { other" (S6P01) }\end{array}$ & $\begin{array}{l}\text { Important to identify staff members with the relevant skills and } \\
\text { experience and use them as role models for other staff. Peer- } \\
\text { mentoring was beneficial. }\end{array}$ \\
\hline & $\begin{array}{l}\text { Having staff with } \\
\text { relevant past experience }\end{array}$ & $\begin{array}{l}\text { "I've got lots of experience working in rehab, a } \\
\text { rehab unit so lots of work with patients doing } \\
\text { exercise and encouraging more activity." (S6P03) }\end{array}$ & $\begin{array}{l}\text { Previous experience helped and less experienced staff could learn } \\
\text { from those who have more experience. }\end{array}$ \\
\hline \multirow{2}{*}{$\begin{array}{l}\text { Related to the } \\
\text { setting / wider } \\
\text { culture }\end{array}$} & $\begin{array}{l}\text { Support from senior } \\
\text { members of staff }\end{array}$ & $\begin{array}{l}\text { "what's made it easier is...the support from the } \\
\text { senior members of staff." (S6P03) }\end{array}$ & $\begin{array}{l}\text { There needed to be supported from above, this was a whole } \\
\text { system approach. }\end{array}$ \\
\hline & $\begin{array}{l}\text { Making changes to the } \\
\text { existing systems that are } \\
\text { already in place e.g., SKIN } \\
\text { assessment }\end{array}$ & $\begin{array}{l}\text { "[the nurses] use what they call a SKIN assessment, } \\
\text { which is part of caring for people's skin integrity. } \\
\text { And part of that, the K is 'keep moving'. And they } \\
\text { tend not to really populate that with anything. So } \\
\text { I've asked, and that's been reinforced by the nurse } \\
\text { manager, that perhaps [nurses] try to put a little } \\
\text { more detail in there." (S6P03) }\end{array}$ & $\begin{array}{l}\text { Change was welcomed but it had to be easy to embed within } \\
\text { existing systems and quick to use. }\end{array}$ \\
\hline
\end{tabular}


What worked well in the CMU pathway

\begin{tabular}{|c|c|c|c|}
\hline Topic & Theme & Quote(s) & Interpretation/implication(s) \\
\hline & & $\begin{array}{l}\text { "I just felt that I wanted to see a little bit more } \\
\text { thought about mobility and activity, but how could I } \\
\text { fit it into something that they're already doing, } \\
\text { rather than add something else on. And so it fits } \\
\text { fairly comfortably in that formula that they already } \\
\text { use" (S6P03) }\end{array}$ & \\
\hline & $\begin{array}{l}\text { Training opportunities } \\
\text { (e.g., Motivational } \\
\text { Interviewing training) }\end{array}$ & $\begin{array}{l}\text { "as part of the pilot a lot of people are doing, in } \\
\text { OUHFT are doing motivational interviewing training, } \\
\text { which Moving Medicine have just rolled out, so } \\
\text { there are quite a few people on the ward are doing } \\
\text { that training as well." (S6P03) } \\
\text { "she did some BMAT training, bedside mobility } \\
\text { activity tool and so she showed me how to do that. } \\
\text { And that was amazing and I really enjoyed doing } \\
\text { that." (S6 P02) }\end{array}$ & $\begin{array}{l}\text { Training needs were identified. It was important to allow time for } \\
\text { staff training, not all staff had been trained and getting all staff } \\
\text { trained would take a long time. The wider system needs to be } \\
\text { supportive - allowing staff time to go on training courses. }\end{array}$ \\
\hline
\end{tabular}

Table 13 Describes the challenges experienced with regards to the SEM pilot in the CMU.

\begin{tabular}{|c|c|c|c|}
\hline \multicolumn{4}{|c|}{ What were the challenges for the CMU pathway } \\
\hline Topic & Theme & Quote(s) & Interpretation/implication(s) \\
\hline \multirow[t]{2}{*}{$\begin{array}{l}\text { Related to the } \\
\text { intervention }\end{array}$} & $\begin{array}{l}\text { The original iCAN tool } \\
\text { did not work to greatest } \\
\text { effect }\end{array}$ & $\begin{array}{l}\text { "apart from the physios who were good at putting in methods of } \\
\text { transfer, my feeling was that it was a bit of blank page and } \\
\text { people weren't really sure how to use it....so we've changed it" } \\
\text { (S6P03) }\end{array}$ & $\begin{array}{l}\text { Taking a trial and error approach to the pilot was beneficial. } \\
\text { The staff recognised that the original iCAN tool was not } \\
\text { working to its full potential. The open-text boxes were not } \\
\text { being used by staff and some staff were concerned about the } \\
\text { patients' privacy. The new iCAN tool was more directive i.e., } \\
\text { staff used tick boxes to state what the patient could do e.g., I } \\
\text { can dress myself / walk to the toilet. }\end{array}$ \\
\hline & $\begin{array}{l}\text { The initiative } \\
\text { (exercise/PA) is not }\end{array}$ & $\begin{array}{l}\text { "No, not with all patients. So, even in this week l've come across } \\
\text { two patients, one of whom, there's obviously on the medical } \\
\text { ward a lot of very elderly patients, some with quite severe }\end{array}$ & $\begin{array}{l}\text { An individualised approach was needed to meet the needs of } \\
\text { each patient on the ward. One respondent explained how PA } \\
\text { and mobilisation is not a priority for many patients when they }\end{array}$ \\
\hline
\end{tabular}




\begin{tabular}{|c|c|c|c|}
\hline \multicolumn{4}{|c|}{ What were the challenges for the CMU pathway } \\
\hline \multirow[t]{3}{*}{ Topic } & Theme & Quote(s) & Interpretation/implication(s) \\
\hline & $\begin{array}{l}\text { appropriate or a priority } \\
\text { for all patients }\end{array}$ & $\begin{array}{l}\text { cognitive issues, so for a patient in that situation I couldn't even } \\
\text { get him to respond to this name, let alone copy me, you know, } \\
\text { go through any exercises or anything with him" (S6P03) } \\
\text { "When I think about priorities that is not the reason why the } \\
\text { patient is admitted into hospital. So we tend more to treat the } \\
\text { reason why the patient is in hospital....So then a few days down } \\
\text { the line that we will think about mobilising the patient more } \\
\text { actively." (S6P01) } \\
\text { "So being in an elderly care ward I think that it's very important } \\
\text { that we work across into patients own needs. Instead of having a } \\
\text { generic approach." (S6P01) }\end{array}$ & $\begin{array}{l}\text { first get admitted into hospital; they need to receive } \\
\text { treatment first and it might a number of days before they } \\
\text { enter the CMU ward, at which point the priority is to treat } \\
\text { illnesses. Nevertheless, mobilisation is valued as a means of } \\
\text { preventing further illness. }\end{array}$ \\
\hline & $\begin{array}{l}\text { Unintended } \\
\text { consequences }\end{array}$ & $\begin{array}{l}\text { "the concern that what you introduce is at risk of causing } \\
\text { unintended consequences, so for example of course falls, and } \\
\text { that's always a big issue in the hospital environment." (S6P03) }\end{array}$ & $\begin{array}{l}\text { Risk assessment was important to help minimise risk e.g., } \\
\text { 'bedside mobility assessment tool'. HCPs are typically risk } \\
\text { averse and might avoid encouraging PA for fear of causing } \\
\text { further harm. }\end{array}$ \\
\hline \multirow[t]{3}{*}{$\begin{array}{l}\text { Related to the } \\
\text { staff involved }\end{array}$} & $\begin{array}{l}\text { Variability among staff in } \\
\text { the level of detail / } \\
\text { attention given to } \\
\text { mobility and PA }\end{array}$ & $\begin{array}{l}\text { "physios will write about mobility, will write very clearly what } \\
\text { [the patients] use, you know, if they walk unassisted and over } \\
\text { what distance. Nurses tend not to mention particularly mobility, } \\
\text { either how they've done it or what they've done" (S6P03) }\end{array}$ & $\begin{array}{l}\text { Some staff were more accustomed to taking PA into } \\
\text { consideration (e.g., physios), others had to change the way } \\
\text { they worked/documented patient notes (e.g. nurses). } \\
\text { Different staff may have different training needs. A needs } \\
\text { assessment for each member of staff may be beneficial. }\end{array}$ \\
\hline & $\begin{array}{l}\text { Staff shortages and work } \\
\text { load }\end{array}$ & $\begin{array}{l}\text { "the staff is very busy and shortage of staff is normal across the } \\
\text { NHS" (S6P01) }\end{array}$ & $\begin{array}{l}\text { PA and mobilisation becomes less of a priority when wards } \\
\text { are short-staffed. This will presumably have negative } \\
\text { implications for staff availability for training. }\end{array}$ \\
\hline & $\begin{array}{l}\text { Finding the right person } \\
\text { to be champion }\end{array}$ & $\begin{array}{l}\text { "it's not necessarily the grade of person, it's the person, and } \\
\text { that's difficult. That makes it difficult, because you can't say oh I } \\
\text { need a band } 7 \text { this or a band } 5 \text { this or a healthcare assistant that, } \\
\text { it's the person. And how they interact with other people, and } \\
\text { how ambitious they are, and willing to run with it, you know." } \\
\text { (S6P03) }\end{array}$ & $\begin{array}{l}\text { Finding the right person to be PA champion is difficult. The } \\
\text { person needs to have the right personal qualities and be } \\
\text { embedded within the system already i.e., not parachuted in. } \\
\text { One respondent mentioned the importance of the champion } \\
\text { already having rapport with the staff on the ward. }\end{array}$ \\
\hline
\end{tabular}




\begin{tabular}{|c|c|c|c|}
\hline \multicolumn{4}{|c|}{ What were the challenges for the CMU pathway } \\
\hline Topic & Theme & Quote(s) & Interpretation/implication(s) \\
\hline & & $\begin{array}{l}\text { "having somebody embedded within the team with that ideal, } \\
\text { and wanting to do it I think is essential" (S6P03) }\end{array}$ & \\
\hline \multirow[t]{3}{*}{$\begin{array}{l}\text { Relating to the } \\
\text { setting / wider } \\
\text { culture }\end{array}$} & $\begin{array}{l}\text { Policy issues and } \\
\text { insurance implications }\end{array}$ & $\begin{array}{l}\text { "we haven't had an update about the insurance of us [nurses] } \\
\text { assessing people, because it's a physio role. So that's a bit } \\
\text { debatable." (S6P02) }\end{array}$ & $\begin{array}{l}\text { Asking nurses to take on some physiotherapy roles has } \\
\text { implications for insurance that need to be carefully } \\
\text { considered. }\end{array}$ \\
\hline & $\begin{array}{l}\text { Difficult to measure } \\
\text { impact of the } \\
\text { intervention when } \\
\text { there's other } \\
\text { contributing factors in } \\
\text { the wider environment }\end{array}$ & $\begin{array}{l}\text { "it's not necessarily mobility that holds people back in that } \\
\text { respect [time to discharge]. So they might be waiting for } \\
\text { packages of care, or they might be moving on to other } \\
\text { community hospitals... [time to discharge] is really difficult one } \\
\text { to measure, because there's so many variables and so many } \\
\text { things that impact on that." (S6P03) } \\
\text { "if you're spending half an hour, } 20 \text { minutes, half an hour with } \\
\text { somebody that otherwise would be sitting looking at the walls, } \\
\text { then whatever intervention is going to lift mood." (S6P03) }\end{array}$ & $\begin{array}{l}\text { The impact of the PA itself is difficult to measure. If time to } \\
\text { discharge is a key outcome then there are a number of other } \\
\text { factors that influence when a patient get discharged. } \\
\text { Implementation teams needs to decide on the key indicators } \\
\text { against which to measure success and these might not be } \\
\text { clinical outcomes. Patients may benefit from having the } \\
\text { contact-time and care from HCPs that comes with the } \\
\text { exercises and it's difficult to disentangle the effects. }\end{array}$ \\
\hline & $\begin{array}{l}\text { Changing the whole } \\
\text { culture and ingrained } \\
\text { practices }\end{array}$ & $\begin{array}{l}\text { "I'm hoping that the culture on the ward becomes more of this } \\
\text { sort of rehab approach" (S6P03) } \\
\text { "I've been working on with a colleague has been put into the } \\
\text { manual handling policy, new manual handling policy" (S6P03) } \\
\text { "the other barrier is then people's ingrained attitude. So there } \\
\text { are some, so like I say we've got lots of support from the new } \\
\text { nurse manager who's very proactive about improving activity on } \\
\text { the ward. But then there are some nurses who just historically } \\
\text { will nurse people in bed because they perceive that to make } \\
\text { their life easier." (S6P03) } \\
\text { "we need to of course train the staff, empower them and make } \\
\text { them competent to do that." (S6P01) }\end{array}$ & $\begin{array}{l}\text { It is likely to take time and persistence to bring about change } \\
\text { to the whole ward culture. This may require training, change } \\
\text { to policies and the way that staff work. These are not simple } \\
\text { infrastructure changes, but cultural changes to the work } \\
\text { place and work practices. }\end{array}$ \\
\hline
\end{tabular}

